University of South Florida

DIGITAL COMMONS

Digital Commons @ University of

@ UNIVERSITY OF SOUTH FLORIDA

South Florida

Integrative Biology Books

Integrative Biology

1869

\title{
Investigations on the Pedicellariae and the Tube Feet of Asteroids and Urchins
}

J. O. Edmond Perrier

John M. Lawrence

University of South Florida, lawr@usf.edu

Follow this and additional works at: https://digitalcommons.usf.edu/bin_books

\section{Recommended Citation}

Perrier, J. O. E. Investigations on the Pedicellariae and the Tube Feet of Asteroids and Urchins (J. M. Lawrence, Trans.). Herizos Press, Tampa.

This Book is brought to you for free and open access by the Integrative Biology at Digital Commons @ University of South Florida. It has been accepted for inclusion in Integrative Biology Books by an authorized administrator of Digital Commons @ University of South Florida. For more information, please contact digitalcommons@usf.edu. 


\section{R. I. TURNI}

\section{No D'ORDRE \\ 314 \\ THÈSES \\ pRÉSENTÉes \\ a la faculté des sciences de paris \\ POUR OBTENIR}

LE GRADE DE DOCTEUR ĖS SCIENCES NATURELLES

PAR

\section{J. O. EDMOND PERRIER,}

Aucien éleve de l'École normale supérieure, agrégé de l'Universitè, aide-natnraliste an Muséum d'histoire naturelle.

1* Thiese. - Recherches sur les Pédicellatres et les Ambulagres des Astéries et des Ounsins

2 Thisse. - Propositions de géologie et de botanique donkées pak LA FACULTÉ.

Soutenues le

novenube 1869 devant Ia Commission a'Wxamen.

MM. HÉBERT,

Président;

DUCHARTRE,

Examinateurs.

PARIS

VICTOR MASSON ET FILS

PLACE DE L'ÉCOLE-DE-MÉOECINE 


\title{
THESIS
}

PRESENTED

\section{TO THE FACULTY OF SCIENCES OF PARIS}

TO OBTAIN

\section{THE DEGREE OF DOCTOR OF NATURAL SCIENCES}

\author{
BY \\ J. O. EDMOND PERRIER, \\ Former Student at the École Normale Supérieure, Agrégé of the University, \\ Naturalist Aide at the Museum of Natural History \\ Defended November 1869 before the Examining Committee. \\ HÉBERT, President \\ DUCHARTRE, Examiners \\ LACAZE-DUTHIERS
}

Paris

VICTOR MASSON ET FILS

Place de l'École-de-Médicine

1869 
Investigations on the Pedicellariae and the Tube Feet of Asteroids and Urchins. J. O. E. Perrier. Translated by John M. Lawrence.

(C) John Lawrence, Herizos Press, Tampa, Florida. 
Translator's note:

I thank Michel Jangoux for help with translation of Perrier's terms for the pedicellariae and their parts. He noted "The problem with Perrier's texts is that he uses abundantly synonyms that are not spontaneously understandable ... as it occurs commonly in the 19th century French language."

An example is "mâchoire" and "mors" in the asteracathions. Perrier stated" "Comme dans celles-ci nous aurons à distinguer, pour chacune d'elles, une partie directement utile, ou mors, et une partie servant simplement au movement et que nous appellerons la queue.” This is translated literally as "In these we will have to distinguish a directly useful part, or jaw, and a part simply for movement that we will call the tail.

"Both "mâchoire" and "mors" are translated as "jaw". "Mors" has a second meaning, the bit of a horse's bridle. Perrier apparently used the terms "mâchoire" for a jaw, "mors" for the distal, functional part of the jaw and "queue" (tail) as the proximal part of the jaw. That is how I translate them.

Perrier says "C'est le veritable mors de la pince." This would be translated as "The distal part of the jaw is the true functional part of the pedicellariae."

Perrier also referred to jaws as "branches”. E.g., "...chez les Luidia, et l'on peut le suivre facilement même sur la face interne des branches des pinces..."; translated as "...in Luidia, one can follow it easily even on the inner surface of the jaws of the pedicellariae..."

"Pince" could be translated as "pliers, "forceps" or "tweezers", but I have translated it in appropriate places simply as "pedicellaria" as indicated by Perrier's statement: "De ces trois pièces, deux pièces sont paires et latérales, ce sont les mâchoires de la pince."; translated as "Of these three pieces, two are paired and lateral. These are the jaws of the pedicellaria."

Perrier frequently uses the term "pédicellaire en pince.” E.g., “...seulement dans le cas des Pédicellaires en pince...." In this case, the terms are not synonymous and the simple translation would be "only in the case of pedicellaria with jaws."

I thank Richard L. Turner for the loan of Perrier's thesis. 
Jean Octave Edmond Perrier (9 May 1844 - 31 July 1921) was born in Tulle. He studied sciences at the École Normale Supérieure, where he took classes in zoology from Henri de Lacaze-Duthiers (1821-1901). Afterwards he was a teacher for three years at the college in Agen. In 1869 he obtained his doctorate in natural sciences and later replaced Lacaze-Duthiers at the École Normale Supérieure (1872). In 1876 he became chair of Natural History (mollusks, worms and zoophytes) at the National Museum of Natural History.

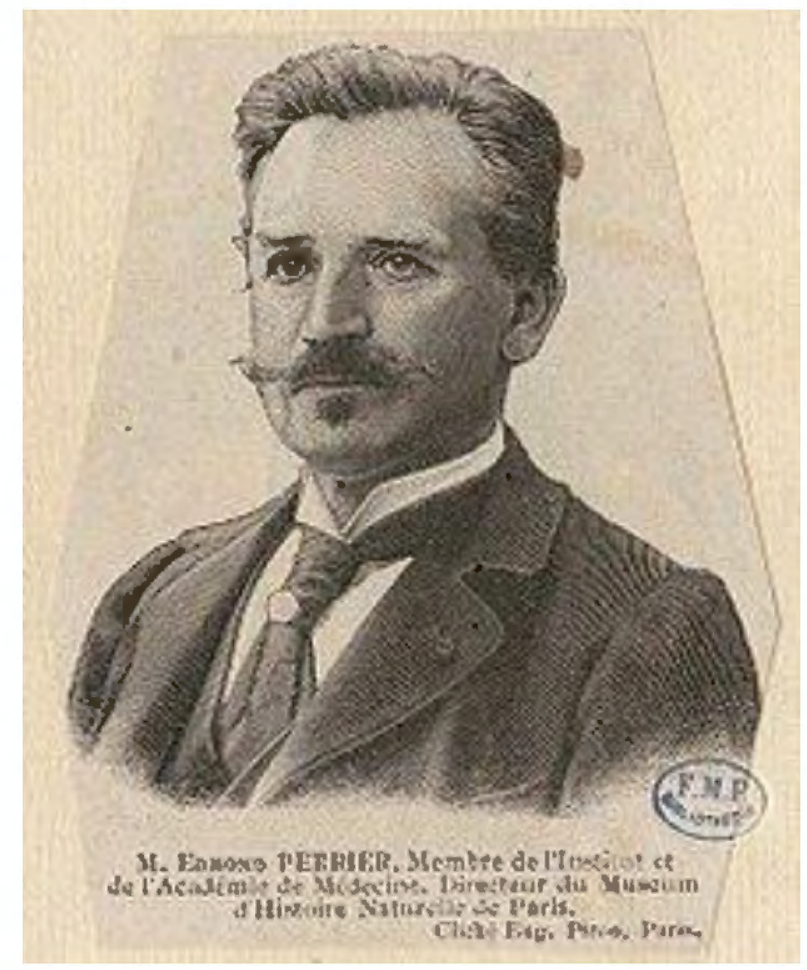


Félix Joseph Henri de Lacaze-Duthiers (15 May 1821 - 21 July 1901) was born in Montpezat in the department of Lot-et-Garonne. He studied medicine in Paris. He travelled to the Balearic Islands to study marine life. In 1854 he became an assistant to Henri Milne-Edwards in Paris. He then became a professor of zoology in Lille. In 1865 he was appointed chair of histoire naturelle des mollusques, des vers et des zoophytes at the National Museum of Natural History. In 1868 became a professor at the University of Paris. In 1871 he was elected to the French Academy of Sciences. He was the founder of the biological station at Roscoff in 1876, and the Arago laboratory at Banyuls-sur-Mer in 1882. In 1872 he founded the journal Archives de zoologie expérimentale et générale.

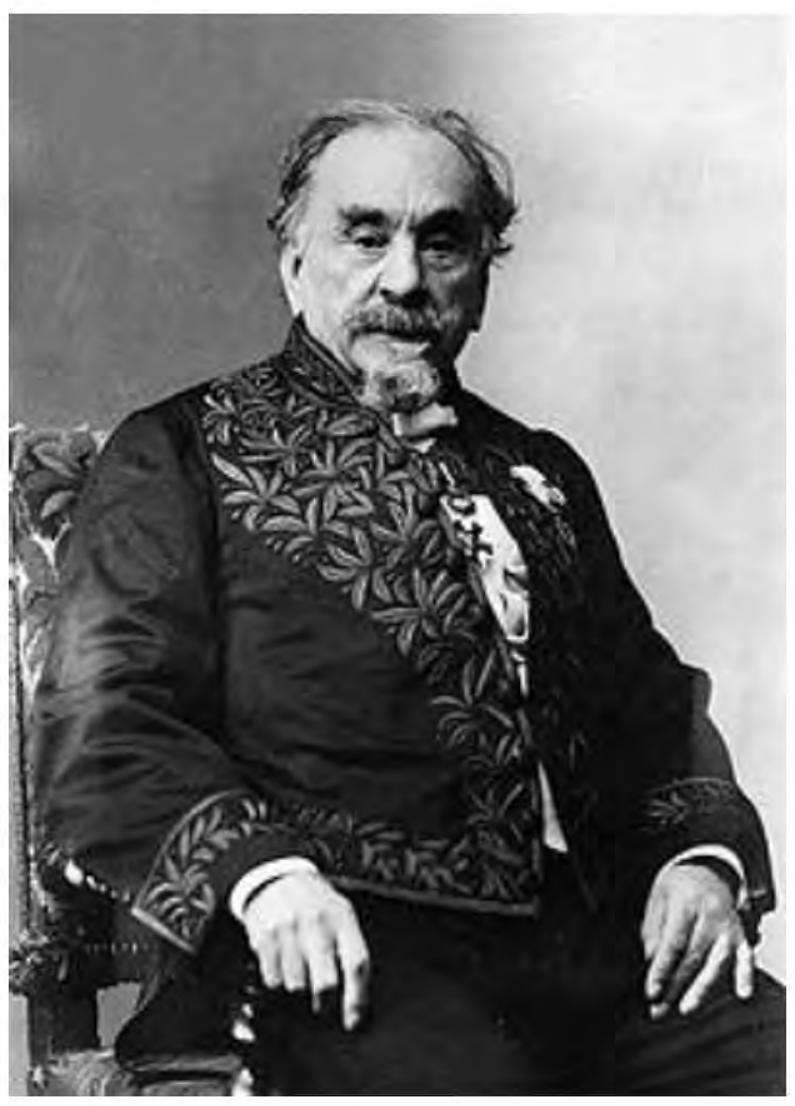


Jean-Louis Hardouin Michelin de Choisy was born 25 May 1786 in Versailles and died 9 July 1867. He was appointed Inspector of Finances in the Court of Auditors in Paris in 1817. He was not associated with an academic institution or museum but was a true amateur scientist, devoting himself to paleontology, first of molluscs, then zoophytes, and then echinoderms. He published a monograph of fossil clypeasteroids in 1861. After his death, on the advice of Lacaze-Duthiers and after examination by a commission, the National Museum of Natural History purchased his collections from his widow for 6.000 francs.

Perrier frequently refers to the "Michelin collection" that had recently been acquired by the Museum and named a species in the collection after him: Goniodiscus Michelini,

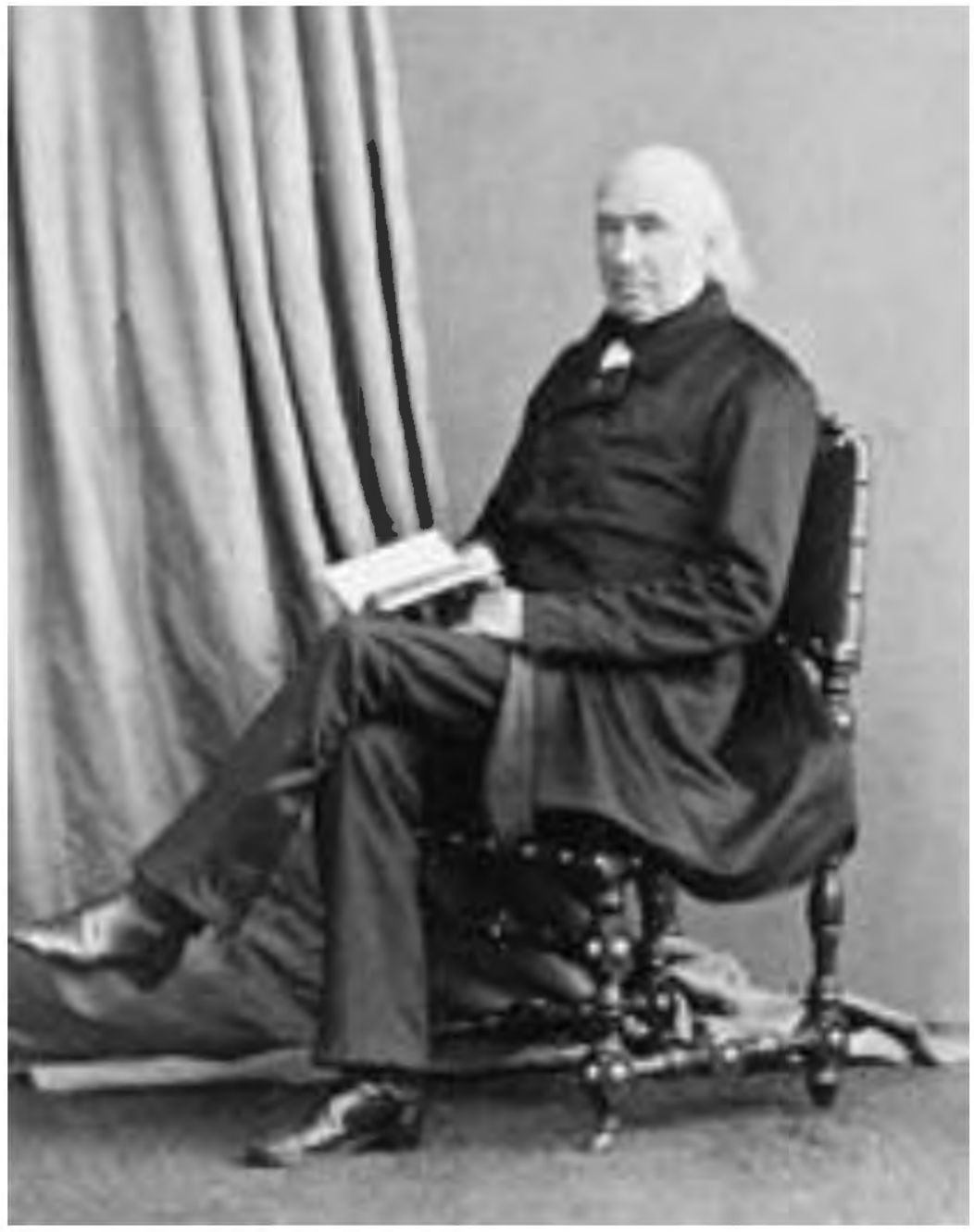




\section{To}

\section{Dr. Henri de LACAZE-DUTHIERS}

Lecturer at the École Normale Supérieure,

Professor at the Faculty of Sciences of Paris.

MY VERY DEAR MASTER,

If gratitude and devotion could affect the scientific value of a work, whatever you allow me to offer you at this time would certainly be perfect.

At the Normal School, in your laboratory in the Jardin des Plantes and since I returned as your student, having been your naturalist assistant, you have never ceased helping me and the advice and the indications of a friendship of which I am very proud and that I want to merit always.

I am happy that it is possible for me to make, in my turn after many others, a public homage to the scholar who has always given a cordial welcome to all workers, to the man who recognizes all who come to him.

May the student one day resemble the master in spirit and heart.

May this first work undertaken according to your advice, my very dear master, not make too ambitious the wishes of

Your very affectionate and very devoted

EDMOND PERRIER 


\title{
INVESTIGATIONS
}

$\mathrm{ON}$

\section{THE PEDICELLARIAE AND THE TUBE FEET}

\author{
OF ASTEROIDS AND URCHINS
}

\section{HISTORY}

O. F. Müller, in his Zoologia Danica (v. I, p. 17), first reported the existence in urchins of certain organs that he took for parasitic polyps and that he described as such under the name of Pedicelllaria. That is still how they were described by Lamarck in his Histoire des animaux sans vertébres.

The question had not advanced further when, in 1841, Valentin published, in Monographies d'Échinodermes of Agassiz, his beautiful anatomy of Echinus lividus.

Müller had described three species of pedicellariae: P. globifera, trihylla and tridens. Valentin (Anatomie du genre Echinus, p. 46) considered them as very probably identical with those that he had found in his Echinus, and described under the names of P. ophicéphale, gemmiforme and tridactyle. However, he wrote in his text that the pedicellariae are for him not parasitic animals, but simply organs either of the test or the buccal membrane. The figures that he gave of these organs (pl. 4) are very substantially correct and it is not surprising that the ideas that he had are also. The description of the buccal pedicellariae seems to have embarrassed him greatly. From the figures in his text, it is difficult to have a correct idea of them.

Valentin studied the pedicellariae of E. lividus, E. brevispinosus and E. sphara.

At the end of the chapter that concerns us, he wrote formally:

"The function of these small organs is still not known in a precise manner. One is naturally led to consider them as prehensile organs, especially since they open and close like the fingers of the hand, as Monro was the first to observe... But although it is likely these are prehensile organs, their function is still not demonstrated, because there is no channel around them by which they can pass objects that they have grasped. Do they pass them from one to the other to the mouth? This hypothesis is scarcely reasonable, because there is at the base of the buccal membrane, beside the external gills, an interruption in their succession.... Whatever it is, whether one considers the pedicellariae as prehensile organs or assigns other functions to them, the number and constancy of arrangement suffices for us to be convinced of their importance."

At this time, Sars published his beautiful work on the development of Asterias sanguinolenta. Under the influence inspired by this discovery, Agassiz proposed that one could clarify the nature 
of pedicellariae only by studying the embryology of urchins. He added a note regarding the statements by Valentin, who regarded pedicellariae as organs of urchins, a remark in which one finds the following phrase: "I cannot resist the idea that pedicellariae are not embryos of urchins that, after eclosion, are fixed on the test of their mother. The striking resemblance the arcs of the pedicellariae has with the masticatory apparatus of urchins does not appear to be a paradox if one considers the diversity of forms of pedicellariae on the same urchin, and especially if one recalls that comatulids, before becoming free, are also pedunculate, as we have learned from Thomson."

We know today the development of urchins, and moreover, the constant presence of pedicellariae with their characteristic form in urchins of all ages, sufficiently oppose the hypothesis of Agassiz.

In studying the embryology of urchins, the son of Agassiz has moreover reported the time at which these organs appear.

Before Valentin, Delle Chiaje (Memmorie sulla storia e notomia, degli animali senza vertebre degli regno di Napoli, v. II, p. 324) declared that he did not agree with the opinion of Larmarck, adopted by Cuvier, that pedicellariae are polyps. "They are, he said, an integral part of the urchins, and function to grasp nearby bodies and also to obtain animals that they use for nourishment.

Delle Chiaje describes and figures, but very roughly, the pedicellariae of Echinus edulis, E. neglectus. E. cidaris, E. Napolitanus, E. saxatilis and E. spatangus. It is necessary to add that his figures are completely insufficient to give even a general idea of the constitution of the organs that concern us (pl. XXII, XXIII, XXIV and XXV).

Delle Chiaje also describes and figures, in a very recognizable manner, one of the species of pedicellariae that are found in an asteroid, designated by him as A. Savaresi, and that we cannot recognize in an Asteracanthion (pl. XVIII).

Delle Chiaje's work was published in 1825.

In 1842, Erdl, in Weigman's Archiv (pl. 2), published some figures of pedicellariae of urchins. But it is absolutely impossible to recognize to which animals these pedicellariae belong.

If we add to these some descriptions given by Sars of the pedicellariae of urchins of the genus Cidaris, we will have a nearly complete list of publications that have been made on the matter.

We are poorer in regard to asteroids. Some faulty figures of Müller and Troschel in their beautiful work System der Asteriden, a good figure of one of the pedicellariae of asteracanthions given by Duvernoy in his Mémoire sur le test des Oursins, a figure given by de Quatrefages in his grand edition of Règne animal of Cuvier are all that we have.

Duvernoy reported in asteracanthions two species of pedicellariae, the second being for him embryos of the first. Dujardin and Hupé have tried to figure this second kind of pedicellariae that we shall designate later by the name of crossed pedicellariae. But the figure that they give is absolutely inadequate.

Finally, in the descriptions of echinoderms published in 1865 in volume XV of Annals and Magazine of Natural History, Normann speaks of these pedicellariae as being formed of two crossed valves and surrounding the base of the spine tubercles. He thus recognized their location, but without saying anything about it. He thinks that the asteracanthions can have only one or two kinds of pedicellariae (characteristic of his asteroids), and found even in their absence a genus that we would not accept as their existence to us appears absolutely constant. This genus, which has the name Stichaster, is formed of S. roseus, in which we describe two sorts of pedicellariae.

We can no longer share the opinion of Normann who denies pedicellariae in some Asteriscus, notably A. verrruculatus. The presence of a special muscular apparatus, that we very clearly show, 
makes us to consider the organs referred to as pedicellariae, very simple it is true but perfectly characterized.

In summary, science is very poor in information, as we see it, on pedicellariae.

The work we have undertaken does not exhaust the question, but it gives, we hope, a very clear idea of the constitution of these organs and the advantages they can provide for classification.

$\mathrm{jWe}$ shall treat successively asteroids and urchins.

We have likewise, for the latter, studied the spicules of the tube feet and their rosettes that, since Erdl and Valentin, have not attracted attention. We shall see further the importance of these parts in characterization.

\section{FIRST PART}

\section{PEDICELLARIAE OF ASTEROIDS}

The pedicellariae of asteroids have not been studied until now in an attentive manner. Most of the authors who have considered them have made only a summary and nearly always incorrect descriptions of them. No one, in all cases, has investigated the modifications they show in the different genera of sea stars. Moreover, they are content to report their presence or absence. Müller and Troschel in their classic work on asteroids and Dujardin and Hupé in Suites ä Buffon, have done nothing else. It is sufficient only to glance at the figures they give of these organs to be convinced of the little importance they give them.

I propose to establish in this work:

$1^{\circ}$ the different forms of pedicellariae in the asteroids;

$2^{\circ}$ the advantages that can be taken from their study, either for their distribution in groups of echinoderms, or for the characteristics of species.

The soft parts of these organs, their functions, and their relations to the rest of the organisms are the object of our work. It will be the principal question we shall publish now on their calcareous skeleton that is always each to study and that we will find, without doubt, in spite of its fragility, among microscopic fossils.

We made our studies not only of all the species, but on all the individuals that compose the collection of the National Museum of Natural History of Paris. We have likewise studied the urchins that are the subject of the second part of this work. If, in these two groups, we reach results of some generality, we will have once again shown the utility for science of the vast collections that are the envy of Europe, that are emulated if not equaled, and that will soon be surpassed, if we do not begin to perceive that the sinews of war are also somewhat the sinews of science.

Before proceeding to the description of the different forms of pedicellariae and the study of the relations with the established groups in the family of asteroids, it is useful to say what these groups are and to indicate their relative value and the value of the genera they contain.

In their System der Asteriden, that today is the law in the science, Müller and Troschel divided the sea stars into three large groups thus characterized:

I. Four rows of tube feet in each ambulacrum. - Anus present. - First group.

II. Two rows of tube feet only in each ambulacrum.
A. - Anus present. -Second group.
B. - Anus absent. - Third group. 
The first group contains two genera: Asteracanthion, Heliaster.

The second contains the largest part of asteroids.

The third group contains three genera: Astropecten, Ctenodiscus, Luidia.

These three groups appear to us far from having equal zoological value. That with the genera Asteracanthion and Heliaster compares well to the ensemble of the two others and is equivalent to each of them in particular.

Strong generalizations cannot be made because of the absence of knowledge on the nervous and vascular system of the different types or of sufficient embryological information, we are forced to judge analogies and dissimilarities by the form and constitution of the tegument and its organs. Among these are the pedicellariae and we shall recognize a constitution completely different according to the type of asteroid with four or two rows of tube feet in the tube feet of each arm.

We shall study first the pedicellariae in the first of these types where they are more complex, more constant and, without doubt, also more useful to the animal.

\section{I. - PEDICELLARIAE OF ASTEROIDS WITH FOUR ROWS OF TUBE FEET.}

In all species belonging to the genera Asteracanthion and Heliaster, there are two kinds of pedicellariae, differing both in their structure and distribution on the surface of the animal's body, but having in common that they are all supported by soft parts that form at the same time an envelope completely closed and a pedicule. Moreover, the calcareous skeleton is always formed of three pieces. It is in the form and the relations of these pieces between themselves that the anatomical differences are shown.

To shorten the discussion, we shall designate immediately one of the forms of pedicellariae as straight pedicellariae, the other as crossed pedicellariae.

The straight pedicellariae ${ }^{1}$ are larger. They have often been described and sometimes very correctly. Duvernoy has figured them in a very recognizable manner, in regards to the hard and soft parts. These are for many the simplest structure. They are found constantly isolated, most in small fascioles, either on the back of the star, between the spines, or on the ventral surface. They are especially abundant and robust in the angle of the arms, and among the spines that border the ambulacral groove. It is in this last place that we most often find them in three or four bundles. There, as in the angle of the arms, they must have a greater development in that location that protects them from damage to which the others are exposed. Nearly always recognizable by the naked eye, they vary in size between about $1 / 2 \mathrm{~mm}$ up to four times of that length at least. In dried specimens, the whiteness of their skeleton makes them immediately recognizable.

The skeleton is always composed of three calcareous pieces, pierced, like most of the calcareous pieces of echinoderms, with numerous vacuoles that give them the appearance of a delicate stony lace. Their fragility is such that the slightest pressure on the plate that covers them to make microscopic observations, is usually sufficient to reduce them to powder. Except for the very large pedicellariae, these pieces are perfectly transparent. We can study across nearly their entire thickness all the details of the parts located below. Two of the three pieces are paired and lateral. These are the jaws of the pedicellaria. One is symmetrically unpaired, placed below the two first. We shall call it the basal piece.

Throughout the genus Asteracanthion, these different parts have a remarkable similarity. It is impossible to confuse them with the parts of pedicellariae of different genera. We are going to give a theoretical description, reserving the details to a special part of each species.

${ }^{1}$ PI. 1, fig. 1, 2, 3, 4, etc. 
Each jaw has a triangular calcareous plate, folded along its height to form a curved outer surface and two substantially flattened lateral surfaces. ${ }^{2}$ Each ends in a free edge, irregularly sinuous and very regularly toothed its entire length. ${ }^{3}$ The lower part of this edge is indented up to the base that is slightly curved and attached to the basal piece on which it can move. A calcareous blade, having the same texture is that of the surfaces, unites their two edges of the latter to make a rather considerable projection. This is shown in the theoretical section that we have represented, ${ }^{4}$ which is drawn by a plane perpendicular to the two lateral surfaces of the pedicellaria. This inner blade is united to the first by small calcareous extensions on its surface that appear to be pieces of reinforcement. We often see at the base a groove, sometimes semi-circular, sometimes angular.This is an open passage with muscles whose fibers fill the cavity of the organ and insert on the inner walls. The grooves we have reported on the inner edges of the folded blade lack the teeth present on the edges in the rest of their extent. They also serve for the insertion of some muscle fibers. It should be noted that the reticulated structure so distinct in the different pieces disappears, for the folded blade after the line of insertion of the inner blade up to the free edge. This region has rare vacuoles.

The free edges of each of the two jaws are related to the edges of the other. I have always observed that their sinuosities correspond so that the projections of one penetrate into the depressions of the other and reciprocally. This is a general fact that is found again in the pedicellariae of urchins, as I have indicated in another part of this work, and that corroborates very well with the opinion, today generally accepted, that the pedicellariae are grasping organs. It remains to know what they grasp. But this question will be examined elsewhere.

In some species, the top of the jaws is extended in a curved hook, but whose point is never very sharp.

In summary, we will describe very well the form of a jaw of a straight pedicellaria by comparing it to a hollow pyramid with one of the edges being replaced by a rounded surface, while the two adjacent surfaces are prolonged under the third.

The two jaws move, we have said, on a calcareous basal piece like them and also have the reticulated structure that we find in all echinoderms. We can represent it as a kind of hollow halfwasher, more elliptical than circular, whose convex portion is turned outwards, while the flat part serves as a support at the base of the jaws. In the middle of this latter surface is an irregular projection that engages in the space formed by the indentation of the lower end of the inner edges of the jaws of the pedicellaria. On this projection are inserted the muscular fibers that function to close the pair. The two upper outer angles of the basal piece are rounded and provides between them and the base of the jaws an empty space where we can see the muscles that spread the jaws of the pedicellaria.

Seen with a microscope from the upper surface, the basal piece seems thus generally a rectangle with a more or less rounded top. It has a border with a median band, parallel to the small sides, more obscure. This is because we see in projection the thickness of the surfaces and that of the median projection that serves to attach to the adductor muscles of the pedicellaria.

Seen laterally by one of its broad surfaces, parallel to the plane in which the jaws move, it will have, more or less, the aspect of a semi-circle with a central projection. Finally, seen from one of the small surfaces, it resumes again a substantially triangular form.

\footnotetext{
2 PI. 1, fig. $2 d$.

${ }^{3}$ PI. 1, fig. $2 a$, , $3 a$, etc.

${ }^{4}$ PI. 1, fig. $2 d$
} 
The clear space that, in the first of these three cases, is observed between the edges of the piece and the median band is the result of the absence in these parts of the calcareous blade framework. As if it were a matter of economizing as much as possible, material, there are solid parts there only where they are really indispensable: i.e., on the whole contour that supports the jaws that are also hollow, and on the median part where attach the muscle fibers that close the pedicellaria.

The crossed pedicellariae have not yet been described. We find an indication in the memoir of Duvernoy on the calcareous pieces of asteroids. But it evident the author has not observed them sufficiently, because he considered them as rudiments of straight pedicellariae. This is not acceptable as will be evident from our description. Dujardin and Hupé give a figure that refers to them, but it is completely unintelligible. Müller and Troschel did not even indicate them as a distinct form.

Their completely particular location and their special character should have attracted their attention.

We always find them around the spines of the dorsal and ventral surfaces, inserted in tufts on a pad that is sometimes little developed as in Asteracanthion rubens or, to the contrary, very considerably as in Asteracanthion glacialis. In the latter, the pad is mobile and sometimes covers the spines, sometimes pulled back on itself to expose them.

The crossed pedicellariae are never isolated. The straight pedicellariae are nearly always isolated. We find them sometimes among sheaths of crossed pedicellariae, at least in Asteracanthion glacialis. We can thus indifferently give crossed pedicellariae the name fasciculated pedicellariae, while straight pedicellariae on the spines that border the ambulacral grooves will be called isolated or solitary pedicellariae. On the spines that border the ambulacral groove, the sheaths of crossed pedicellariae form only half-belts.

I shall recall here, in the first place, the very special structure of the muscular apparatus of these organs that alone would be sufficient to reject any idea of relationship to unite them with straight pedicellariae. These are two kinds of organs, having evidently a certain physiological relationship, but as distinct as our anterior and posterior limbs. Although there are some relationships between these two sorts of limbs, no one will think of saying that some are rudiments of the others.

The study of the different solid pieces that make up a crossed pedicellaria shows moreover that Duvernoy had barely seen them and that, consequently, his opinion was not based on any serious foundation.

Like the straight pedicellariae, the crossed pedicellariae are composed of three pieces, one basal and two forming the jaws of one strong solid piece.

We shall first study the basal piece ${ }^{5}$, which will facilitate understanding the relations of the different pieces of the organ.

This piece is unpaired and symmetrical. We can use for it terms analogous to those that are employed in the study of vertebrates and separate it into a fundamental part or body and four apophyses. The four apophyses are in turn symmetrical in shape and location relative to the body.

Two of them end in a very regular round edge, free towards the interior. We designate them regular apophyses. The two others do not have a geometric form. They end at the upper part in a more or less irregular edge. These are for us, irregular apophyses.

We shall study each of these parts separately.

$1^{\circ}$ The body of the basal piece is a flat blade, pierced, as always with numerous vacuoles that

${ }^{5}$ PI. 2, fig. $2 f$. 
are sometimes round, sometimes oval and arranged in linear series We note, in general, near the upper edge, three openings or sometimes three quadrangular vacuoles larger than the others.

The body determines the general form of the basal piece. It is a demi-ellipse whose long axis is directed transversally. This general form has some slight modifications that we shall indicate in the specific descriptions.

The regular apophyses ${ }^{6}$ are located one in front and to the right, the other in back and to the left of the body of the basal piece, at least in the most general case. ${ }^{7}$ They form a kind of rounded heel on which is supported and moves the proximal part of one of the jaws. The various figures we give of the crossed pedicellaria ${ }^{8}$ show this arrangement that is remarkably constant in the genus Asteracanthion. The calcareous substance that constitutes apophyses is not areolated as usual. We add that the muscle fibers that close the pedicellaria insert on their inner edge.

The irregular apophyses occupy locations exactly symmetrical to those that we have indicated for the regular apophyses. As a result, each edge of the body of the basal piece has, in front, a regular apophysis, behind, an irregular apophysis and vice versa. The irregular apophyses go first towards the edge opposite that which produced them, then turns and finally goes towards the top where they pass the upper edge of the body. There, they end in a horizontal free edge on which is attached a part of the corresponding jaw.

The irregular and regular apophyses that are found on one side of the body make, by their projection, a kind of gutter in which each jaw of the pedicellaria is enclosed, without being however so tight to prevent the free movement in the lateral direction.

The presence of two pairs of apophysis results in the basal piece, seen by its upper part, having the appearance of a figure eight whose two openings are full and separated from each other by a very elongated linear space. ${ }^{9}$ Seen by one of the lateral surfaces, it has a very irregular form as one can see in figures $5 b$ and $8 b$ of plate 1.The irregular apophysis is raised much higher than the regular apophysis and thus takes a very marked asymmetry.

A view by the lower surface has nothing interesting.

We shall note here the particular type of symmetry of the crossed pedicellaria that is shown very clearly in its basal piece. While the straight pedicellaria is symmetrical in relation to two rectangular planes, one perpendicular to the broad surfaces of the basal piece, the other parallel to those surfaces, the crossed pedicellaria is no longer symmetrical in relation to the line of intersection of these two plans. This is shown in figures $2 f, 5 b, 8 b$, etc. in plate 1 . Figures $2 c$ and $2 e$ are a horizontal section of the basal piece of the two kinds of pedicellariae.

We now consider the jaws. All are identical but are arranged in relation to the ensemble of pedicellariae, according to the mode of symmetry described in such a way that one is found before and to the left in relation to the basal piece, the other is found behind and to the right.

The two jaws thus are separated by the basal piece are separated like the two arms of an X or, to make a more correct comparison, like the arms of scissors. As in them, we have to distinguish for each, the directly useful distal part and the proximal part for movement.

The latter being simpler, we describe it first.

Except in one of the species that we have examined and that, moreover, is distinguished by other very remarkable unique characters, the calcareous material of the proximal part of the crossed

\footnotetext{
${ }^{6}$ PI. 1, fig. $2 f$..

${ }^{7}$ This position can be reversed.

${ }^{8}$ PI. 1 , fig. $1 a, 2 b, 3 b, 10 c$, etc.cul

${ }^{9}$ PI. 1, fig. 2 e.
} 
pedicellariae lacks vacuoles. It has only some projecting lines that seem to be pieces of reinforcement. y

Its form is very variable in different species. But it is always curved up from one of the upper edges of the basal piece to the opposite lower edge, following a diagonal line. It has an upper concave edge and a lower groove by which it is attached to the regular apophysis. It ends in a convex edge that is usually combined by means of a regular curvature with both concave edges. ${ }^{10}$ A more detailed description would only complicate what our simple figures clearly show.

It is important to recognize towards the rounded end of the proximal part, a kind of calcareous coating that envelopes it like a more or less flat case and that ends, in its upper free portion, in an irregular fringe. This part is remarkable for its constant existence and also for its physiological role. It serves for the second point of attachment of the muscle fibers from the inner edge of the regular apophysis that close the jaws of the pedicellariae. ${ }^{11}$

The form of the distal part is as variable as that of the proximal part. The general description will be brief. We shall return to it later when we indicate the specific differences of the pedicellariae that we recognize. On one of their surfaces, the distal part of the jaws are continuous with the proximal part of the jaw. But their calcareous leaf is curved from the side opposite the basal piece to the top of the irregular apophysis. It thus constitutes kind of spoon whose dorsal surface is very generally much larger at it top than at the base.

The curved leaf that is not continuous with the proximal end of the spoon remains free at its lower edge, which comes to rest on the top of the irregular apophysis. It rolls on this top during the movements of the jaws of the pedicellaria, which ensures regularity. This arrangement will have the effect of giving more solidity to the pedicellaria in opposing any kind of longitudinal slipping of it jaws.

This curved leaf still has a more or less vertical edge. When the pedicellaria is closed, the edges are applied to the edge of the other jaw that is continuous with the proximal part of the jaw to which it belongs. The same arrangement is reproduced on the opposite surface, so that if one gives a name to the two edges of the type of spoon that makes up each jaw, we can say that the edges in contact when the pedicellaria is closed are edges with different names.

The calcareous pieces that make up the distal part of the jaw that we just described are always more of less vacuolated. However, these vacuoles are neither as numerous nor regular in their form and characters as those of the basal piece or the different pieces of the straight pedicellariae.

It remains to us to complete this theoretical description of crossed pedicellariae, to speak of two calcareous blades that would be placed, in order to continue our comparison, in front of the concavity of the spoon and are located one below the other: the upper inner blade filling the kind of vault that forms the top of the spoon while bending; the lower inner blade starting from the line of its union with the bottom of the concavity of the distal part of the jaw, in order to join with the upper end of the proximal part. It is by far the most conspicuous. These two blades are very solid, armed with several rows of very strong teeth, very apparent, arranged sometimes in staggered rows so that the teeth of one longitudinal series are in relation with the empty intervals of the second adjacent linear series. It is this that one perceives easily when one looks at one of the distal part of the jaws from its back ${ }^{12}$ It is, moreover, very difficult to recognize the number of these rows of teeth and the number of teeth that make up each row.

\footnotetext{
${ }^{10}$ PI. 1, fig. $2 b, 3 b, 5 a, 6 a$, etc.

${ }^{11} \mathrm{Pl} .1$, fig $1 a, m$.

12 PI. 1, fig. $3 c, 19 c, 14 c, 15 b, 6 b$.
} 
The blades of each distal part of the jaw, opposite the blades of the opposite jaw obviously make an extremely powerful grasping apparatus.

Without any doubt, this description means crossed pedicellariae are incomparably more complicated in their structure than the straight pedicellariae. I do not think anyone could believe we consider them as an undeveloped kind of the latter. Indeed, their size is constantly smaller and it is impossible to recognize their form, even roughly, with the naked eye. Their smallness has thus misled after a superficial examination and suggests an opinion that a simple glance with a microscope is sufficient to destroy.

The impression that results from a careful study of these organs is an astonishment of their complexity and the special care that nature has put into making grasping organs that are so solid and precise. One is not used to encountering organs so finished, if I can used such an ex0resin, in beings so simple as sea stars. We shall find nothing similar in urchins that seem to be higher on the ladder than asteroids.

We are far from considering, in spite of the extent of our work, as resolved all questions relative to pedicellariae.

We have combined all the possible details of the structure of their hard parts, and we believe to have placed without doubt that they are grasping organs. But there is still much to do on the soft parts that are part of their constitution.

These soft parts are active, nutritive or simply protective. The active parts are the muscles and the nerves. The vessels are the nutritive parts. The protective parts are the epidermal covering of the pedicellariae.

We know the muscles very well. But we still have no perception of the nerves nor of vessels. We have always found an epithelial covering. But we know nothing of the connection of the epithelium to the hard parts or the muscles.

We still do not know if the pedicellariae communicate with the general cavity of the body and how this communication functions. We have nearly no information on the development of these organs and the period when they appear.

Finally, it is not sufficient to know that they are grasping organs. It is necessary to know what they grasp and how what they grasped is used by the animal.

All these questions can result in an extensive memoir for which we will gather information that will form second part of our work. We will give here, nevertheless, the little that we know now on this subject.

All the pedicellariae of Asteracanthion, whether they are straight or crossed, are always completely enclosed in an epithelial sheath that covers both their outer and inner parts.

In the straight pedicellariae, we can very easily follow this sheath along the inner surface. ${ }^{13}$ We see it separates into two parts the adductor muscles of the pedicellaria that it covers and is inserted on the median apophysis of the basal piece. This envelope is much more separated at the outer part of the pedicellaria than at its inner part. One can recognize most often a small empty space, linear, very fine, between the calcareous piece and the inner wall of this envelope. The outer wall is lined by a very distinct cellular epithelium, having a great analogy with the ciliated epithelium that we have often indicated as actually ciliated. I still have not been able to distinguish the cilia that we attribute to them. This epithelium is much less distinct on the inner surface of the pedicellaria. What is there between it and the calcareous piece? Is it an empty space in which the liquid of the general cavity penetrates to make the pedicellaria project? Is there a characteristic

\footnotetext{
${ }^{13} \mathrm{Pl}$. 1, fig. $1 b$.
} 
tissue? We believe we have seen some kind of areolar spongy tissue appropriate to fill with liquid, a true erectile tissue. But this must be studied again in numerous fresh animals.

Whatever it is, the epithelium is continuous the entire length from the stalk of the organ up to the skin. Often the membrane of the covering has folds, partial invaginations. This indicates the pedicellaria can be retracted and is protected in its interior. There is no histological difference between the epithelial covering of straight and crossed pedicellariae. The anatomical arrangement necessarily varies in a way to accommodate various forms of the organs.

It is necessary to distinguish two categories of muscles. Some move the ensemble of the piece. Others, to the contrary, simply move the jaws of the crossed pedicellaria on the basal piece.

It is necessary for us to examine these muscles in the two types of pedicellariae.

In the straight pedicellariae, the general motor muscle is composed quite simply of bundles of very delicate fibers that are inserted on one part of the solid part of the test and the other on the basal piece. This insertion is made on the lower surface of the basal piece. This muscle has not yet been reported to our knowledge. This muscle is not antagonistic. It evidently has the function of retracting the pedicellaria. Extension is produced, very probably like those of the retractor organs of mollusks, for example, by means of an injection of liquid from, the general cavity.

The motor muscles of the jaws of the crossed pedicellaria have been correctly figured by Delle Chiaje $^{14}$ for A. Savaresi that is A. tenuispinus of Müller and Troschel and Ast. rubens for Duvernoy $^{15}$.

Some are adductors, the others abductors. There are two adductor muscles ${ }^{16}$. They insert on the sides of the single apophysis of the basal piece, and their fibers form a kind of fan towards the jaws of the pedicellaria. These jaws are sunken in this region and allow a good part of the fibers to be seen. This led Duvernoy to believe that they were at the point where their path is cut by the edge of the groove of the border of the crossed pedicellaria. But it is nothing like that. In a large number of cases, we have seen most of the fibers penetrate into a groove variable in form at the base of the inner blade of the pedicellaria, to form a bundle at the interior of the cavity of each arm and to insert finally into the area of the top of the inner wall of this cavity. These fibers thus have a great length and their insertion at the top of the pedicellaria evidently gives them movement much more forceful and precise.

The abductor muscles ${ }^{17}$ form two small bundles having the appearance of pads placed at the two outer edges of the organ, between the basal piece and the lower part of the pedicellaria. Their lack of development is perfectly related to their functions. It takes much less force and precision in their movements to open the crossed pedicellaria than in those that seize and retain an object.

The crossed pedicellariae, despite their smallness, have a muscular apparatus much more developed than the straight pedicellariae.

A rather singular thing, the general motor muscle ${ }^{18}$ does not insert on the basal piece, but on the jaws themselves of the crossed pedicellaria. It has two planes of fibers that are superposed and parallel for most of their path, but that separate into two divergent bundles in the vicinity of the pedicellaria. One of these bundles attaches to the end of the proximal part of the right jaw of the crossed pedicellaria, the other goes to the left jaw of the crossed pedicellaria. This arrangement, as we see, is very curious. But it is a result, so to speak, of the arrangement of the adductor muscles

\footnotetext{
${ }^{14}$ Memorie sulla storia et Notomia, etc.

${ }^{15}$ Compte rendus de l'Institut, v. XX.

${ }^{16}$ PI. 1 , fig. $1 b, m, f$.

17 PI. 1 , fig. $1 b, m, o$.

${ }^{18} \mathrm{PI} .1$, fig. $1 a, m, r$.
} 
of the jaws of the pedicellaria. They are inserted, on one hand, on the mesh of the proximal part of the crossed pedicellaria and on the other hand, on the edge of the regular apophysis of the opposite side. They thus form a kind of muscular covering over all the free portion of the corresponding surface of the basal piece. Moreover, we sometimes see fibers that go from one jaw to the other and obviously act in the same direction as the first. The general motor muscle or retractor could unite on the basal piece only by transverse layers of the adductor muscle. These intercrossed muscles would not have much power without mutual stimulation.

Some muscle fibers are inserted, on one hand on the irregular apophysis, and on the other on the inner wall of the cavities of the pedicellaria. ${ }^{19}$ They are still part of the system of adductor muscles and once appeared very clearly striated. But this observation, from a specimen of Ast. violaceus conserved for a long time in alcohol, for us does not have much value. Nothing proves that the very clear striations that we saw are not a product of changes due to the alcohol. We have seen nothing that resembles the striations of the muscle fibers of living specimens of $A$. rubens and A. glacialis that were available to us.

The abductor fibers form a bundle between the upper outer edges of the basal piece and the lower part of the distal end of the crossed pedicellaria. To us, they appear to insert on the free edge of the border of the calcareous blade.

What are the functions of the pedicellariae? Everything about their structure makes us consider them as grasping organs. We have even found in specimens of the Museum an individual showing this opinion in a very clear way. This was an Ast. glacialis (A. Rissoi, Val.). Around its spines, we saw with the naked eye long filaments, white, straight, stiff, ending in a slight swelling. Removing these filaments, we saw their second end was much more swollen than the first. Examining these filaments with the microscope, we were not a little surprised to recognize pedicellariae of Echinus lividus. In observing this more closely, we assured ourselves that these pedicellariae had been seized near the bottom and grasped by the crossed pedicellariae of the Asteracanthion. As all these pedicellariae found thus were seized near the bottom, it is evident that the asteroid had seized them from a living urchin. It, in search of prey, had doubtlessly with its moving pedicellariae, encountered those of the asteroid that grasped them.

The pedicellariae thus play a defensive role. Are they also used in feeding? I ignore this. As to their relation to reproduction. They are more than problematic. They are always identical in all individuals of the same species that I have examined. I can confirm only that they are present during the entire life of an individuals and that they have no relation with its sex.

I sometimes encountered at the end of the arms, some pedicellariae in the process of formation I regret not having been able to study them in animals in process of regeneration. But in Ast. glacialis I once found a straight pedicellariae in process of formation that seemed to grow on another perfectly developed that serve for its support

I shall content myself for the present in reproducing the figure of this case of growth ${ }^{20}$ that is probably exceptional.

I shall only remark that the basal piece is already nearly entirely developed while the jaws of the pedicellaria are only represented by some spines. Finally, the entire calcareous network is enveloped in a kind of bud that serves as a matrix.

We thought we should mention this fact that is interesting to us. But we could not avoid remarking that before making any conclusion relative to the development of pedicellariae, it is necessary to be quite certain that we have not have a case of abnormality, related both to the place

\footnotetext{
${ }^{19}$ PI. 1, fig. $1 a, m, f$.

${ }^{20} \mathrm{Pl}$. 1 , fig $1 b, p$.
} 
where the organ is developed and the conformation of the parts that make it up. It is something only later studies can decide.

That is all we presently know about the embryology and the structure of the soft parts of pedicellariae. Gaps of knowledge are numerous and we are limited in what we can say on the subject. We begin immediately the study of the various forms of the parts in Asteracanthion.

\section{SPECIFIC DESCRIPTON OF THE PEDICELLARIA OF ASTEROIDS OF THE GENUS ASTERACANTHION.}

We reach the specific part of our work. It was done completely on the specimens in the magnificent collection of the Jardin des Plantes.

We have at the same time reviewed this collection and verified all the identifications that concern it. This study led us to recognize some species that had not yet been described and of which some have an unedited name given by Valenciennes. We have carefully kept this name and its origin. Each of these species will be described at the same time as its pedicellariae.

Here is the list of the species we studied:

\begin{tabular}{|c|c|c|}
\hline 1. & Asteracanthion & glacialis, M. and T. \\
\hline 2 , & $\overline{-\cdots--}$ & gelatinosus, M. and T.[ \\
\hline 3. & ---- & rubens, M. and T. \\
\hline 4. & ----- & violaceus, M. and T. \\
\hline 5. & ----- & roseus, M. and T. \\
\hline 6. & ----- & africanuos, M. and T. \\
\hline 7. & ---- & tenuispinus, M. and T. \\
\hline 8. & ---- & Linckii, M. and T. \\
\hline 9. & ---- & striatus, M. and T. \\
\hline 10. & ---- & graniferus, M. and T. \\
\hline 11. & ----- & margavitifer, $\mathrm{M}$. and $\mathrm{T}$. \\
\hline 12. & ----- & aurantiacus, M. and T. \\
\hline 13. & ----- & polaris (?), M. and T. \\
\hline
\end{tabular}

It is necessary to add the following species named by Valenciennes:
14. Asteracanthion australis,
15. ---- gemmifer,
16. ---- Nova Boracensis,
17. ---- inermis,
18. ---- Stellionura,
19. ---- $\quad$ Undetermined species from Australia.

These species do not appear to us sufficiently described anywhere. We believe it necessary to give in our work a complete description while keeping the names they have in the collection of the Museum, and adding to ordinary characters the interesting characters furnished by their pedicellariae.

Following Asteracanthion, we shall place:

20. Heliaster heliantus, Gray, 
whose separation as a genus does not appear sufficiently justified to me.

1. ASTERACANTHION GLACIALIS ${ }^{21}$. The pedicellariae of the first kind have jaws about five times as long as the basal piece, pointed, slightly curved inside. The basal piece is small and very thin on its free border, straight and slightly concave on the lateral surfaces. The free edge of the jaws is fine and regularly toothed. The interior surface has at its base a semi-circular groove by which enter the muscular mass that serves to bring the two jaws together.

The pedicellariae of the second kind form groups around the spines. They are small straight pedicellariae but very few in number. They are implanted on a fleshy sheath that can either completely cover the spine or mass at its base.

The proximal part of the jaw has two inflexions on its outer surface. The distal part of the jaws is slightly enlarged, elongated. The inner surface has, from top to bottom, 1) two or three rows of small, very dense teeth; 2) in the cavity, of its curved portion, two or three rows of large teeth, two or three in each row; 3) in the lower inner blade are three longitudinal rows of very large, very regular teeth. These three rows extend near from one end of the blade to the other.

The basal piece is oval. Its vacuoles are circular in form. At its upper part are four or five perforations, larger than the others and often rectangular in form.

We have sometimes found in the distal part of the jaws of this specimen, numerous pedicellariae of Echinus lividus. It therefore cannot be doubted that these organs are used for grasping, despite their small size.

Nota. - The description that we just gave of the pedicellariae of Asteracanthion glacialisis is made: $1^{\circ}$ from individuals from Portrieux; $2^{\circ}$ from a series of individuals preserved in alcohol that are part of the collection of the Museum. They have different names given by Professor Valenciennes that, it is necessary to say, are not justified in any way. At the most, we ascribe to them very slight differences in number, arrangement and size of spines that, in our opinion, are entirely individual differences.

We combine here, consequently, under the same name, Asteracanthion frigidus, gelidus, glacians and Rissoî from the collection of the Museum.

2. Asteracanthion Gelatinosus, M. and $\mathrm{T}^{22}$ - The straight pedicellariae of this species have a very characteristic form. They are large, thick, often also wide and long. Their size is very variable. The largest is found as usual in the vicinity of the ventral groove. They are up to 2 millimeters in length.

The basal piece has the form of a trapezoid, whose wide base is turned down and replaced by a curved line. Its thickness is not great. It is pierced its entire length with round vacuoles, all with nearly the same size and no longer different, in this regard, from the holes in the jaws.

These are curved, ended in a point finely toothed on their inner edge. Their inner blade has at its base a groove for the passage of the muscle.

The crossed pedicellariae are arranged nearly like in the preceding kind. Their size is much more constant than those of the straight pedicellariae and their general configuration is little different from that we found in A. glacialis. Only the curve of the proximal part of the jaw is

\footnotetext{
${ }^{21} \mathrm{Pk}, 1$, fig. $1 a$ and $b$.
}

22 PI. 1, fig. 4. 
regular and not bent several times. Moreover, the end of the proximal part of the jaw is large but does not have appreciable enlargement.

The upper inner blade has about six longitudinal rows of large teeth. Each row has four or five teeth. The lower inner blade has only four longitudinal rows of teeth as large as the preceding on its entire length.

3. ASTERACANTHION AFRICANUS, M. and T. ${ }^{23}$ - The straight pedicellariae are nearly four times as long as wide. The basal piece is nearly a fourth of the height.

Seen from the upper surface, it appears nearly square. Nevertheless, its thickness is a little less than its width.

The jaws are elongated, three times longer than their entire width, finely toothed on their border. The inner blade stops at the level of the top of the muscle groove and ends there with a horizontal line. Its midline barely shows a slight groove. As a result, the inner groove seen from the surface has nearly the configuration of a square.

The crossed pedicellariae are very numerous around the spines of the back. They are relatively elongated. The basal piece has the same form as in the preceding species. Its irregular apophyses are very elongated as shown in figure $5 b$, plate 1 , representing one of these pedicellariae seen by its lateral side.

This figure also shows that the back of each jaw is enlarged more and more towards the upper part, through which are seen the base of the teeth of the upper inner lamella.

The preceding figure ${ }^{24}$ shows the same pedicellaria seen by its surfaces. The distal part of the jaws is nearly the same width its entire length. That of their other part that corresponds to the upper inner blade is relatively much extended.

The upper inner blade has two rows of small teeth forming parallel curves to those of its border, one row of larger teeth, and finally two rows always parallel to the first of large, slightly curved and pointed teeth.

The lower inner blade has teeth of the same size and form as the larger teeth of the upper blade. They form four longitudinal rows of unequal length so that ensemble looks like a triangle. The teeth of each row alternates with those of the adjacent rows so that they appear staggered.

The proximal part of the jaw is short, rounded, swollen. The irregular blade of attachment that is near the end is very developed.

Some small teeth are found either on the lower border of the free wing of the distal part of the jaw or on the calcareous blade that is connected to the proximal part of the jaw. These teeth seem to continue the rows of the lower inner blade of the distal part of the jaw.

4. AsterACANTHION TENUISPINUS, M. and $\mathrm{T}^{25}$ - The straight pedicellariae together have the form of an elongated oval, whose basal pieces form the large end. It has nearly a sixth of the total length of the organ and can be compared to a demi-ellipse whose axes are between them as 3 is to 4. Its holes are circular, smaller towards the edge, larger to the center.

The inner border of the jaws is finely toothed. The lower part of this border has itself a long groove at its upper part to form several teeth. The holes of its lateral surfaces are also rounded.

\footnotetext{
${ }^{23} \mathrm{Pl} .17$, fig $5 a$ and $b$.

${ }^{24} \mathrm{Pl} .17$, , fig. $5 a$.

${ }^{25}$ PI. 1, fig. $3 a, b$ and $c$.
} 
The jaws, finely toothed on their inner border, has on the lower part a long groove that is itself toothed on its upper part to form several teeth. Their width is nearly the same their entire length. The holes of its lateral surface are also rounded.

The crossed pedicellariae have nothing remarkable in their form. They are always characterized by certain structural details that are easy to see.

The holes of the basal piece, rounded in the area of the irregular apophyses, become elongated in the body of the piece and seem to form slight curves radiating from its top. At the upper part is a large median hole and other smaller ones in the same median horizontal line. The proximal end of the jaw is short with the same width throughout. The distal end of the jaws has a groove on the upper inner part. If one examines the inner blade, one sees that the upper has two or three rows of very fine teeth on its outer border. Then above three rows of large teeth are arranged transversally in a curved line so that the upper envelopes the other two. The first and the second have the greater number of teeth.

The lower inner blade has three of four rows of teeth arranged in longitudinal series and fill up most of the median part.

5. Asteracanthion violaceus, $M$ and T. - Very elongated pedicellariae. Basal piece forming near a seventh of the height, two times as wide as high.

Jaws end in a point, finely toothed on the inner border.

Crossed pedicellariae greatly resembling those of Asteracanthion rubens, but less delicate. All their parts more massive.

6. AsteracANTHION POLARIS ? - We conserve for this species the name given it in the collections of the Museum. We cannot however confirm that it is the species of Müller and Troschel. In doubt, we believe it is necessary to give a complete description of the single individual we have observed.

Six arms, three times as long as the diameter of the disk, a little more than three times longer than wide, very convex.

Disk covered with rounded tubercles, strongly grooved longitudinally, having a tendency to be arranged in irregular groups of five or six. Each of them is surrounded by a belt of crossed pedicellariae. This belt is sometimes a single circle, sometimes several circles. Other times it is irregular, having on one side up to four rows of pedicellaria and on the other only one or two. The madreporite is surrounded by a circle of tubercles with pedicellariae. They have projecting sinuous lines, wider than the intervals that separate them and having here and there some recurring parts. It is slightly projecting and located about 2 millimeters from the line separating the arms.

These are pointed but not elongated. Their dorsal surface is covered with tubercles and pedicellariae completely like those of the disk and having no regular arrangement. The intervals that separate the circles of pedicellariae relative to these tubercles is filled with papulae. The edge of the dorsal surface of each side has a slightly regular row of spines, with a height nearly twice the diameter of their base and not projecting, if sometimes slightly at the top.

On the ventral surface we see the spines of the ambulacral grooves appear to form sometimes two rows, in which all the spines are in contact with each other, sometimes, and this is the most general case, four or five rows of spines arranged so that the spines of one row alternate with those of the following row. These spines are cylindrical, rounded at the top, relatively thinner than the other spines of the ventral surface and separated from each other by a large quantity of straight pedicellariae. 
After the spines of the ventral groove are two very regular rows of large, smooth spines, rounded at the top with the diameter nearly double those we just described. Some smaller isolated spines sometimes occur between the most outer row of these spines and those that border the dorsal surface. These two latter rows have a longitudinal space between them in which are usually only the tube feet.

The collection of the Museum has only a single individual of this species. It comes from the north of Greenland by L. Rousseau, who collected it during his voyage with Prince Napoleon.

This individual is from 15 to 16 centimeter in diameter.

The two forms of pedicellariae are very remarkable.

The straight pedicellariae ${ }^{26}$ are elongated. They are quadrilateral with rectangular diagonals and a blunt end. The greater diagonal is the smallest as 12 is to about 7 . They meet at a fourth of the total length of the first. As the smaller diagonal is formed by the upper part of the basal piece, it forms a fourth of the total length of the organ.

It is a trapezoid whose small base coincides with the free part of the piece. This small piece has a slight concavity in hi middle. It is to the large base as 1 is to 3 . The inner blade has its base a demi-circular groove to contain the muscle.

The jaws form a kind of isosceles triangle whose top is replaced by an arc and whose base is to the height as 7 is to 10 .

The crossed pedicellariae ${ }^{27}$ are not very numerous and their form is like the preceding, geometric. The edges do not have a curve parallel to that ordinarily found in other species.

The distal parts of the two jaws form a kind of equilateral triangle. The proximal ends of the jaws are elongated with nearly parallel borders.

We must note the great development in this species of the calcareous lattice that covers the proximal end of the jaw. It goes nearly to the top of the distal end of the jaws.

The basal piece becomes closer to the usual form. It has round holes. The upper ones form a horizontal line. Their diameter is scarcely above those of the holes of other parts.

The upper inner blade has a curved row of large, long teeth that is most interior and above which are two or three rows of small, very numerous teeth. The interior inner blade is short and has five or six longitudinal rows of teeth of the same size as the largest ones of the upper inner blade. The number of teeth is variable from one row to the other. They extend up to the second part of the stalk of the jaw.

7. AsteracANTHION RUBENS M and $\mathrm{T}^{28}$ - In A. rubens, the two kinds of pedicellariae are arranged as usual. The straight pedicellariae are distributed in more or less great numbers on the dorsal surface, in the vicinity of the ambulacral groove and in the angles of the arms. They are large, a little elongated with a basal piece that is rectangular with rounded edges. This is surmounted with jaws ending in a round spoon and, consequently, lacking a terminal hook.

The jaws have an irregular free border, scalloped and toothed. We have been able in this species to assure ourselves of the sensitivity of pedicellariae. It is sufficient to place the point of a needle between their jaws, when they were open, to see them close immediately, seize the point and sometimes detach rather than let go. Only, with the weakened individuals at our disposition, it has not been possible to see spontaneous movements of the pedicellariae.

\footnotetext{
${ }^{26}$ PI. 1, fig. $6 b$.

27 PI. 1, fig. $6 a$.

${ }^{28}$ PI. 1, fig. $2 a, b, c, d, e, f, g$.
} 
The crossed pedicellariae are found as usual around the spines. In life, we very clearly see them with the naked eye. The white color of their skeleton is very clear on the violet background of the fleshy mass that supports them and that does not cover and uncover them as in Asteracanthion glacialis.

In Asteracanthion rubens, the crossed pedicellariae form at most two belts around each spine. Still, most often the exterior belt is incomplete.

These pedicellariae are those that we have studied first. The jaw and the proximal part are inclined towards each other at about 60 degrees. They have nearly the same length. Both are two times longer than wide.

The inner border of the basal piece is rounded. Its two apophyses are very marked.

8. ASTERACANTHION ROSEUS, M. and T. ${ }^{29}$ - The straight pedicellariae are wide and short. Their length is at their greatest width as 8 is to nearly 10 .

The basal piece is about a fourth of the total length. Its width to its height is 2 to 1 . The grooves on each side of the median apophysis are inconspicuous.

The jaws are rounded exteriorly, finely toothed in the interior and each ending in a hook. One side only of the surfaces of each jaw is prolonged to form the hook. The other continues its path. This results in a hollow in which is found the hook of the other jaw. If, in fact, it is the lower surface of the left jaw that forms the hook, this will be the upper surface of the right jaw that contributes to form this part. We shall find again a similar arrangement in Asteracanthion aurantiacus with which Asteracanthion roseus shows moreover numerous analogies of form.

The crossed pedicellariae differ little from the ordinary forms.

The proximal part of the jaw is very developed but not swollen. It has a fenestrated blade that reaches nearly to the distal part of the jaw.

These have a lower inner blade with three rows of staggered large teeth.

9. ASTERACANTHION LINCKII, M. and T. - It exists in the collection only in the dry state. I have not been able, for this reason, to study the pedicellariae.

10. ASTERACANTHION STRIATUS, M. and T. - There exists in the collection only a single dried individual in very bad condition. I have found neither the straight nor crossed pedicellariae but am sure of their existence.

This species is remarkable by the addition to the two kinds of pedicellariae that we find in other Asteracanthion, of a third kind that we shall see later nearly constantly in oreasters and culcitids. I want to speak of valvular pedicellariae.

In the animal that concerns us, two elongated calcareous blades, attached to the tegument, surrounded by a kind of rampart composed of spines, constitute these pedicellariae. They are found on the ventral surface where they found a row on each side of the ambulacral groove.

In the individual we have examined, the two exit pores of the tube feet of one side were joined by a slit, while in the other species the pores are generally perfectly circumscribed. Are these conditions sufficient to form a generic section? I do not think so. But this character is good to report.

${ }^{29} \mathrm{Pl} .1$, fig. 7. 
11. AsteracANTHION AURANTIACUS, M. and T. - The straight pedicellariae of Asteracanthion aurantiacus are remarkable. They have the general form of an isosceles triangle whose height to the base is nearly 11 to 7 .

The basal piece is a kind of trapezoid whose large base is rounded and the small is five sixths of the first. The total height of this piece is a little less than half its largest width. The basal piece, like the rest of the organ, has a large number of round holes.

The jaws are about four fifths of the total height of the pedicellaria. Each of them ends in a blunt hook, very elongated and formed only at the expense of one of the surfaces of the jaw. The other surface continues without any modification of curve. As in Asteracanthion violaceus, the surface without a hook on one side comes to be opposite the surface with one, so that the pedicellaria is symmetrical in relation to a line but has no plane of symmetry.

The crossed pedicellariae are especially distinguished by the considerable enlargement of the spoon that forms the distal part of the jaws.

We place in the genus Asteracanthion, the animal designated by Gray under the name of:

12. HELIASTER HELIANTHUS. - It does differ from the ordinary Asteracanthion by the multiple arms, their form, and finally by the very particular color. But these reasons appear insufficient to us to establish a new genus. There are asteroids in the collections of the Jardin of Plantes that we are going to have to describe, that also have very numerous arms, but that have nevertheless all the other characters and up to the exterior appearance of Asteracanthion with five arms. These species with multiple rays lead us without abrupt changes to Heliaster and we conclude to maintain these in the genus Asteracanthion.

In the absence of anatomical investigations that we have not been able to make, or embryological studies that it would be interesting to do, we do not believe it necessary to conserve a genus based only up to now on the exterior so close, moreover, to ordinary forms. We are confirmed in our opinion by the absolute identity that we give in all respects the pedicellariae of Heliaster and those of Asteracanthion.

We still have not found straight pedicellariae.

The crossed pedicellariae are placed, as usual, around the spines. They are relatively few and of ordinary size, but much enlarged.

The basal piece is nearly two times as wide as high.

The proximal part of the jaws after its first curve is nearly horizontal. It is nearly, after this point, two times as wide as long. The distal part of the jaw also is not curved in other species.

The lower inner blade has only three longitudinal rows, each with four or five large teeth. These arrangements are very apparent if the organ is observed from the inner surface.

The perforations are numerous and circular. The fenestrated blade of the proximal part of the jaw has only a very ordinary development.

We come now to a series of species of the genus Asteracanthion whose precise determination is not possible because of the brevity of the descriptions that are given by most of the authors. It is possible that these species are already known, and we do not claim any priority in this regard. We will be happy to give each its due as soon as it appears to us sufficiently justified.

Our desire for the moment is to make known what is in the collection of the Museum of Natural History of Paris. We conserve, as we have already said, to each of the species already named but not described by Valenciennes, the name that he has given them. Our task is thus to fix these names 
by means of a precise description. We shall add only characters that are usually given, the valuable characters furnished by the pedicellariae. We will have made thus, as naturally as possible, a first application of the results of our research.

13. ASTERACANTHION NOVÆ BORACENSIS, Val. - Five arms, nearly four times as long as wide, three and a half times larger than the diameter of the disk, slightly flattened.

Disk with a large number of spines, thick, short, rounded at the end, and irregularly distributed on the surface. Very large madreporite, projecting, not surrounded by spine and very near the border.

The dorsal surface of the arms has three very regular lines of spines, one median and the other two absolutely lateral. These three lines form keels, especially those of the border. Between them are a large number of scarcely small spines distributed irregularly as usual at the top of the angles of the calcareous network formed by the skeleton. Numerous slender papulae are on the surface of the back.

On the ventral surface is the ambulacral groove, bordered by a double row of spines, nearly cylindrical or slightly flattened at the end. These spines are very short. Those of the outer row are shorter than the others. Outside these spines of the ambulacral groove is a double row of spines united by twos at their base that are in the middle of the space between the ambulacral groove and the line of spines that of the dorsal region. In addition, towards the inner third of the arms, this double row of spines if flanked on each side with a new row of simple spines. This make in all four rows of spines on the ventral surface. Finally, the spines of the lateral keel becomes double near the angle of the arms.

The pedicellariae of the first kind, straight pedicellariae ${ }^{30}$, are a little longer than wide. They have nearly the form of an equilateral triangle with curved sides.

The basal piece is smaller than the bases of the jaws. Its height is a little more than a third of its width. This is nearly the same everywhere, a kind of geometric figure that approaches the form of the basal piece, a rectangle. The height of the basal piece is nearly a fourth of the total height of the pedicellaria.

The other three fourths are formed by the jaws that are very finely toothed on the inner border up to the edge of the groove for the adductor muscles.

The entire length of the calcareous pieces are perforated with round holes except, as usual, the space between the inner border of the jaws and the line of insertion of the inner blade. We see only in this space thicker portions that are kinds of bars of reinforcement.

The crossed pedicellariae ${ }^{31}$ have, like the straight pedicellariae, a more or less thick form.

The basal piece has the ordinary elliptical form. We note on its upper part an unperforated horizontal line and, what strikes the eye, as soon as it is put under the microscope, by its glow. The jaws are very short. Their proximal part is little developed and has nothing special. The figures here, as in any description, says more than words. Our role must thus be to simply call attention to the particularities that appear to us most characteristic.

The upper inner blade is covered with a large number of small teeth that make it resemble a combing card. The lower inner blade has only a limited number of these teeth that are in contrast larger.

These teeth are arranged in a kind of $\mathrm{V}$ that encloses the groove which will contain the basal piece. The top of the $\mathrm{V}$ is formed by two teeth.

\footnotetext{
${ }^{30}$ PI. 1, fig. 9, $a$.

${ }^{31}$ PI. 1, fig. 9, $b$.
} 
The fenestrated part of the proximal part of the jaws is moderately developed.

A single individual from New York with a diameter of about 25 centimeters, as best we can judge on an individual preserved in alcohol.

The color in this liquid is a uniform pale grey.

14. ASTERACANTHION SULCIFER. - Val. ${ }^{32}$ - Five elongated arms, rounded, at least four times as long as the diameter of the disk, pointed, with five to six times longer than wide.

The entire surface of the body is granular because of the large number of pedicellariae that cover it. These pedicellariae are nearly all crossed pedicellariae.

On the disk are irregularly scattered a very large number of small cylindrical spines with a blunt end. The madreporite is located on the border of the disk. It is elevated and surrounded with a circle of spines analogous to those of the back. The number of these spines is not constant. The average number is fifteen.

On the dorsal surface of the arms is a slightly projecting median line with spines that are often arranged transversely three by three. This arrangement is especially well marked in large specimens and principally towards the base of the arms. Then on each side are three irregular lines of spines that are often double. Between these lines are some spines, also double. This is a very regular line of spines, nearly all simple, that we can consider as the edge of the dorsal surface.

All the spines being elongated, the lines that they form are not very apparent at first. The frequent doubling of spines and the isolated spines on the disk increase again the uncertainty of the number of lines. But it is sufficient to recognize them rapidly with a little inspection.

On the ventral surface, we see many spines that form both three, four or five transverse rows and longitudinal rows. These spines again have a tendency to be double. At the base of the arms they become very much larger and longer. They are rounded at the end and nearly in contact with each other. The spines of the ventral surface aee generally much laager and longer than those of the dorsal surface.

We come finally to the ambulacral grooves whose spines are thin, elongated, pointed or wide and flat at the end. These spines are arranged in two rows.

The straight pedicellariae are very numerous and found principally at the angle of the arms and among the spines of the ambulacral grooves. They are very elongated.

The basal piece is about a fourth of the total height. Its height is nearly half its width. The jaws end in a blunt hook. The calcareous substance that compose them has an innumerable quantity of very small holes, or to say better, the rods of the calcareous network that constitute it are so close together that they scarcely leave between them spaces with a diameter equal to their thickness.

The crossed pedicellariae are extremely numerous, arranged in groups around the spines and found between them. The basal piece is ellipsoid as it is usually seen. But its height is scarcely equal to its width.

The jaws are slightly elongated with a straight proximal part from the elbow. It has a fenestrated piece going up to its middle.

The upper inner blade is completly bristly with teeth forming three or four curved rows. The teeth alternate in two consecutive rows. Those of the inner row are large. On the lower inner blade, immediately above this latter row is a longitudinal row of teeth going up to the end of the border that is not related to the proximal part of the jaw. These teeth are not cut into the border itself. They are found slightly to the interior. Nearly on the median line, below this inner blade, is a small groove around which are small teeth. Lower is a row of three large, very apparent teeth, separated

${ }^{32} \mathrm{Pl} .1$, fig. $14, a, b$ and $c$. 
from the preceding by another large tooth placed between the two that are more inner and above. Above the large outer tooth, three or four other smaller ones form an irregular longitudinal row.

The Museum has five specimens of this species coming from Port Famine. They were collected by Hombron and Jacquinot (Voyage de l'Astrolabe).

It is impossible for me to determine their color.

Their size reaches about 3 decimeters in diameter.

15. ASTERACANTHION GEMMIFER, Val. ${ }^{33}$-A large and beautiful species with eleven arms, each four times the diameter of the disk in length. This is equal to six or seven times their width.

Disk covered with very elongated, pointed spines, each surrounded by a sheath that can cover it at some times as in Asteracanthion glacialis. In the state of retraction, which is found after a long period of the animal in alcohol, these sheathes form large pads covered with crossed pedicellariae around the base of the spines. There is only one small madreporite located near the border of the disk in the interval of two arms.

The arms are rounded, five or six times as long as the diameter of their base, with five longitudinal rows of perfectly regular, very pointed spines. Each spine is surrounded by a sheath like that of the spines of the disk and with pedicellariae. Between these rows are tufts of papulae.

On the ventral surface, the spines of the ambulacral groove are thin and slightly flattened at the end. They are arranged in a single row. Each angle of the arms shares two or three divergent spines that are directed towards the mouth and protect it. Outside the spines of the ambulacrals and filling the space separating them from the last row of the dorsal spines is a new row of sharp, elongated spines. They are arranged transversely, three by three or two by two. The most inner spine, in the case where they are three, is more pointed and narrower than the two others and is less tightly connected to its neighbor than to the outer one. This latter has only a bunch of pedicellariae forming only a demi-crown.

The straight pedicellariae are abundant in the interior of the ambulacral grooves and I have scarcely encountered them there, at least in the single specimen I have under my eyes.

They are small (about 1/3 millimeter). The basal piece is a fifth of the total height. It is nearly two times wider than high and its greatest width is nearly that of the jaw.

These become thinner towards their end and the exterior border is slightly concave so that the entire pedicellaria has the form of an oval. It greatest rectangular dimensions are between them as 2 is to 5. The inner border of the jaws is very finely toothed and a little sinuous. The inner blade is irregularly grooved at its base for the passage of the muscle. The end of the jaws is rounded and lacks hooks.

The crossed pedicellariae have a basal piece that is ellipsoid, as usual, with the median part formed of a simple blade pieced with round holes. This blade is reinforced in its upper part. Below the reinforced part are two or three larger perforations arranged in the same horizontal line. The regular apophyses are little developed.

The jaws have a short, round proximal part. Their fenestrated blade is well developed. The distal part of the jaws are elongated, but their width is not great. The upper inner blade has four or five curved rows of teeth. Those of the upper row are small, but those of the lower rows are large and nearly superimposed on each other. The lower inner blade has in this cavity five longitudinal rows of large teeth arranged a little staggered. These rows contain a variable number of teeth, from four to six. The median row has the most. In the wing of the jaw, that is not continuous with the

${ }^{33}$ PI. 1, fig. 12, $a, b$ and $c$. 
proximal part of the jaw, are two or three rows of small teeth parallel to the border. They appear to continue the two nearest longitudinal rows.

The size of this species is about 25 centimeters of diameter, the measurement being taken of an individual conserved in alcohol since 1832.

Its color has become a uniform yellowish white.

The single specimen possessed by the Jardin was collected in Chile by Eydoux.

16. We must bring closer to Asteracanthion gemmifer another single individual in very bad condition in the collection.

The length of the arms is three or four times greater than the diameter of the disk. But they are so damaged the form cannot be recognized. There are twelve of them and each has five rows of spines as in Ast. gemmifer. On the rows are less regular and the fleshy pad of the pedicellariae is less developed.

On the ventral surface, the spines that border the ambulacral grooves are arranged in two rows. Between the two grooves and the last row of the dorsal spines, there are two rows of spines as in the preceding species.

The straight pedicellariae are found especially in the interior of the ambulacral grooves. They are small as in the preceding species.

The basal piece is a fifth of the height. Its form is that of a trapezoid with a large convex base.

The distal part of the jaws have a height that is to the width of their base as 3 is to 4 . The upper inner blade has only a single row of large teeth. It is the lowest. Two or three rows are above and formed of very small teeth.

The lower inner blade has above two lateral holes that are symmetrical and oval. It has five rows of teeth. The median one has five teeth. The two adjacent ones also have five teeth alternating with those of the median rows. The most elevated is above the most elevated tooth of this latter row. The extreme rows have only three or four teeth, a little smaller than the others. Finally, small teeth are still visible on the free wing of the jaw.

Size, about 2 decimeters.

Origin, Australia (Quoy and Gaimard, Urville expedition).

17. ASTERACANTHION STELLIONURA, Val. - Species with five arms, elongated, pointed, having a length about four times the diameter of the disk. A little convex.

Disk continuous with the arms, having scarcely a few rare slightly elongated, blunt spines. Covered with a very large number of straight pedicellariae. Madreporite slightly projecting, without a border of spines, located a few millimeters from the angle of the arms on the ray that goes to the top of this angle to the disk.

Arms having on the dorsal median line a row of small, thin spines. Each side of the arms with scattered spines, still smaller than those of the median line, or three rows of these same spines that are not distinct or regular. The entire surface of the arms is covered with papulae and straight pedicellariae in so great a number to make the spines unapparent in individuals preserved in alcohol, the only ones we have at our disposal. It should be noted that the spines of the back are not surrounded by a circle of crossed pedicellariae that we have seen up to here constantly. The straight pedicellariae being perfectly preserved I do not believe it is necessary to attribute the absence of crossed pedicellariae of the dorsal region to an accidental cause. I have had, moreover, in my hands five individuals of this species that are all in this condition. - The dorsal region is 
limited by a very regular line of straight pointed spines which, this time, are surrounded by crossed pedicellariae.

On the ventral surface are: $1^{\circ}$ spines that border the ambulacral grooves. They are short, dispersed in two lines. The inner one is turned back on the grooves and the outer one is turned back to the contrary outside it and has smaller spines. - At the angle of the arms the lines are turned back towards the mouth, at least in general. $-2^{\circ}$ a row of very large, very strong spines surrounded on the outer side by a sheath covered with crossed pedicellariae.

The pedicellariae have a special, very characteristic form.

The straight pedicellaria have a basal piece ${ }^{34}$ whose lower surface is convex, the lateral surfaces concave, and the anterior and posterior surfaces flat. As a result, they have the form of a curvilinear trapezoid whose large base would be convex, the two lateral edges concave, very inclined at the base and the irregular upper base. The height of the trapezoid is scarcely a fourth of its small base and about three fourths of the large one. In its median line, this basal piece is prolonged into a long pointed pyramid that is engaged between the two jaws and is elevated a little above half of their height. It is a unique character in the genus Asteracanthion. This pyramid evidently represents the slight protuberance that is noted in the same place in all the other species and that serves as the point of attachment of the adductor muscles of the jaws. - The functions of the pyramid in question are exactly the same. But the special form results in a special arrangement as well of the muscular apparatus.

The jaws form together an isosceles triangle with convex sides and whose base is to the height as 3 is to 4. - Basal piece and jaws are reticulated their entire length, except on the inner border that is homogeneous and finely toothed on its side. These very regular teeth are only seen at a magnification of about 140 diameters (Oc. 1 - obj 2 of Nachet).

The crossed pedicellariae are also remarkable no less than the straight pedicellariae. The basal piece, although of a form little different than usual, as can be seen in plate 17, figure $10 c$, is nevertheless much smaller relatively to the size of the jaws.

These $^{35}$ do not have any smooth part, which is an exceptional condition. The proximal part of the jaw, like the distal part of the jaw, has a reticulated structure their entire length.

It would be difficult to distinguish for the distal part of the jaw an inner surface and still less to subdivide it into two blades, one upper and the other lower. The distal part of the jaw is rather a kind of triangular pyramid whose ridge turns towards the interior. This ridge or rather the rounded facet that it represents has three rows of very large, staggered teeth. - At its lower part, the two calcareous leaves that form it are separated so that one forms the free wing of the pedicellariae while the other rejoins the proximal part. In this course, the borders of both leaves have two rows of small teeth, one on their side, the other above at a small distance.

The top of the pyramid has a hook formed of two very large teeth one exterior, one interior. Between them are three or four small ones.

On the inner blade, each tooth is flanked by two small holes. The ensemble of these holes forms two very regular rows of perforation that can delude at first glance of the number of rows of teeth when observed with a microscope.

Asteracanthion Stellionura is about 18 centimeters in diameter.

It was collected at Iceland by Gaimard in 1825 in the expedition of the Recherche.

The color of individuals preserved in alcohol is uniform whitish grey. The Museum has five very well preserved specimens.

\footnotetext{
${ }^{34}$ PI. 1, fig $10 b$.

${ }^{35} \mathrm{PI} 1$, fig. $10 d$.
} 
ASTERACANTHION LACAZII, Ed. PL. - We have been able to test with this species the value of the character furnished in some genera by pedicellariae. - It is found in the collection of the Museum under the name Echinaster echinura, Val. In fact, its exterior appearance is that of some Echinaster and the tube feet have been so greatly compressed that they seem at first glance to form two rows. We ourselves were for a moment mistaken and we ourselves were about to describe our animal as a new Echinaster, when in examining the ventral surface with the microscope, we saw there pedicellariae. The microscope showed us these pedicellariae were completely identical with the straight pedicellariae of asteracanthions. We then had some doubts. We found without difficulty around the spines of the dorsal surface, crossed pedicellariae. Finally, a more careful examination of the ambulacral grooves of the individual we have before our eyes, and three other smaller individuals preserved in alcohol that were with it, allowed us to confirm that the ambulacral tube feet were really arranged in four rows and not two. - The Echinaster echinura of Valenciennes is thus really an asteracanthion. I add to its specific name that of our wise master, Lacaze-Duthiers, who in his courses at the Normal School and in his special advice had indicated to me the pedicellariae as a subject of some interest.

Asteracanthion Lacazii has five arms whose length, from the center, is nearly five times as large as the length of the ray from the disk. These arms are slightly convex, ended in a point, six times as long as the diameter of the base. - Their entire dorsal surface, as well as the disk, is covered with a large number of large cylindrical spines, truncated at the end, each surrounded at their base with a single or double circle of crossed pedicellariae.

The spines of the ventral surface have a tendency to form multiple rows in the vicinity of the borders. There is then a vacant space where are, especially in the vicinity of the angle of the arms, many straight pedicellariae. - The spines of the ambulacral grooves are arranged in two rows, slightly flattened and truncated at the end. Those that form the inner row are a little larger than the others.

The straight pedicellariae have a rectangular basal piece at least four times as wide as high. They jaws abruptly become thinner at the end so to end in a point. They are finely toothed on their inner border.

The madreporite is large, projecting, located between the center of the disk and its border. It is marked with grooves that dichotomize and radiate from the center.

Collected in 1846 by Smith from South Carolina.

The descriptions we just gave, the figures that accompany them, show how constant are the two kinds of straight and crossed pedicellariae in the entire genus of Asteracanthion. - It is difficult to distinguish slight specific variations. The most absolute identity to the least detail is found in all species. - We can conclude from that, and also the care with which the pedicellariae are constructed, that these organs play a role of some importance in the functioning of the animal. Observations made along the same lines, and in favorable conditions where we find ourselves, will be necessary to clearly define this role. We are forced to do this at another time, - at least that another naturalist happier than we does not preempt us. - Our study still has importance because it will have called attention to the organs whose size is negligible but that show nevertheless, as we see it, numerous interesting particularities.

If now we note that the form is absolutely constant and absolutely characteristic of the pedicellariae coexisting in the genus Asteracanthion with the presence of four rows of tube feet, a character which alone appears to us to have an importance more than generic, we will have to 
separate the asteracanthions from other asteroids more than is usually done. - For us, the animals making up the genus Asteracanthion should form a group of value equal to that forming all the asteroids with only two rows of tube feet. We now are going to study this new group.

\section{PEDICELLARIAE OF ASTEROIDS WITH TWO ROWS OF TUBE FEET}

The asteroids with two rows of tube feet form a group much less homogeneous in all regards than the group formed by asteroids with four rows of tube feet. We divide them into two very natural groups characterized by the presence of absence of an anus. It is not necessary to think that this division will be as fundamental as the character to which it taken would indicate.

The anus is in fact extremely reduced in asteroids. Its role is unimportant and no one will deny that there is a very great affinity between Archaster which has one and Astropecten in which it is completely missing. - We are thus led to think that all asteroids with two rows of tube feet, where they are lacking an anus, must be a unique group, parallel with that of asteroids with four rows of tube feet. It is anatomy and embryology that will decide the question. But we can now bring some considerations have some value to support our opinion.

In fact, in the same way that the transition between the asteroids with four rows and the asteroids with two rows of tube feet is made abruptly in terms of the number of these organs, likewise the form of the pedicellariae changes as abruptly and their presence also ceases to be constant. In a general way, in the group in which the asteracanthions are the type, all straight or crossed pedicellariae have three pieces of which one is simply the support for the other two. In the group that concerns us, this basal piece has completely disappeared. It is the body itself that supports the pedicellaria, so that in most cases the two jaws of the pedicellaria seem nearly to be only two spines near each other of even a single spine that has split. - As a result, the pedicellaria is absolutely sessile. - In the asteracanthions, to the contrary, it is supported by a retractile stalk, whose presence explains and requires in turn the presence of a solid piece to support the jaws and the point of attaching the muscular apparatus that makes it move.

In the majority of cases, the pedicellariae that concern us are thus exclusively formed of two pieces, both active. - In only one genus, Luidia, some species have pedicellariae formed of three pieces. But these three pieces are also, in this case, active pieces, jaws. - Instead of being a pedicellaria with two jaws, the pedicellariae become a pedicellaria with three jaws as is seen in all urchins. It is however not possible - we shall see later - to confuse the pedicellaria of a Luidia with the pedicellaria of any echinoid.

In spite of this simplicity of the structure of the pedicellariae of asteroids with two rows of tube feet, they belong nevertheless to two distinct groups and that have been designated for a long time as pedicellariae with jaws and valvate pedicellariae. We shall accept these names. But we must nevertheless make some remarks on this subject.

The pedicellariae with jaws and the valvate pedicellariae are isolated in some species or coexist, but in different regions of the body as we have seen for the straight pedicellariae and crossed pedicellariae. - In the first case, they are perfectly distinct. But in the second, it frequently happens that all in the intermediaries between the pedicellaria with jaws and the valvate pedicellaria can be found. This is especially apparent on the backs of culcitids and in the dorsal papular areas of oreasters. - We add that in both cases, there are on the ventral surface of the animal better characterized valvate pedicellariae

Similar transitions have nothing to surprise us. The same pieces, identically arranged, make up our two kinds of pedicellariae. Only in the case of pedicellariae with jaws, the two pieces are 
elongated perpendicularly to the body of the asteroid while in the case of valvate pedicellariae they are elongated parallel to the body. As a result, unimportant modifications pass from one variety to the other. We shall find in Oreaster and culcitids all that is necessary to favor these variations.

In all cases, it is easy to recognize that all pedicellariae here, as in the genus Asteracanthion, are covered with an epithelial envelope, perhaps ciliated, but it has been impossible for us to demonstrate that in individuals preserved in alcohol. - This cylindrical epithelium is perfectly distinct, notably in Luidia, and one can follow it easily even on the inner surface of the jaws of the pedicellaria that it completely covers. Nevertheless, it is greatly thinner in this region.

The muscular apparatus is extremely simple. - In the pedicellariae with jaws, it is constituted by a first series of fibers that connect the outer surface of the jaws to the surface of that body and that evidently act to separate the jaws of the organ. — These fibers are vertical. — A little above the base of the pedicellaria are two jaws of these pedicellaria connected by a second series of fibers, this time horizontal, often arranged above a slight indentation in the jaws of the pedicellaria. These fibers constitute the adductor muscle of the jaws. We must note that they have nothing comparable in power with the adductor or abductor muscles of the pedicellariae of the asteracanthions.

As for the arrangement of the pedicellaria, it is also far from being fixed and a clear parallel to those that we have already seen. As usual the ventral surface and the area of the ambulacral grooves are particularly favored. We shall return to the question of distribution in treating each genus.

We have already said that the existence of pedicellariae is not constant in all genera. We have carefully investigated these organs in all the genera that are available to us. We have reached in this regard the same conclusion as Müller and Troschel.

The genera Solaster, Chataster (?), Ophidiaster, Septaster and Astropecten are absolutely devoid of pedicellariae. We thus will have nothing to concern us with them in this report. However, to give our conclusions their true value and to avoid suggesting a broader generalization than what our investigations indicate, we believe it is necessary to give here the list of species that we have examined in each genus.

We shall find in that the double advantage of making known those in the collections of the Jardin des Plantes of Paris and consequently, what will be useful at the same time, that we will have the opportunity to describe new or little species they contain.

Our work will thus be as complete as possible.

\section{GENUS ECHINASTER.}

No pedicellariae

The following species were examined:

Echinaster spinosus, M. and T. ---- crassus, $\mathrm{M}$. and T. ---- gracilis, M. and T. ---- eridanella, $\mathrm{M}$. and $\mathrm{T}$. ---- serpentarius, M. and T.
Echinaster oculatus, M. and T.

---- fallax, M. and T.

----- brasiliensis, M. and T.

----- sepositus, M. and T.

To this list we must add the species in the collection of the Museum not yet described. These are the following: 
EChinASTER Clouei, Val. (Coll. Mus.). - Five arms, rounded, tapering at their end, - three and a half times as long from the center of the ray of the disk and nearly four times longer at the base - Network of ossicles not distinct, all the body appearing covered with a thick skin that envelopes even the spines. - These are short, numerous, pointed or slightly blunt and forming up to eleven longitudinal irregular rows. Some of these can nevertheless be very incomplete or nearly completely absent so that the number of rows is reduced to seven. The spines of the ambulacral grooves are short, dene, obtuse and arranged in at least two rows at the base of the arms.

The madreporite is small, placed near the middle of the ray of the disk, rounded and marked with a small number of large projecting lines and knobs arranged nearly parallel,

The three individuals preserved in alcohol in the Museum are brown in color. But a part of their surface has a nearly black tint that one should consider perhaps the general true color of individuals preserved in alcohol

Diameter of 8 to 9 centimeters. Provenance: Madagascar. - Cloué (1827).

ECHINASTER AFFINIS, Ed. P. - Species very close to Echinaster eridanella, Val., but distinguished from it by the form of the arms that are less elongated and more obtuse — by at least two rows of spines adjacent to those of the ambulacral grooves, after which is a new slightly separated row. The ossicles that connect the spines of this last row to those of the preceding enclose spaces in which is a single papular pore. Nearer the border is a new row of papular pores, likewise isolated or only paired. In E. erinadellus there are never isolated pores. ${ }^{36}$

All the other characters are common to the two species: - six arms, two madreporite plates, etc. White color in alcohol. Origin: North of India.

Obs. - It is possible this species should be united with E. erinadellus, - although the difference in location makes this improbable. Unfortunately, the only E. eridanellus in the Museum is dried, while the E. affinis is preserved in alcohol, which makes comparisons difficult.

ECHINASTER (CRIBELLA) ORNATUS, Ed. P. - Five rounded arms, gradually tapering from the base to the end; four times as long from the center as the radius of the disk, likewise four times as long as their width at the base. - Dorsal surface completely covered with granular papillae that are arranged in dense rows on the ossicles of the network and circumscribing consequently the naked spaces in which are found several papulae. Madreporite located at the border of the sloping part of the interval between two arms, i.e., towards the middle of the ray of the disk. The projecting ridges radiate dichotomously from an eccentric point.

The spines of the ambulacral grooves are cylindrical very large, truncated at the end and arranged in two rows. - Outside are two longitudinal rows of groups of papillae.

Diameter about 75 millimeters (alcohol).

Origin: Cape of Good Hope. (Collected by de Castelneau, 1858).

\section{GENUS SOLASTER}

No pedicellariae.

\footnotetext{
${ }^{36}$ The calcareous network appears to us likewise les projecting and denser.
} 
The species examined are the following:

\begin{tabular}{l|l} 
1. Solaster papposus, M. and T. & 2. Solaster endeca, M. and T.
\end{tabular}

GENUS CHÆTASTER, M. and T.

We have found no pedicellariae

GENUS OPHIDIASTER, M. and T.

No pedicellariae.

Species in the collection of the Museum.

$\begin{array}{cl}\text { Ophidiaster } & \text { ophidianus, } \mathrm{Ug} . \\ ---- & \text { cylindricus, } \mathrm{M} \text { and } \mathrm{T} . \\ ---- & \text { miliaris, } \mathrm{M} \text { and } \mathrm{T} . \\ ----- & \text { multiforis, } \mathrm{M} \text { and } \mathrm{T} .\end{array}$

$\begin{array}{cl}\text { Ophidiaster tuberculatus, } \mathrm{M} \text { and } \mathrm{T} . \\ ---- & \text { echinulatus, } \mathrm{M} \text { and } \mathrm{T} . \\ ---- & \text { attenuatus, } \mathrm{M} \text { and } \mathrm{T} . \\ ---- & \text { ornithopus, } \mathrm{M} \text { and T. }{ }^{37}\end{array}$

It is necessary to add to this list the following new species.

Ophidiaster ATTENuAtus, Ed. P. - Five arms, tapered at the end and nearly ending in a point, nearly six times as long as the disk ray. The dorsal region has numerous oval spines whose long axis is directed transversely and that contains polygonal, flat granulations. These plates are sometimes contiguous in the direction of the arm length to form kinds of longitudinal series broken very irregularly, but most often they are irregularly arranged. Between them are papular areas that are poorly delimited and covered with much smaller granules than those of the plates.

On the ventral surface the spines of the ambulacra grooves are arranged in three rows. There are four or five on each inner row, elongated and slighted flat at the end. - Then come larger spines, short, nearly prismatic that make the transition to polygonal granules that cover the ventral surface. Beyond the ambulacral spines are two regular series of contiguous plates that are separated from each other only towards the base of the arms by a short row of papular areas. The adjacent plates of the ambulacral groove are however not distinct. Finally there is on the ventral surface a third regular row of plates separated from the preceding by a no less regular row of nearly regular papular areas.

Madreporite at the border of the sloping area of the disk, triangular.

Color uniform gray in alcohol. Provenance: Zanzibar. (Grandidier, 1864).

OPHIDIASTER DIPLAX, M. and T. - We refer some asteroids from two different provenances and that have very distinct differences in color to Ophidiaster diplax of Müller and Troschel.

One - coming from Zanzibar (1864) becomes completely white or reddish in alcohol; — the other, collected from the voyage of d'Urville by Hombron and Jacquinol, has taken to the contrary, a brownish tint with large patches of deeper color on the arms. It has seemed to us likewise that in the latter the dorsal plates are a little larger and less dense. But this is very transient character. -

${ }^{37}$ In addition: Ophidiaster diplax, M and T. Locality: Zanzibar. - It can have six arms. 
Color does not seem to us to be a really serious character, especially since the quality of alcohol used for perseveration can have a great effect on these variations.

We must thus maintain together these animals under the same specific name until more information is available. It was necessary however to report the difference that has struck us.

OPHIDIASTER IRREGULARIS, Ed. P. - Species very close to O. diplax, but having dorsal plates very much larger and seven to nine pores in the papular areas. - With only three rows of small, dense ventral plates, then one row of papular areas. Finally, a row of plates larger than those of the back that are irregularly arranged.

A single specimen with four very small regenerating arms and a single very much larger arm.

Mayotte: Cloué, 1841.

OPHIDIASTER PURPUREUS, Ed. P. - Near Ophidiaster cylindricus, but distinguished nevertheless by the dorsal plate, much less projecting and much less regularly arranged. Among the granulations that completely cover the dorsal surface are small projecting tubercles rounded and not forming transverse lines as in O. cylindricus. - Finally, the line of spines located outside the adambulacral grooves is composed of spines a little less dense.

Well preserved in alcohol, the animal we have under our eyes still has a very clear purple color intermixed with dirty brown irregular plates. The papular areas have a maximum of a dozen pores.

Origin: Seychelles. Collected in 1841 by Rousseau.

Ophidiaster (?) Vestitus, Ed. P. - We find it referred to the genus Ophidiaster, but we have some doubt about this, an asteroid collected at Mayotte by Cloué and that is unfortunately much deteriorated. It has five arms that taper slightly towards their end All the body is covered by a smooth skin, thick, perforated above by numerous holes making way for papular pores and having above them sunken lines starting from the intervals of spines of the ambulacral grooves and crossing transversely the entire lower surface of the arms.

Here and there are small spines, short and pointed, numerous especially towards the end of the arms.

$O b s$ - It is necessary to note that the dorsal plates characteristic of Ophidiaster are not visible. The skeleton appears composed simply of a network of elongated ossicles that would lead to referring the species that occupies us to Echinaster instead of Ophidiaster.

\section{GENUS SCYTASTER.}

No pedicellariae.

We have examined:

1. Scytaster variolatus, $\mathrm{M}$ and $\mathrm{T}$.

2. ------ milliparvellus, $\mathrm{M}$ and $\mathrm{T}$.

3. ----- pistorius, $\mathrm{M}$ and $\mathrm{T}$.

4. ----- subulatus, $\mathrm{M}$ and T. or
Ophidiaster linearis, of Valenciennes, Coll. Mus.

5. Scytaster monilis, very near S. pistorius, and distinguished by Valenciennes (Coll. Mus.) 
The latter is remarkable only for the large marginal plates spaced from each that that gives to the border of the arms a mamellated appearance, analogous to that of a string of very flattened beads. This is at least the appearance that Valenciennes wanted to describe.

It is necessary to add to this list a new species that we propose to name for its origin:

SCYTASTER INDICUS, Ed. P. - Six arms tapering gradually to their end scarcely two times as long as the ray of the disk. Dorsal surface having large plates, rounded, thick, projecting, strongly granulated, leaving large spaces between them equally granular that appear subdivided into distinct polygonal areas, with a papula at each apex. - The madreporite is small, with projecting lines of the same width as the valleys and unevenly sinuous. On the border of the arms the analogous plates with large dorsal plates forming two rows, one dorsal, the other less marked, ventral, little regular. - The ventral surface is, moreover, lacking in large plates, is regularly granulose. One vaguely recognizes three rows of plates covered with small tubercles a little divergent. - The spines of the ambulacral grooves are arranged in groups of four or five, divergent on each pates. They form two rows, one lying in the groove, the other turned back outside and formed of small spines. They are cylindrical and truncated at the end. Near the mouth, the spines of the two rows greatly elongate, becoming pointed and turned back outside and thus forming, at the ends of the angles where the ambulacral grooves meet, a kind of very marked covering.

This nice species comes from the Indian seas.

\section{GENUS CULCITA.}

From the point of view of the ornamentation of the skin, the culcitids form with Oreaster a more natural group; same form of tubercles, spines, etc., same form of pedicellariae.

These organs are in general of two kinds. But it is not necessary to suppose from this that they always share these two kinds, either pedicellariae with jaws or valvular pedicellariae. All the pedicellariae can be pedicellaria with jaws or all are valvular. But in these two cases their form differs as to whether they are located on the ventral surface or the dorsal surface - We can say in general, except in the ambulacral groove, every time there are pedicellariae on the ventral surface, they are valvular while the pedicellariae of the dorsal surface have a tendency to be pedicellaria with jaws. We find in the form and in the arrangement of the pedicellariae of calcites good specific characters. The muscular apparatus has an arrangement so simple that we have already indicated in a general way.

CUlCITA DISCOIDEA, Ag. ${ }^{38}$, - In Culcita discoidea, we do not find valvular pedicellariae on the ventral surface, but behind the spines of the ambulacral groove is a row of large spines There is one per plate. - Each of these spines is separated from its neighbor by a pedicellaria with jaws about one millimeter in length. The jaws are thick, massive, finely toothed on their inner border. The texture is very dense and consequently they have very small gaps. Each of these jaws ends in an obtuse point.

The dorsal surface is covered with fine granulations implanted in the skin. These are also found in the papular areas as on the network of calcareous pieces that separate them Among the granulations are found numerous valvular pedicelleriae that are barely twice as large. This often makes them inconspicuous. - Each pedicellaria appears as a round granulation having a

${ }^{38}$ PI. 2, fig. $5 a, b$, and $c$. 
diametrical slot that is immediately seen with a microscope. - These pedicellariae being nearly as wide as long can be considered as forming the intermediate between the pedicellariae with jaws and the valvular pedicellariae.

Culcita Grex (?), M. and T. ${ }^{39}$ — The calcitid in question does not appear to me to be in any way the animal described under this name by Müller and Troschel. I thus believe it necessary to give it a new name to accompany my description of the pedicellariae and a complete description of the animal.

The body is a regular pentagon with slightly concave sides. The ventral surface is flat, entirely covered with fine granules and shared by the lines embedded in more or less pentagonal areoles that are slightly convex. All these areoles are absolutely contiguous like a cake of wax. Along the ambulacral groove are thirteen or fourteen very distinct areoles. An unpaired one in the angle is part of two series at the same time. In the interior of each areole are often some tubercles and some very elongated valvular pedicellariae. Sometimes the pedicellariae can be missing, sometimes the tubercles. - They are in general in inverse number to each other. When there is only a single pedicellaria, the tubercles have a tendency to be in a circle around it. Both can be missing.

In the ambulacral groove, each plate has four spines, nearly the same size. These spines become much larger towards the mouth. They then form with those of the adjacent groove a circumscribed angle a space at the end of which are accumulated a large number of very large tubercles pressed against each other. - Behind the spines of the ambulacral groove is another row of two tubercles behind each plate. - A little behind each pair of these tubercles is a pedicellaria whose jaws are nearly as wide as tall and are not strictly either pedicellariae with jaws or valvular pedicellariae although they are close to them.

On the dorsal surface, the papular areas are depressed between the network that circumscribes them. They have some short needles with a wide base but a very sharp tip. - In the interior of these areas are one or two spines. They are moreover covered with fine granulations, among which we distinguish pedicellariae that are a little larger, a little longer than wide and with toothed jaws on the border. This tissue appears made of a series of calcareous parallel rods connected by very dense crossbars.

The madreporite is located in the interradius about a third from the border. It is slightly projecting — The diameter of the animal is 8 to 9 centimeters. It comes from the expedition of d'Urville.

Culcita CORIACEA, M. and T. - The Museum has only dried individuals that are too deteriorated to speak of their pedicellariae.

We find in the collection of Michelin some culcitids connected with this species. But their identification does not appear certain enough for us to speak of them.

Culcita Novæ GuineÆ. - A single specimen in the collection of the Museum, so deteriorated that it impossible to say anything of the pedicellariae.

CUlCITA ARENOSA, $\mathrm{Val}^{40}$ — Body forming a regular pentagon, but with slightly concave sides. - Top of the body very finely granular and dotted with a large number of short pointed spines on the back. - The papular holes are numerous, dense, small, likewise distributed on the dorsal

\footnotetext{
${ }^{39}$ PI. 2, fig $8 a$ and $b$.
}

${ }^{40}$ PI. 2, fig. 6. 
surface. - We also note towards this region numerous pedicellariae with jaws. Each of the latter is slightly curved on its dorsal part. At the same time it is slightly raise in the middle of its length. These jaws have very clear teeth only on the edge of the terminal spoon. Also, these irregular teeth and spaces resemble especially the simple lacunae of the calcareous material.

The madreporite is large, flat, irregular, every projecting. Instead of having, as in most cases, a series of groove bifurcated several times forming numerous convolutions with its surface without any radiation arrangement. - Its form, instead of being rounded, approaches the form of the cross that results from describing half circles on the sides of a square.

On the ventral surface are two kinds of granules, one relatively rare and larger, the other very numerous and contiguous. We do not find here the alveolar arrangement that we have noted in Culcita grex and Culcita discoidea. - Among these granules are pedicellariae with jaws sometimes longer than wide, sometimes, to the contrary, sometimes longer than wide, sometimes, to the contrary, wider than long, so that one finds nearly all intermediaries between pedicellariae with jaws and valvular pedicellariae, without sometimes having either one or the other.

Along the ambulacral groove, the plates have 4, 5, 6 or even 7 spines whose oblique rows are imbricated so that two or three spines nearest the center, which are smallest, are often partly hidden. Behind this row of spines is a row of large paired tubercles that look like two rows.

At the top of the angular areas limited by the grooves, the marginal spines reach nearly the size of these tubercles that themselves become more robust in such a way that it seems to have in these points an accumulation of large tubercles.

Between two pairs of consecutive tubercles are two united spines, smaller, often unequal and that recall by their location pedicellariae with jaws that area found in their place in some species.

The individual, preserved in alcohol, used in this description, measures 18 centimeters in diameter between the ends of two arms separated by a third.

This calcitid was collected in the Hawaiian Islands by the Bonite. (Eydoux and Souleyet, 1837.)

Culcita PUlverulenta, Val. ${ }^{41}$ - The Museum has only one specimen of this animal. It is preserved in alcohol but badly damaged.

The top of the body is very finely granulated having wide and irregular papular areas, separated by very finely granulated spaces, nearly naked or with only a few small spines

The dorsal pedicellariae are found only in the papular areas. They are small, numerous, in the form of forceps, with very delicate jaws, noted largely on their border, wider toward the middle of their length and slightly recurved at their top. The calcareous blade that constitutes these pedicellariae is pierced with numerous holes and even has some small spines.

I have not been able to see the madreporite. It was found in a portion of the dorsal surface that has been destroyed.

On the ventral surface are numerous flat tubercles, dense and between which are small granulations and pedicellariae. The tubercles become larger near the ambulacral groove where they form a double irregular border. The tubercles located at the angle of the grooves are, as usual, larger.

The pedicellariae located between the tubercles are small, indistinct, very numerous, taking clearly the valvular form. The height of each of the valves is nearly equal to its width.

In the ambulacral grooves, each plate has five or six spines, dense, nearly cylindrical, all nearly the same size, on each plate. The two last plates nearest the mouth have much larger and fewer spines.

${ }^{41} \mathrm{PI} .2$, fig $7 a, b$, and $c$. 
Diameter: about 14 centimeters.

Individual collected in 1829 from the Sunda Strait by Raynaud, expedition of the Chevette.

\section{GENUS OREASTER.}

In spite of the notable difference in the exterior form, it seems to us necessary to consider Oreaster as very close to the culcitids. Indeed, they always have five perfectly distinct arms. These arms have in turn enormous tubercles and reticulations that one does not find in these latter asteroids. But if the ornamentation is examined more carefully, one discovers almost exactly all that we have had to report in the culcitids.

The flat tubercles of the skin, the finer granulations of the papular areas, and the two kinds of pedicellariae are found, for example in Oreaster with the same characters as in culcitids. - Here again we can confirm that all species of this genus have pedicellariae. Some have both valvular and pedicellariae with jaws, other have only pedicellariae with jaws. But we know that between these two forms of organs the connection is much narrower than those that exist between the two sort of pedicellariae of Asteracanthion, so much that we can sometimes on the same individual, find all the transitions between these two forms We have never, to the contrary, found an intermediary form between the straight pedicellaria and crossed pedicellaria of asteracanthions.

There is more: in Oreaster, as in culcitids, one sometimes sees valvular pedicellariae looking like granulations of the skin and the way that a flat tubercle can take the place of a pedicellariae in the pattern or the groups they form on the ventral surface. This nearly permits considering pedicellariae as organs of the same nature as granulations. Thus they seem to be only granulations modified to fill a special role.

Such an assimilation would never come to mind if one studied only pedicellariae in the genus Asteracanthion, where they are always complicated, recalling in no way the ornamentation of the skin.

Also, in spite of a real similarity in the functions of these organs, we have been tempted to ask ourselves if there is a true homology between the pedicellariae of Asteracanthion and those of the second group of asteroids. Would it not rather be analogous organs? It remains for embryology to decide this question. We hope to be able to direct our research in this direction. Science does not have at this moment any work on the sea star that resembles that of Carpenter and Thomson on Antedon rosacea.

The species of Oreaster that are available to us are very numerous, and we have been able to assure ourselves however that the identification of pedicellariae with granules of the skin was not seriously based. In fact, if one examines specimens sufficiently deteriorated that all the ornamentation of the skin is lost on the surface, on the calcareous pieces thus denuded, one sees cavities sometimes nearly circular, sometimes very elongated, sometimes regularly arranged, sometimes to the contrary dispersed without order and whose depth is not very great. These cavities are nothing other than the location of valvular or pedicellariae with jaws of the Oreaster. They exist constantly below each of these organs. - If one then scrapes with a scalpel in the area of a pedicellaria, one can easily see the calcareous piece that the granules that covered it did not allow any indication. These are thus true epidermal productions. The pedicellariae, to the contrary, cross the epidermis and are implanted directly in the very interior of the pieces that make up the skeleton of the Oreaster, exactly like teeth implanted in the alveoli of the jaws. - Only here the tooth can move in the alveolus. 
These arrangements have inspired us to the idea of searching how the pedicellariae and the muscles that make it move were placed in relation either with the circulatory system or with the nervous system. We have likewise pursued research to study the pedicellariae of asteracanthions. No reagent, no dissection, no microscopic examination that was made with some care allowed us to show anything that resembles a nerve of a vessel. In the present case, to reach the pedicellaria, the nerve or vessel it is necessary cross the skeletal piece supporting this pedicellaria. We could think from this that the existence of nerves or vessels would be shown by the presence of a perforation opening into the alveolus of the pedicellaria in each of the pieces of the skeleton that support one or several of these organs. Now, in every case, the alveolus appears to us to end in a cul-de-sac. We have not perceived any orifice on the surface of the calcareous pieces themselves after having carefully isolated and cleaned them.

We are thus led to assume that the pedicellariae that we study at this time receive neither nerves, nor vessels, strictly speaking. However, they can be moved: they live consequently, and everything leads us to think that they are sensitive and that they obey the will of the animal. - We ourselves, in summary, are perfectly assured that we made the asteracanthions close the pedicellariae by touching them even very slightly with the point of a needle.

It is possible however that the orifices of entrance of the nerves and vessels, as the supposed canal that led to the pedicellariae, was too small to be perceived with a simple microscope. To remove all kind of doubt, I made a thin section of one of the skeletal pieces having three impressions of pedicellariae and observed them at a magnification of 140 diameters. This section, made in the area of the base of the alveoli necessarily had to cross the canals if they existed and thus provide evidence of them. Now the microscope showed me the structure of the skeleton of the Oreaster was perfectly homogeneous and showed no trace of canals. These pieces are formed of an extremely dense network of calcareous substance with a mesh perfectly equal and square. These meshes are much too dense for one to assume they give passage to any nerve net, to any vessel. I conclude thus that in Oreaster at least, the pedicellariae have no connection with either the vascular system or with the nervous system if it really exists.

On the other hand, the implantation of the pedicellaria in a distinct alveolus makes the hypothesis that these organs depend on the integumentary system extremely improbable.

The relation between the pedicellaria and the pieces of the skeleton remains to be known. This is what we must ask of embryology, — this we are not able to say at this moment.

OREASTER RETICULATUS, M. and T. - The ventral surface has a large number of scattered valvular pedicellaria having nearly the side of granules but easily distinguished, even with the naked eye. - There are no pedicellariae with jaws in the ambulacral groove.

As to the pedicellariae of the dorsal surface, we are forced to report what authors say. They are smaller and narrower than those of the ventral surface. We find them between the papular pores.

The state of desiccation of the individuals that we have examined prevented us from distinguishing diverse kinds of ornaments of the skin of the back.

We believe it necessary to ascribe to this species two small individuals in the collection of the Museum without indication of location that Valenciennes had separated under the name of Oreaster coronatus. 
OREASTER TURRITUS, M. and T. ${ }^{42}$ There are no pedicellariae on the dorsal surface. - The pedicellariae indicated by Müller and Troschel on the papular areas are only small tubercles surrounding the orifice of each pore.

On the ventral surface, we have seen pedicellariae only on the plates that border the ambulacral grooves. Each of them has in general two, forming nearly two rows parallel to the grooves. Sometimes there are three of them on the same plate, of which two are in line, very near the ambulacral groove and one behind. - These pedicellariae are valvular and nearly one millimeter long. Their constitution shows nothing in particular.

On the closest angle of each of the calcareous pieces of the mouth that border the ambulacral grooves is a pedicellaria with jaws. It is between the first and second row of spines and separates the group of spines on each piece. The jaws of this pedicellaria, as we found in nearly all the Oreaster, are thick, nearly cylindrical and formed of a reticulated calcareous substance with a very dense mail. This substance seems to be made up of longitudinal bars, very slightly divergent at the base and joined in all directions by small cross bars, irregularly arranged. Each of these bars ends freely at the surface of the pedicellaria in a projecting point of different heights. The surface of the organ appears spiny. The spines become more projecting near the free end of the pedicellaria. They give the profile of the outer border of each piece the appearance of a saw with all teeth directed towards the top. - The inner border of the pedicellaria with jaws has a denture composed of short teeth, rounded at the top, very unequal but obviously directed perpendicularly at the border. Each pedicellaria with jaws has an inner surface, obviously flat.

The first bars, very irregular, of the same diameter as the crossbars and distinct only by the general appearance of the calcareous substance, seems to come from the area of the inner border of the pedicellaria with jaws to then go up towards the upper end of the organ. This radiated appearance is also apparent from the uniform linear arrangement of the perforations of the calcareous substance and the spines on the nodes of the network. The spines are very oblique and nearly hidden in the surface of the organ.

The length is twice the width.

\section{OREASTER MURICATUS, Duj. and Hupé ${ }^{43}$. \\ SYN. - Pentaceros muricatus, Linck. Asterias Linckii, de Blainv. \\ Oreaster Linckii, Val. (Coll. Museum).}

On the dorsal surface, in the papular areas, interspersed with granules of the skin, are a large number of small valvular pedicellariae, slightly elongated transversally so that the pedicellaria has the appearance of a small round button, split diagonally. These pedicellariae are scarcely larger than the granules of the skin.

One can distinguish two kinds of pedicellariae on the ventral surface, one, a pedicellaria with jaws, the other valvular. Each of the calcareous pieces that border the ambulacral grooves has in its inner angle nearest the mouth a pedicellaria with jaws. These pedicellariae are thus found placed as in the preceding species. These pedicellariae are very elongated (about three time as long as the ensemble of the width of the two jaws). - The calcareous piece that constitutes them is less dense

\footnotetext{
${ }^{42}$ PI. 2, fig. $1 a, b$, and $c$.
}

${ }^{43}$ PI. 2, fig. $3 a$ and $b$. 
than in the preceding species. One does not see as many points. They are reduced to simple small projections, irregular and rounded.

The pieces of the second row also have most often one and sometimes two valvular pedicellaria, very elongated when they are isolated. These pedicellariae form a very regular row along the ambulacral grooves. The following pieces can likewise have valvular pedicellariae, but the distribution of these organ is irregular. They are abundant only towards the top of the triangle between two consecutive ambulacral grooves. In this species, each calcareous piece has at least one. Beyond half the distance that separates the top of this triangle and the top of the arc between the arms, the calcareous pieces with pedicellariae are the exception.

The marginal plates of the arms always lack valvular pedicellariae.

OREASTER HIULCUS, M. and $\mathrm{T}^{44}$. - In Oreaster hiulcus, the back has two kinds of pedicellariae. Some are obviously valvular, although small and little elongated, is found principally on the projecting reticulation. They are found nearly always among the dorsal granules and tubercles. Their location is marked, as these granules are sunken by the alveolus in which they are implanted.

In the preceding species we have seen, to the contrary, always the absence of pedicellariae on the reticulations and tubercles.

The second kind of pedicellariae is seen in the papular areas. They are larger and more projecting than the granules that cover the area. - The width of each of their jaws is nearly equal to their height, so that these pedicellariae are truly intermediate between valvular pedicellariae and pedicellariae with jaws. - The jaw, after being slightly narrow at its base, widens again in a way to return to its original diameter when it is inserted on the base of the alveolus. - The free border is finely toothed and the calcareous tissue that constitutes the point has very loose mail.

The pedicellariae of the ventral surface are likewise of two kinds. Those of the ambulacral groove are pedicellariae with jaws and located in the same position as in the preceding species. Each jaw of the pedicellaria is nearly six times as long as wide and ends in a blunt point. It is enlarged slightly on near its base. The calcareous tissue that constitute them is not very dense. The surface of the pedicellaria has, in addition, irregular projections, pointed and that are directed towards the top of the organ.

The pieces of the skeleton that come immediately after those that form the ambulacral groove have one or two small valvular pedicellariae, - one is most often, - two rarely. They are exception in those that come next. We have not seen them in other regions of the ventral surface in three individuals that we have examined. But two other small one have two or three valvular pedicellariae of the same form as the others in the median parts of the triangular space between the border of the animal and two consecutive ambulacral grooves.

OREASTER MAMMILLATUS, M. and T. - We have under our eyes seven individuals of this species, of which five have been in the collection of the Museum for a long time that were collected in 1850 in the Red Sea by Clot-Bey. The two others are from the Michelin collection and have no indication of provenance.

These individuals have among them in relation to the pedicellariae some very remarkable differences. In one of them, coming from the Red Sea, one finds very small valvular pedicellariae in the papular areas. These pedicellariae are found in all individuals. We have nothing more to say about them. - On the ventral surface, the plates that form the first row after those of the

${ }^{44}$ PI. 2, fig. $2 a$ and $b$. 
ambulacral groove have each two or three valvular pedicellariae nearly a millimeter in length. We still find some of these pedicellariae on the other place of the ventral surface. Most of the lower marginal plates, especially those that lack tubercles, also have some.

On the upper marginal plates, the valvular pedicellariae have a great development. Either they are very numerous, or they are very elongated, or the place they should occupy is taken by a strong tubercle. - One plate has a single pedicellaria 3 1/2 millimeter long. One other has seven small pedicellariae. These pedicellariae are arranged without order on the plate. But often two or three of them are contiguous and arranged in a straight line in a way that they seem to result from fissiparity of a single pedicellaria that is divided. In this case, the pedicellariae are located in a common alveolus that is retracted a little only at the point of separation.

These same valvular pedicellariae are found finally on the projecting reticulation of the back, principally on the node without tubercles. One also sees them on the side of the same dorsal tubercles.

Each of the plates that border the ambulacral groove has its pedicellaria with jaws as usual. This pedicellaria is very similar to that of the preceding species.

We can apply without any change the preceding to two other individuals from the Red Sea. But in these two remaining, the valvular pedicellariae of the ventral marginal plates either are absent or are very small. It is the same of those of the dorsal plates: they are absent on many of them and are very small on all the others, although found in large numbers on some. The nodes of the dorsal network also lack valvular pedicellariae, as well as the base of the tubercles. But these pedicellariae are again relatively small.

This reduction of the pedicellariae is again more marked in one of the individuals of the Michelin collection. Finally in the other, no marginal plate, dorsal or ventral, has pedicellariae.

We have no information that can indicate to us the cause of these variations in the arrangement of the pedicellariae. - That which appears to use very certain in any case, and that demonstrates the existence of transitions, it that they have nothing to do with the sexes. - All the individuals on which our descriptions are made having nearly the same size, age seems at first to have little influence - On the other hand, the development of the tubercles is only one cause of secondary variation, because the individual that has the fewest tubercles is also the one in which the pedicellariae of the marginal plates are the least developed. Season and locality remain.

It would be interesting to know if the pedicellariae absent at one season can develop in another. - It would be likewise be interesting to know the influence that the environment can have on the development of these organs.

These researches cannot be made on our coasts, where the asteroids with pedicellariae that are found are asteracanthions in which these organs are never missing.

OREASTER MAMMOSUS, Val. Coll. - Oreaster mammosus still has not been described. Its form and ornamentation is near Oreaster turritus and Oreaster hiulcus. But if one accepts that the specific characters used ordinarily have a constant value, it is nevertheless easily distinguished. Its forms are thicker. On the disk, opposite each arm, there is a large tubercle in the form of a sugar cube and covered with polygonal flat granules. Each of these tubercles commences a series of small tubercles that fills the median line of the arms. None of these tubercles, the only ones that exist on the body of the animal, have pedicellariae. There is a very large number of pedicellariae intermediate between valvular pedicellariae and pedicellariae with jaws in the papular areas. There are no others on the back. The marginal plates, both dorsal and ventral, also lack pedicellariae. There are fifteen on each arm. 
The ventral surface is covered with polygonal irregular granules larger in the center of the calcareous pieces that support them. Those of other pieces form the first two after those of the ambulacral groove, have each from outside in: $1^{\circ}$ two large flat spines at the top; $2^{\circ}$ at their internal angle, as usual, a pedicellaria with jaws, analogous to those of Oreaster hiucus; $3^{\circ}$ on its internal border a row of three to five spines, of which the middle ones are much more elongated. As a result, the ambulacral grooves have two rows of spines.

The madreporite is rounded. Projecting and ramified ridges come from the center, others towards the middle of the radius, often anastomosing and seeming to pass into each other. In $O$. hiulcus, the madreporite to the contrary has the form of a diamond.

Zanzibar. (Louis Rousseau, 1841.)

Oreaster Clouei, Ed. P. - This nice little species is especially notable for its swollen marginal plates, that make its border look scalloped. There are thirteen plates for each side and each surface. Some of them towards the end of the arms have a sharp needle. All are covered, as the rest of the surface of the body with small projecting and rounded granules. None has pedicellariae. The pieces that form the frame in the middle of the arms are sometimes projecting in a way that simulates tubercles. They form a kind of keel that ends at each of the tops of the pentagon of the disk. Each end of this pentagon has a blunt needle. In the papular areas are pedicellariae with jaws. Each jaw is rounded at the end, narrows at the end and then enlarges again at reaches at its base of insertion a width nearly twice that of the width it has at half its height. Seen in profile, each jaw is about three times high as wide.

Each of the plates of the ventral surface that forms the frame is separated from its neighbors by a groove, so that this surface is divided into very distinct polygonal alveoli. Most of the plates nearest those that form the ambulacral groove have a valvular pedicellaria about 1 millimeter long.

Each of the plates of the ambulacral groove have from outside in: $1^{\circ}$ one or two large cylindrical spines rounded at the end; $2^{\circ}$ a pedicellaria with jaws of ordinary form at the inner angle; $3^{\circ}$ finally, in the interior of the groove a row of five small spines, the two lateral ones very small.

The madreporite is round with radiating, dichotomous ridges from the center.

The diameter of the single individual of the collection that is preserved in alcohol is 6 centimeters.

I have given to this species the name of Captain Cloué, who collected it in 1847 from DiégoJouarès, and from whom the Jardin des Plantes has received a considerable number of packages.

OREASTER OBTUSANGULUS, M. and T. - Most ventral plates have a large valvular pedicellaria filling the entire length of the plate. The pedicellariae of the marginal plates are smaller, but usually two or three in number. I do not believe there are pedicellariae with jaws among the spines of the ambulacral groove. I can say nothing about the pedicellariae of the dorsal surface. The state of deterioration of the single individual possessed by the Museum prevents a careful examination of them.

OREASTER OBTUSATUS. Oreaster obtusatus allows us to consider pedicellariae with jaws located, as usual, at the inner angle of each of the plates of the ambulacral groove, and not in pairs as Müller and Troschel said and, after them, Dujardin and Hupé. These pedicellariae are very elongated. All the plates that come after have one or two small valvular pedicellariae. 
The pedicellariae of the back are pedicellariae with jaws. Each is supported by a small calcareous piece located between the large pieces that constitute the principal frame of the back.

These pedicellariae with jaws are slightly elongated and widened at the end.

The Oreaster we know at the present and which we have not been able to examine are the following:

Oreaster affinis, M. and T., O. sinensis, M. and T., O. tuberculatus, M. and T., O. verrucosus, O. clavatus, M. and T., O. carinatus, M. and T., O. aculeatus, M. and T., nodosus, armatus orientalis, valvulatus, lapidarius, Dujardinsii. In all, the presence of valvular pedicellariae at least is reported.

\section{GENUS ASTROGONIUM, Müller and Troschel.}

In the genus Oreaster, we have constantly found pedicellaria and, except in one or two cases still a little uncertain, we have found the simultaneous presence of valvular pedicellariae and pedicellariae with jaws. We could have said the same about the Culcita. In such a way, the pedicellariae should be considered as characteristic of these genera.

It is not the same in the genus Astrogonium and in the other genera that remain for us to consider and that are close to these two types. Up to the present there are three species of the genus Astrogonium with pedicellariae. These pedicellariae are bivalvular. We have not found pedicellariae with jaws. These bivalvular pedicellariae show, moreover, the same characteristics as in Oreaster and Culcita. Each of them is lodged in an alveolus dug into one of the calcareous pieces of the skeleton. The two valves sometimes have teeth on their border.

The three species in which we have shown the presence of valvular pedicellariae are the following:

$1^{\circ}$ Astrogonium phrygianum, M. and T. ${ }^{45}$ In this species, valvular pedicellariae are found on the both the ventral and dorsal surfaces. Those of the ventral surface area larger. They form a regular line on each side of the ambulacral grooves are sparse on the rest of the surface. Their length is about 2 millimeters. The height of the valves is about 1 and a half or millimeters. These jaws have teeth on their inner border.

The dorsal pedicellariae have completely the same form as those of the ventral surface. They are only a little smaller and thicker.

$2^{\circ}$ Astrogonium pulchellum, M. and T. - The pedicellariae are borne principally by the plates closest to the outer border of the animal and by those that follow. The other plates of the ventral surface can also have them. This tendency of the pedicellariae to be found on the plates nearest the marginal plates is already here an exceptional fact. Up to here, we have seen constantly that the privileged plates were either the marginal plates themselves or especially the plates nearest the ambulacral grooves.

But the singularity is not limited to this. Ordinarily the plate that has the pedicellaria has a very rectangular alveolus, very wide and elongated in which are the valves that open perpendicularly in the direction of the alveolus. They generally of half the height. Here it is completely to the contrary. The alveolus is very narrow at its ends, widened a little in the middle. The pedicellaria is located in its interior and does not pass it. It is formed of two small pieces, little developed and which open perpendicularly to the length of the alveolus, but in the same direction as its length.

${ }^{45}$ PI. 2, fig. 9. 
This is the first time we have encountered such a form of pedicellaria. We do not know it in any other species of asteroid.

Müller and Troschel saw this peculiarity but do not appear to us to have given a perfectly correct account. They describe it, in fact, in the following manner (Syst. Der Asteroiden p. 55):

Die Bauchplutten sind glatt, jede von einem Kranze dikerer Granula ungeben; auf fast allen findet sich eine meist etwas gebogene Furche welche offenbar dem Sitz einer Pedicellariae entspricht. In dieser Furche liegen immer zwei kalkige Stücke, die sich gegen einander bewegen zu können scheinen; zuweilen stossen auch drei in einen Punkt zusammen und viele andere Combinationen."

We can translate with Dujardin and Hupé (Histoire naturelle des Échinodermes, p. 392):

"Smooth ventral plates, each surrounded with a border of thick granules and nearly all having a groove a little arced that corresponds to the emplacement of pediceellaria that has two or three calcareous pieces that are capable of moving closer together"

For us the groove does not correspond to the emplacement of a pedicellaria, it is actually the emplacement, the alveolus of a pedicellaria, and the calcareous pieces that it contains and that we have never seen exceed two in number. These are the pieces constituting the pedicellariae in question. They form a new kind of pedicellaria.

$3^{\circ}$ Astrogonium australe M. and T. - There are ordinary bivalvular pedicellariae on the back very near the border of granules of the plate.

After these three species, we must report those that we have examined and have not found pedicellariae. They are the following:

\section{Astrogonium magnificum M. and T. \\ ----- astrologorum M. and T. \\ geometricum $\mathrm{M}$. and T. \\ ---- cuspidatum, M. and T.}

$\mid \begin{gathered}\text { Astrogonium granulare, M. and T. } \\ ---\quad \text { Souleyeti, Dujardin and Hupé, in their Hisstoire } \\ \text { des Échinodermes from the Roret collection. }\end{gathered}$

This latter species in the Museum collection was named Archaster lucifer by Valenciennes but is actually an Astrogonium.

Astrogonium EMILII, Ed. P. - Flat body about 1 decimeter in diameter. Upper surface covered with rounded plates, smooth, each surrounded by a circle of granules. Madreporite triangular, having a reticulated structure that scarcely radiates to the borders. It is located in the first third of the ray of the disk from the center.

Twelve dorsal marginal plates on each border plus a very small unpaired one. Sixteen ventral marginal plates on each border, six dorsals and eight ventrals on each arm (sic). The ventral plates decrease slightly in size towards the angles. The dorsals nearly keep their size. The last alone is abruptly reduced. All these plates, dorsals and ventrals, are surrounded by a double row of granules.

The ventral surface is covered with irregularly polygonal plates that are entirely granular. Some have a very large central area, oval or circular, that is completely bare. The ambulacral groove spines are arranged in three rows. The inner two have two spines on each plate, the inner having three. Behind these is found very large numbers of large granules that make the passage between the spines and granules of the ventral surface. The largest and the smallest rays of the body are as 7 is to 11 . 
Unknown Provenance.

The label in the Museum collection has the incorrect name of Goniodiscus Sebre, M. and T.

ASTROGONIUM DUBIUM - I describe this species with doubt. It appears to be only a monstrosity of Astrogonium cuspidatum of Müller and Troschel, of which it has all the principal characters. However, the specimen that I have in my hands has only four arms and the curve of its borders is much less marked than in Astrogonium cuspidatum. One side is damaged and new marginal plates, irregularly arranged, are developed in the area of the wound in larger numbers than normal. These new plates are granulated, like those of the disk, in those parts that are adjacent to the latter. The madreporite, instead of being located between three plates of the disk, as in $A$. cuspidatum, is located between four. It is the most striking difference. Finally, at first glance, the ambulacral spines appear arranged in three rows and not two. But this seems to be accidental and due to the disorder of the spines of the specimen I have in my hands, or an unusual development of small tubercles that are ordinarily located behind the last row of spines.

I believe it is only a simple affair of an accidental and monstrous variety of Astrogonium cuspidatum, M. and T.

Diameter: 7 centimeters.

Provenance unknown.

I find finally in the Museum collection an individual very near A. Emilii that is distinguished from it by the number of marginal plates that is ten above and twelve below, and by uniformly granulated ventral plates.

No pedicellariae — Provenance unknown.

\section{GENUS GONIODISCUS.}

Like those of the genus Astrogonium to which it is very near, species of the genus Goniodiscus are very different in regards to the pedicellariae. Some have valvular pedicellariae, some others (one at least) pedicellariae with jaws. Others completely lack them.

The constitution of the pedicellariae do not differ here from that we have met in the three preceding genera. They are sessile and each is inserted into its own alveolus sunken into the pieces that make up the calcareous skeleton. This is as true for the valvular pedicellariae as for the pedicellariae with jaws.

We shall speak first of the species with pedicellariae.

GONIODISCUS PlAyAdELlA, M. and T. - The pedicellariae are valvular, small and located on the plates that are nearest those that border the ambulacral grooves. One never sees them on the marginal plates, nor on the dorsal surface.

GONIODISCUS CUSPIDATUS, M. and T. - Here the pedicellariae are pedicellariae with jaws. Two kinds can be distinguished: Some a little behind the spines of the ambulacral groove, but inserted on the same plates, the others four or five in number on the plates that immediately follow and on some of those in the median part of the body. 
The first are elongated with jaws attenuated towards their end and at least two and half times as long as wide. The second have, to the contrary, jaws scarcely as long as wide and a little enlarged at their free end.

On the dorsal surface are likewise in the area of the papular areas long pedicellariae with jaws.

Goniodiscus articulatus, Ed. P. - Astrogonium articulatum, Val. (Coll. Mus.). The relation of the smallest and largest diameter is about as 4 is to 7 . The arms are distinct and separated from each other by a deep groove. The dorsal surface is covered with very fine granules and have at the same time a large number of small, irregularly distributed tubercles that are swollen at the end. The madreporite is located a little before a fourth of the smallest ray from the center of the disk. It is oval and has grooves that diverge and divide from the center. There are thirty dorsal marginal plates on each border or fifteen on each arm (sic), without counting the unpaired ones at the end of the arms. They are covered with irregular granules, very large and not contiguous. Each of them has one or two small valvular pedicellariae. These plates decrease towards the end of the arms. They are wider than long. It is the same for the ventral marginal plates that have thirty-two on each border or sixteen for each arm (sic), the last being very small. These plates are covered with granules more dense and more regular than those on the dorsal plate they have, in addition, two or more valvular pedicellariae like those of the back.

The entire ventral surface appears formed of plates, each surrounded by a crown of large granules and have a valvular pedicellaria that fill their entire length. Towards the end of each of the triangles cut by the ambulacral groove, one of these plates is more projecting and has a tendency to from a kind of horn or ridge. The spines of the ambulacral grooves are in two groups: those that form the inner row are arranged in a group of five on each plate, those of the middle being larger and stronger. The spines of the second row are shorter, larger, truncated at the end and arranged in groups of three on each plate. Between the spines of the first and second row, at the inner angle of each piece is in addition, as in Oreaster, a large, short pedicellaria.

The greatest diameter of the dried species is 18 centimeters.

Two individuals of the Museum collection and two in the Michelin collection, From Seychelles Islands.

Nota. - A very large number of small valvular pedicellariae are seen on the dorsal surface.

GONIODISCUS ACUTUS, E. P. - Five arms ending in a point, elongated. The relation between the longest and smallest ray being 2. Dorsal surface with a very large number of scattered irregular tubercles spaced from 1 millimeter or 1 and a half millimeters and interspersed with some valvular pedicellariae. Madreporite located in the first third of the ray from the center, with very deep grooves, much wider than the strips that separate them. Thee form a kind of network towards the center of the plate, then diverge towards the border in irregular dichotomy.

Thirty dorsal upper marginal plates on each border, or fifteen on each arm (sic), without counting the unpaired apical. They are convex, granular, with irregular granule, not dense, larger towards the inner border. Thirty-two ventral marginal plates, sixteen for each arm (sic), flat, uniformly granular and often with a large valvular pedicellaria. All ventral plates with a valvular pedicellaria their entire length surrounded by a double crown of granules. The exterior ones are at least 2 millimeters in length. Ambulacral grooves having behind two large short spines and some tubercles. There is a large short pedicellaria between these two rows of spines, at the inner angle of each of the plates of the groove. 
Diameter: 1 decimeter in the dried state.

Provenance: Australia. Collected by J. Verreaux, 1844.

Such are the species that we have been able to examine and which have pedicellariae. Müller and Troschel reported valvular pedicellariae on the ventral surface and the marginal plates of $G$. pentagonulus; only on the ventral surface of $G$. Sebo; on the ventral surface, marginal surfaces, and less abundant on the back of $G$. seriatus; finally $G$. mammillatus had also very small pedicellariae that we have not seen.

As a result of all that we just said, in the known Goniodiscus, Oreaster and Culcita, the preferred place of valvular pedicellariae is the ventral surface. The pedicellariae are found to the contrary in the ambulacral groove and very often on the dorsal surface in the papular areas.

The collection of the Jardin des Plantes does not have any of the species of Goniodiscus that Müller and Troschel indicated as lacking pedicellariae, i.e., Goniodiscus placenta, G. regularis, G. singularis and perhaps G. capella, or the species indicated by Philippi, in Weigman's Archiv, 1857, under the name of G. verrucosus. But we find in the Michelin collection, acquired recently by this establishment, a very interesting specimen that has this characteristic only on the lower surface. We give it the name:

GoNiODISCUS Michelini, E. P. - Pentagonal body with very strongly indented arms to make five very distinct arms. The largest ray is about one and a third times the smallest. The upper surface entirely and finely granular with granulation intermixed with bivalve pedicellariae, having a length nearly double that of the diameter of the granules. On the median line of the arms are four enormous spines, very large and very obtuse, of which the last is smallest and sometimes scarcely visible (sic). The first, i.e., those that are nearest the center, form a pentagon whose side have a spine in the middle. At the center of the disk, which is also a pentagon, is again a spine: finally there are two or three spines arranged as a triangle on the triangular surface between the median lines of the arm. These spines have granulations only at their base. They are smooth in all their height that is at least 1.3 centimeters at their base. These spines taper gradually towards their end and end in a round surface. The madreporite is located immediately outside and at the base of one of the spines that is in the middle of the sides of the pentagon of the disk. It is slightly triangular and has irregular grooves that radiate by dividing from the center. There are fourteen marginal plates on each border or seven for each arm (sic), more convex towards the end of the arms than in the angles. They are entirely covered with flat, dense granules. The latter is nearly always lacks spines, but the three preceding always have a spine like those of the back but that are reduced sometimes in the plates nearest the end of the arm to a simple tubercle. There are eighteen ventral marginal plates on each border, or nine on each arm (sic), the two last being much smaller than the other, curved and raised almost vertically on the round surface at the end of the arm. All these plates are uniformly covered with flat granules and each has a spine much small than those of the back and the dorsal plates, but of the same form. The better developed spines are found on the plates nearest the end of the arms. In the triangular areas between the marginal plates and the ambulacral grooves are series of lines of tubercles forming a series of triangles similar to the triangle on which they are located. These tubercles are especially more elevated, as they belong to a line nearest the ambulacral groove. On this line they are especially larger as they approach the top of the triangle. All the ventral surface is covered with a perfectly regular granulation. The spines of the ambulacral groove form two rows: those of the inner row are in the very interior of 
the groove. There are four on each plate. Those of the middle are larger than the others. All are thin and flat. The spines of the second row are on the exterior of the groove. They are large, erect, very projecting, round at the tip, and slightly conical. They become smaller and smaller towards the end of the arms. The four or five spines of each series that are nearest the mouth are a little shorter than the preceding ones, much denser and their form, as a consequence, of a kind of reciprocal compression, tends to become triangular. The ten series of spines thus slightly transformed form a kind of very clear buccal armament.

The anus is located at the base of the central dorsal spine contiguous with it and to its left putting, as usual, the madreporite behind it.

The width of the only dried individual that we have is 85 millimeters.

Locality: Mazatlan (west Mexico).

Collection of the deceased Michelin, to whom we dedicate this species.

\section{GENUS NECTRIA, Gray}

Nectria ocellifera, only species up until now in its genus, did not show me any pedicellariae. I have examined two dried specimens of the Museum.

\section{GENUS STELLASTER, Gray.}

STELlASTER ChILDRENI, Gray. - The pedicellariae with jaws of this species have been figured by Müller and Troschel. But the figure they give of it is certainly a figure of fantasy. One never finds in the pedicellariae of asteroids this regular dentition shown in plate VI of the System der Asteriden. The same, in addition, has a completely incorrect figure of the crossed pedicellariae of Asteracanthion gelatinous, and is scarcely happier for the straight pedicellariae of the same species. The pedicellariae with jaws of Stellaster Chidreni are located a little behind the spines of the ambulacral groove, between them and the line of flat spines that follow. They are very elongated, thin, formed of a reticulated calcareous tissue, very irregular, concave at the interior and with a bristly border of a large number of calcareous points perpendicular to this border.

The valvular pedicellariae are located on most of the ventral plates, dorsals and marginals. They are not numerous and relatively very small. Plate IV of the System der Asteriden of Müller and Troschel gives in figures 3 and 4 a good idea of their number, size, and arrangement.

Stellaster Childreni shows thus in its pedicellariae the same general arrangement as the species of the preceding genera. All these genera are moreover intimately related.

\section{GENUS ASTEROPSIS, M. T.}

In the genus Asteropsis, the variety of the pedicellariae is even greater than in the preceding. We find, in fact, one species with pedicellariae, one species with valvular pedicellariae, and finally some species completely lacking in these organs. There is thus in general nothing to say about the pedicellariae of Asteropsis. It is that they do not seem to us, as in the preceding genera, lodged in special alveoli in the calcareous pieces of the skeleton. This is obvious for Asteropsis carinifera, which has pedicellariae all along the dorsal border of the arms. These pedicellariae are found in the middle of the papular areas of this region. They are small, slightly elongated and show something analogous to what we have seen in Asteracanthion. 
Here also the pedicellaria is composed of three pieces, basal and two forming the jaws. The basal piece has a slight cavity in which are implanted the two valves of the jaws. These are short and irregular. They are connected to the basal piece by two vertical muscle fibers that separate the two jaws from each other. At their base, these two jaws crisscross slightly and can serve each other as a point of support. Horizontal muscle fibers can close them. It seems at first glance that these remarkable pedicellariae can be an exception to the general type that we have described for the pedicellariae of asteroids with two rows of tube feet. But it is easy to be convinced that these organs are moving away more from those of Asteracanthion than from those of other sea stars. In fact, the piece that serves as support is not, as in Asteracanthion, in the same plane as the jaws of the pedicellaria and supported by a soft stalk. It develops to the contrary in the skin itself and in a plane perpendicular to that of the jaws of the pedicellaria. It occupies as a consequence, relative to them, the same position as the calcareous pieces taken from the skeleton to support the pedicellaria.

In Asteropsis carinifera, the skin is filled with small calcareous spicules, sometimes a little bifurcated, most often to the contrary rounded at both ends.

Asteropsis vernicina has valvular pedicellariae. I would not have been able to determine their mode of insertion without damaging too greatly the two specimens of the Museum. The arrangement of these pedicellariae is remarkable. There are ten on the dorsal surface located by oblique pairs in the interval of the arms near the border. The ventral surface has only five located alone near the top of each triangular area limited by the ambulacral groove.

We have found no trace of pedicellariae in Asteropsis ctenacanthus and pulvillus. We have observed two Asteropsis pulvillus preserved in alcohol.

Grube reported no pedicellariae in his Asteropis imbricata (Weigm. Archiv, 1857, p. 340).

\section{GENUS ARCHASTER, M. and T.}

The genus Archaster belongs to a type very different from those that we have just studied. By their exterior appearance the species that compose it recalls completely Astropecten. They are a different genus only by the presence of an anus and well developed pedicellariae. The valvular pedicellariae have disappeared with the large calcareous pieces that form the skeleton in which they are lodged. The pedicellariae that exist only have, moreover, this general type, common to all species of asteroids with two rows of tube feet and to which we have found as a half-exception in Asteropsis carinifera. The two jaws of the pedicellaria rest directly on the ossicles of the skeleton. They are formed of a reticulated calcareous tissue, but that does not show nevertheless the appearance of a folded calcareous leaf. The jaws are, to the contrary, massive and sometimes spongiform. They are entirely covered with an epithelial membrane that unites with the skin, to which attach the muscle fibers that separate them. These jaws have, in addition, at the lower part of their inner border, a groove covered by horizontal muscle fibers that close the pedicellaria. ${ }^{46}$ There is nothing, as one can see, that resembles what we found in Asteracanthion.

The usual location of the pedicellariae in Archaster is the ambulacral groove, as well as the angles of the arms. But they can be found among the paxillae of the back.

Of the three species presently described of Archaster, two are available to us:

Archaster typicus and Archaster angulosus.

ARCHASTER TYPICUS, M. and T. - In Archaster typicus, we find pedicellariae only in the angles of the arms and the ambulacral grooves.

\footnotetext{
${ }^{46} \mathrm{Pl} .2$, fig. 12 and 13.
} 
The jaws of the pedicellariae ${ }^{47}$ are not always perfectly equal, nor are they perfectly regular. The length of each of them is a little more than four times the greatest width. This greater width is reached nearly at the top of the inner muscular groove. From this point, the inner border of each jaw becomes slightly oblique in a way to narrow the jaw that ends in a round tip. The inner border of each jaw is very finely toothed its entire length to end at the top of the groove.

ARCHASTER ANGUlatus, M. and T. - Two kinds of pedicellariae; one among the paxillae of the back, the other among the spines of the ambulacral grooves.

The jaws of the dorsal pedicellariae ${ }^{48}$ are nearly the same width their entire length. The relation of their length to their width is 5 to 1 . Each valve is finely toothed around the inner border.

The pedicellariae in the ambulacral groove ${ }^{49}$ are about two and a half times longer than those of the back. Their jaws are very tapered at the free end and their teeth are not very apparent. The groove in which is found the adductor muscle is an extremely elongated groove. The length of the entire organ is nearly eight times the greatest width of each of the jaws. This maximum width is at an eighth of the height from the base, a little above the point where the groove that has the muscle begins.

These pedicellariae have no other pertinent particularities.

\section{GENUS ACANTHASTER, Gervais.}

The species we have examined is Acanthaster solaris, Dujardin and Hupé, the Echinaster solaris of Müller and Troschel, the Stellonia echinites of Agassiz. It is under this last name that is placed the beautiful specimen in the collection of the Museum.

The pedicellariae ${ }^{50}$ are numerous, located among the spines of the dorsal surface and composed of two thick jaws, nearly cylindrical, pierced with numerous vacuoles, bristly on their entire surface and toothed on the inner surface of the borders. We do not see a groove for the muscles.

The entire organ is covered with an epithelium. It is connected to the body of the animal by muscle fibers that one can see below the sheath up to their point of insertion on the solid pieces. These fibers evidently function to spread the two jaws of the pedicellaria.

\section{GENUS ASTERISCUS, M. and T.}

Although I have been able to examine a very large number of species belonging to the genus Asteriscus. Many of them in good condition and preserved in alcohol, it has been possible to find pedicellariae in only two species: Asteriscus verruculatus, M. and T., and Asteriscus marginatus, Val. (sic). This latter species still has not been described.

These pedicellariae have the characters that we have found in all asteroids with two rows of tube feet. Two jaws supported by a small calcareous piece making part of the skeleton, connected to this piece by the common skin and by muscle fibers constituting the essential part of the organs. It is necessary to add that these horizontal muscle fibers that connect the two jaws function to close them. We will give a very exact and very simple idea of these organs. The calcareous pieces that form the solid part are aureolated as usual, but their tissue is compact and thick as we have seen in

\footnotetext{
47 PI. 2, fig. 13.

${ }^{48}$ PI. 2, fig $12 b$.

${ }^{49}$ PI. 2, fig $12 a$.

${ }^{50}$ PI. 2, fig. 14.
} 
Oreaster and the related genera. There is nothing to recall the transparency and delicacy of the calcareous tissue that make up the pedicellariae of Asteracanthion.

In the species of the genus Asteriscus we have examined we have never found pedicellariae on the ventral surface, nor in the area of the ambulacral grooves. We have found them, to the contrary, always on the back and on the nodes of the calcareous network that fills the empty smooth space between the dorsal scales and border at the same time the papular pores. They are likewise in great number on the dorsal border of the arm where the papular pore are missing. But there again, they are located between the scaly plate that have small spines, never above.

We remark in passing that the exclusively dorsal location of the pedicellariae of Asteriscus is singularly favorable to the hypothesis that assigns them a role to carry food to the mouth by transferring it between each other.

ASTERISCUS MARginAtUS, Val. - Pentagonal body with the intervals of the arms very notched. The relation of the smallest to the largest ray measured from the mouth as 1 is to 2 . Above, the body is not very convex. Dorsal plates scaly with six or eight small spines arranged transversally in two rows, dense so as to form a kind of ridge or fan. Three of the largest ridges are inclined on the madreporite that is located a quarter from the smallest ray from the anus which is central. In the madreporite, the projecting line leaving from the center are as wide as the intervals that separate them. The papular pores are numerous and on the network that borders them are numerous pedicellariae ${ }^{51}$ with very elongated and curved jaws having numerous spines directed towards the top. They are arranged in longitudinal and very visible series only in profile. The upper curve has numerous small teeth, sometimes the vertical borders have long pointed teeth perpendicular to their section. The teeth are not numerous.

On the edge of the disk each plate has a bouquet of divergent tubercles. On the ventral surface are four spines elongated, pointed, arranged in a transverse line becoming longer as they approach the ambulacral groove. These have only one row of long spines, thin, truncate at the end, with blades, four by four on each plate. Those at the top of the buccal angles are longer, more divergent than the others and form thus a kind of armature.

Diameter: 6o centimeters.

Countries: Brazil (Castelneau and Deville); — Goree (Robert).

ASTERISCUS VERRUCULATUS, M. and T. - In Asteriscus verruculatus the pedicellariae ${ }^{52}$ are as numerous as in the preceding. They are constructed in nearly the same fashion, but one distinguishes spines only in the terminal portion. The jaws of the pedicellaria are nearly straight and no longer curved. They also have long teeth pointed perpendicularly to the inner border. Finally, in this species the pedicellariae are more pointed than in the preceding.

ASTERISCUS PULCHELlUS, Val. - This asteroid is identified in the collection of the Museum as identical with $A$. pulchella de Blainville. If this is so, one cannot confuse this species with the preceding as done by Müller and Troschel. It is close to A. marginatus, but it is distinguished by its much smaller size, the absence of ridges, spines and scales on the back and also by its pedicellariae that are large, numerous, with slightly arced valves, very separated, a little enlarged at the end, thorny and with erect spines near the end, and with a region of the inner border having

\footnotetext{
51 PI. 2, fig. 11.
}

52 PI. 2, fig 10. 
some teeth not acute and small. The grooves of the madreporite are very convoluted, much larger than the projecting lines that separate then and they appear crenulated. Each plate of the ventral surface has two or three spines very elongated and often very pointed. The spines of the ambulacral groove are elongated, thin, obtuse and arranged in a single row. Each plate in general has four of them, united by a membrane, very little divergent.

Provenance: Messines. Collected by Constant Prévost.

Diameter: 2 centimeters.

Such are the only species of Asteriscus that we have found pedicellariae. It is necessary to add, according to Müller and Troschel, Asteriscus trochiscus of the Indian Ocean. We have not been able to find any other character of value that separates them from their congeners lacking these organs.

We have examined the following species:

Asteriscus australis, M. and T., A. calcar, M. and T., preserved in alcohol; A. minuta, M. and T., A. Cepheus, Val. (coll. Mus.) and M. and T., A. setaceus, Val. (coll. Mus.) and M. and T. These latter were dried and perhaps their state of preservation was not sufficient to see the pedicellariae

To these species, all described by Müller and Troschel or by Gray, it is necessary to add some others that we believe new and thus we give a description.

ASTERISCUS CALCARATUS, Val. - Body pentagonal, with the sides a little notched. Each dorsal scaly plate has a double or triple rose of granular spines rounded at the tip, dense against each other. All the rows are nearly contiguous, and separated sometimes by some rounded bouquets of spines entirely similar to those formed by them. The madreporite is very large, at the first fifth of the distance from the center of the disk to the border. Sharp borders slightly incurved towards the ventral surface that is concave. The triangles, that cut the ambulacral grooves on this surface in the half of their surface nearest the end, have incomplete rows of isolated spines that change in the second half into double rows of short and obtuse spines. The spines of the ambulacral grooves are in a single row. They are very thin. There are two of them on each plate. They are reinforced behind by a row of spines belonging to the ventral surface strictly speaking, but more elongated than usual.

Diameter, 3 centimeters.

Provenance: Valparaiso.

ASTERISCUS EXIGUUS, Val. - We conserve for this species in the collection of the Museum the name Valenciennes gave it. But we do not adopt in any way the synonymy that makes it the Asteriscus exiguus of Lamarck.

Outside the singularities that can be attributed to a monstrosity, this species has in fact some very clear distinctive characters. Here is the description of the single individual in the collection of the Museum. Quadrangular body slightly notched. Dorsal surface entirely covered with scaly plates a little attenuated behind. It has on the anterior border a small demi-circular depression that circumscribes a papular pore. Each plate around this depression has one or two curved rows of small short spines, granular, rounded at the end. They are lacking, without doubt accidentally, on many of them 'there are two madreporites located symmetrically near the anus, on each side of the line diagonally to the square formed by the disk. The grooves of these plates are little bypassed 
and much wider than the intermediary projecting lines. The ventral surface is covered with imbricated sales whose rounded free border is turned towards the mouth. These scales are slightly concave. Those nearest the disk have each a spine. There are two on the lower marginal row. The spines of the ambulacral groove are in a single row, isolated on each plate, and reinforced by a row of larger spines belonging to the ventral surface strictly speaking.

Diameter: $14 \mathrm{~mm}$

Provenance: Australia. Collected by J. Verreaux, 1844.

ASTERISCUS SQUAMATUS, Val. — Large pentagonal species sometime irregular, with five well marked arms. The back entirely covered with imbricated scales on the borders, more spaced towards the center of the disk and surrounding then a papular pore. Some of these scales are sunken in the middle. All have on their border towards the disk a vertical row of small spines. The madreporite is large, very near the center of the disk, marked by very regular radiating striations, bifurcated and sinuous, nearly the width of the space that separates them. The scales are wider and shorter towards the center of the disk. The ventral surface is likewise covered with imbricated scales, each with a spine in the middle of their border towards the center. Only the marginal plates, which are more elongated, have each on their lateral borders a row of small spines, inclined and dense. The spines of the ambulacral groove are in a single row. There are two on each plate. More behind, on a projecting tubercle belonging to the ventral surface, is another spine

Diameter: 8 to 10 centimeters.

Provenance: Unknown.

ASTERISCUS WEGA, Val. - Six to eight irregular arms, very marked, covered with scales depressed anteriorly, dense, truncated and slightly imbricated, each limiting by its anterior depression a papular pore. Each of these scales has at it anterior part small divergent spines that make it appear bristly in this region. The ventral surface is likewise covered with dense scales that, seen with the microscope, has pores. Each plate has a spine on its central border. The spines of the ambulacral groove appear arranged in two rows. There are four or five on each plate. These spines are greatly elongated at the tops of the triangular areas limited by the ambulacral grooves. They then gradually widen from the base to the top.

Diameter: 2 to 3 centimeters

Provenance: Red Sea.

\section{GENUS ASTROPECTEN, Linck.}

The Astropecten do not have pedicellariae. Species examined:

1. Astropecten Brasiliensis, M. and T.

2. ---- polyacanthus, M. and T.

3. ---- platyacanthus, M. and T.

4. ---- hystrix, M. and T.

5. ---- armatus, M. and T.
6. Astropecten Andromeda, M. and T.

7. ---- Johnstoni, M. and T.

8. ---- serratus, M. and T.

9. ---- hispidus, M. and T.

10. ---- spinulosus, M. and T. 
New species:

ASTROPECTEN PERARMATUS, Ed. P. - L Large species with five arms, at least four times as long as the ray of the disk, with thirty-three granular plates each with one or two large spines, short and pointed. One of these spines is found in the inner border of the plate, the other in its middle.

The madreporite is near the inner border of the marginal plates that are very elongated at this point. Each of the ventral plates has on the upper border a long pointed spine, slightly recurved, erect. Along the inner border of these plates is a row of four or five spines crossing the arms, pointed, elongated, flat, becoming shorter as they approach the ambulacral grooves. The ventral plates are covered with flat scales, rounded at their free end.

The spines of the ambulacral groove are in two rows. Those of the inner row are arranged three by three on each plate, thin, elongated, and pointed. The middle one is longest. The outer row has two on each plate, wide, flat and rounded at the end. Behind them especially in the area of the arm angle, the scales of the ventral surface are elongated to take a form analogous to spines thus simulate one or two incomplete new rows.

The tube feet end in a kind of cone that is wrinkled along its edges and that replaces the disk seen in the asteroids of other genera.

Diameter: 25 centimeters.

Provenance. Southern Ocean (from the voyage of Hombron and Jacquinot, d'Urville expedition).

Astropecten Samoensis, Ed. P. - This species is as remarkable as the preceding by the considerable development of its spines

It has five arms about two times as long from the center as the disk radius. These five arms are covered with paxillae finer than those in the preceding species. They madreporite is a little convex, irregularly rounded, nearly touching the marginal plates, covered with thin lines, sunken, of the same width as the ridge that separate them, very sinuous and nearly ending at the inner border of the five plates. The dorsal marginal plates are covered with numerous setae, rounded at the end. These plates are very projecting, angular, three located at the angle of the arms making a kind of crest flattened transversally with setae on the border. The innermost has a long spine pointed towards the center of the disk. The two following lack spines. The others have the ordinary form, each with a spine large at its base but very pointed at the end, pointed towards the median line of the arms.

The plates of the ventral surface are all flattened transversally. They all have a large quantity of small, thin spines, elongated and obtuse at the end. In addition, along their outer transverse border is a row of large pines, vey elongated, very pointed and becoming larger towards the ambulacral groove. The plate nearest the angle of the arms have the same form as those corresponding to them at the dorsal region. Their spines are particular by having, instead of increasing in size from the ambulacral groove to the border of the arms, to the contrary decrease. In addition, these spines, equal otherwise, are smallest like those of the three plates that are nearest to the angle of the arms.

Each plate of the ambulacral groove has along the border three very divergent spines, the middle one the longest. Then, behind, two lateral rows, each with three or four small spines, obtuse, thin and elongated. The tube feet are pointed. Their tissue is transparent. 
Diameter: about 20 centimeters.

Provenance: Samoa (voyage of d'Urville, collected by Hombron and Jacquinot).

I shall describe again two species designated by Valenciennes by the names of A. Mulleri and A. myosurus.

ASTROPECTEN MULLERI, Val. - Five arms, whose length from the center is a little more than three times the ray of the disk. Thirty-eight granular marginal plates, with granules larger towards the inner border. Paxillae composed of three to six central tubercles surrounded by a radiating club-like spines. Madreporite formed of projecting spines, wide, nearly straight, radiating from a point on its inner border. At the ventral surface, the arms have a border of three rows of spines more or less complete and whose outer row alone has spine flat to the angle of the arms. Each ventral plate has several rows of small, projecting scales. The ambulacral groove has three rows of spines. The outer row has three spines per plate. The median one is compressed and slightly curved. The following row also has three spines per plate, flattened, enlarged at the end. Those of the first row has two spines.

Provenance: Copenhagen (Lœwen).

Diameter: 12 to 13 centimeters.

ASTROPECTEN MYOSURUS, Val. - Species with five pointed arms, very thin, covered with paxillae with long and thin setae, five to six times longer from the center than the ray of the disk. Madreporite small, indistinct. Dorsal marginal plates are twenty-eight in number, each with an erect spine pointed very elongated, and conical. Each ventral plate has on its marginal border two recumbent spines: one round, elongated pointed, thin, a little curved; the other smaller. The lateral borders of these plates also have small spines flat and recumbent, while their part is covered with small, short spines in the form of setae. The spines of the ambulacral groove are spaced and in a single row.

Diameter: 6 centimeters.

Provenance: Mediterranean.

GENUS CTENODISCUS, M. and T.

We still only know one single species of Ctenodiscus, Ctenodiscus or Anodiscus crispatus. The collection of the Museum has very beautiful specimens of them. We have confirmed they are, like Astropecten, lacking in pedicellariae.

\section{GENUS LUIDIA, Forbes.}

Luidia has a characteristic that is exceptional in the family asteroids, but that is not constant in all the species. This is the presence of three jaws in the pedicellaria. We know that it is the general case in the family of echinoids. There is no relation between the pedicellariae of Luidia and those of urchins. It is not possible, as will be shown in the descriptions of the pedicellariae of urchins that we have studied, of confusing a pedicellaria with three jaws of Luidia with a pedicellaria with three valves of an urchin. The pedicellariae of Luidia are always sessile or resting directly on a 
thick calcareous stalk, supporting sometimes a variable number of jaws, kind of blunt spines, thinner than it. The three jaws of the pedicellaria are connected to this stalk by a general cutaneous envelope, then by two systems of muscle fibers, one inner and one outer.

The outer muscle fibers evidently separate the jaws of the pedicellaria. They insert on the periphery of the basal piece and at different heights on the jaws of the pedicellaria. We often see them go below the epithelial envelope up to their point of insertion.

The inner muscle fiber form at the base of each jaw of the pedicellaria an ovoid swelling, very distinct by its yellowish color in individuals preserved in alcohol. They insert on the central part of the basal piece and on the inner surface of the pedicellaria, as least in Luidia granulosa of Valenciennes.

Luidia cililaris has a slightly different arrangement. The base of the inner surface of each jaw is evident, as we have seen in some Asteracanthion, and the muscle fibers probably penetrate into the interior of each jaw and insert on the wall of the pyramidal cavitty of its three surfaces.

In all cases, one never finds the special calcareous piece that is the surface of attachment of the muscles, while this piece is constant in the urchins.

The structure of the calcareous network that makes up the solid part of the jaws varies with the species. In general, the pedicellariae are found in the area of the ambulacral grooves. We are inclined to believe that they are constant. But we have not always been able to find them. It is impossible that it was otherwise, because of the extreme fragility of all Luidia.

We note finally that in some species, such as:

LUIDIA SAVIGNYI, Audouin. The pedicellariae do not have three jaws, but instead two only as in other asteries ${ }^{53}$. We have not been able to study the pedicellariae in a very good state of preservation. They are sessile, as always, and the jaws are connected to the piece by a very thick cellular envelope, completely covering the jaw both interiorly and exteriorly. Below this covering we distinguish very well the inner muscle fibers that go the length of the jaws to insert onto their surface at different height. Between the jaws we see a bundle of horizontal fibers that are attached to the internal blade of the jaws of the piners and that close them

The calcareous blades that make up the solid part are thin, transparent and formed of a calcareous tissue with large areoli. These blades have numerous wrinkles as on the internal surface of the teeth that are directed upwards. Each jaw is a little less than four times long as wide, rounded at the tip and keeping its dimensions nearly their entire extent. These pedicellariae are found in the area of the ambulacral grooves.

LUIDIA CILIARIS, GRAY. - Luidia ciliaris has been confused with the preceding species by several authors, notably by Mülller and Troschel. In their Histoire des Échinodermes (p. 433), Dujardin and Hupé distinguished it but only on the basis that the proportions of this Luidia are thinner than those of Luidia Savignyi. This character, purely relative, is obviously completely insufficient as a characteristic. The study of the pedicellariae gives us a new character that clearly separates the two species. Indeed, the pedicellariae of Luidia ciliaris nearly all have three jaws and not two as in the preceding. Moreover, their calcareous tissue is much denser and much more compact. The pedicellaria ${ }^{54}$ has the form of a cone very regular at the top with a round tip, divided longitudinally into three jaws so well applied against each other that sometimes they can hardly be distinguished. The inner surfaces of the jaws are flat, so that they circumscribe a space having the

\footnotetext{
53 PI. 2, fig. 16.
}

${ }^{54}$ PI. 3, fig 17. 
form of a triangular pyramid. The inner surfaces have at their base, as we have said, a demi-circular portion, while the very base of the organ has a kind of irregular projection that with the homologous reciprocal projections of its neighbors makes a fulcrum during the movement of the jaws. We have not studied the internal muscles. But the external muscles or adductors form a kind of belt that connects with the conical tubercle with some elongated calcareous branches. This tubercle is the basal piece of the pedicellaria, its conical form explains the necessity of the horizontal extension of the base of the jaws that we have already described.

Finally, a common epithelial envelope connects again all these pieces with the skin of the body.

These pedicellariae are found in the area of the ambulacral groove.

LUIDIA GRANULOSA, Val. - The pedicellariae ${ }^{55}$ in this species have three jaws, as in the preceding. But their form is very different. The three jaws are thin, enlarged at the base, but taper rapidly at first and then slowly to end in a round summit. The calcareous tissue that forms them is thin, transparent, regularly pierce with numerous round vacuoles. The jaws also have teeth on their border. The upper border of each tooth is short, directed perpendicularly to the general border, while the lower border is very long and very oblique. The inner surface has numerous small points uniformly directed upwards.

These jaws, contiguous only at their base, rest on a cylindrical stalk, slightly enlarged at the top, to which they are attached by their epithelial covering and by the two systems of muscular fibers. The system of abductor fibers form a kind of belt uniting the jaws to the circumference of the basal stalk. The adductor fibers, to the contrary, form three distinct projecting bundles, inserting by one part on the basal stalk, by the other on the inner surface of the jaws but without penetrating into the interior of the cavity that limits the surfaces of the latter.

The basal stalk has in general, three long smaller toothed stems on their border and areolated as usual.

The pedicellariae are found in the area of the ambulacral grooves.

We have not seen the pedicellariae of Luidia maculata M. and T, nor those of Luidia Senegalensis, although the collection of the Museum has these two species.

\section{SECOND PART}

\section{ECHINOIDS}

Generalities. - The revision that we have made of the sea stars has shown us that the pedicellariae can be used in the classification, either to characterize the genera or even to characterize the species.

${ }^{55}$ Pl. 2, fig. 18. 
A quite similar study, of all the species of urchins possessed by the Museum of Natural History has led us to analogous results.

Moreover, in these animals, our research has been able to consider other organs that have been up until now neglected. The classification of urchins is, as we know, based in part on the form of the tube feet and the arrangement of their pores. The very names of several genera are taken from the diverse arrangements: such are the names of the genera Tripneustes, Amblypneustes, Hemipneustes, etc.

Through each tube foot pore passes a tube in connection with the respiratory apparatus, and also for the locomotion of the animal. Each of these tubes is a tube foot. Longitudinal muscular fibers and rings form the principal parts of the soft tissue of these organs, tissue that is itself supported by special calcareous pieces constituting either spicules or the rosette.

It is to these calcareous pieces that we want to especially call attention. They have been perfectly described by Valentin in the Monographies of Agassiz. But his descriptions are limited to two species: Echinus miliaris and Echinus esculentus, the only ones he examined.

Our work shows that the form and arrangement of spicules, like the presence or absence of the rosette, give again good characters to add to those that we have usually used.

We indicate first by a rapid listing of the genera that we have between the hands and of those that we have missed, the degree of generality of our work. Nearly all the genera of cidaroids and echinometrids have been studied. But it is in irregular urchins that the gaps are numerous and especially extensive. This results principally from the great fragility of the appendices of these animals. Most of the collections we have only tests nearly completely denuded, and lack nearly always pedicellaria and tube feet. Nevertheless, that which we have been able to study of this family has given us very clear results for a generalization that is not rash.

The pedicellariae and the tube feet of urchins are constructed of a nearly constant type and that we must first give an idea.

1. Pedicellariae. - Generally, on the same individual, we find several kinds of pedicellariae. These organs always have a form of two parts: $1^{\circ}$ a head or pedicellariae with three jaws; $2^{\circ}$ a stalk that, on one hand, supports the pedicellaria and, on the other hand, is fixed to the test.

The stalk and the pedicellaria always have soft part and had parts. The latter have a calcareous nature.

For the pedicellaria, the calcareous part are simply three jaws, whose bases ae triangular, in contact with each other. These jaws have moreover variable form that we will have to study in detail. Always a calcareous blade is inserted the length of the height of the triangle from the base and climbs vertically to be inserted on another part along the median line of the body of the pedicellaria, generally in the first third This bade has a free border rounded, turned towards the interior. It is formed, like the other part of the pedicellariae of a calcareous blade perforated with numerous holes that gives it this usual reticulated appearance of echinoderms.

We shall simply call this blade, the apophysis; it has a considerable physiological importance because it serves for the insertion of the muscular fibers that will close the three jaws of the pedicellaria. The second points of insertion of these fibers are the two adjacent jaws

There are three lateral muscular bundles, whose contractions results in closing the three jaws of the pedicellaria. The arrangement of the fibers for opening the organ is more variable. We will indicate it elsewhere.

On its upper part, the apophysis is often divided in a way that is continuous with the borders of the jaws. At its lower part it is enlarged. Often it appears to be formed at this point of a series 
of horizontal calcareous pieces, connected to each other by thin vertical crosspieces. These pieces enlarge towards the base. They are continuous with the analogous pieces of various sizes that form the triangular base of the pedicellaria, and have on their edges indentations that interlock with each other. This contributes to give the organ a greater solidity.

The only active part of the pedicellaria is that constituting the jaws. They vary in form for the same species of sea urchin, for pedicellaria of the same kind, and to the species of sea urchins to which they belong. Their details will be much better considered when we describe the various forms of pedicellariae that we have observed.

The stalk of the pedicellaria or mace, to use the slightly improper word of Valentin, always exists, as far as I can convince myself. But it is far from always having the same development. The figure that Valentin ${ }^{56}$ gives of them are excellent. But they are true only for the species he studied: Echinus lividus. Note, however, a slight inexactness. This stalk rarely seems to enlarge gradually. Towards the base it enlarges, to the contrary, abruptly and thus appears like a column placed on a pedestal. The figures of Valentin show, moreover, very clearly that, in E. lividus as in many other species, the stalk is fibrous, i.e., composed of calcareous filament, thin, hair like, united by small, scarcely visible crossbars. Other times, to the contrary, the stalk seems to result from the joining of long, calcareous rods, very thick, transparent, united by some very distinct crossbars and making sometime projection to the end of the stalk (some Cidaris), or going to the contrary to merge into the stalk.

In the small pedicellariae, seen already by Valentin ${ }^{57}$ but which this anatomist hesitated to consider forming a separate group, the stalk is remarkable by the enormous development of the swelling, while the body of the stalk is formed by two or three calcareous shafts united here and there by horizontal crossbars.

We shall return naturally to the arrangements of the stalk of the pedicellariae and we shall see that it can give good general characters in some cases.

2. Tube feet. - In the tube food, the calcareous parts have principally attracted our attention. It would be difficult for us at this time to give a very clear idea of the relations of the soft parts, either in the anatomical arrangement or in their mode of development. The study of these latter parts appear to us must make a special work that we would undertake if possible, and if we could call to our aid all embryological resources. It was impossible to think of doing such a work at the Museum of Natural History The difficulties of installing in the laboratories a sea water aquarium, the demands of the budget for this type of research, the imposibility of making a serious histological study of animals preserved for a long time in wine spirits have obliged us to restrict our researches to the study of calcareous parts. In spite of this, we have obtained some interesting results that we are going to briefly present here.

We have already said that the calcareous pieces preserved in the tube foot are of two kinds: the rosette and the spicule.

a. Rosette. - The rosette is found in all regular urchins. It has the same striking uniform character in all genera and in all species. We accept completely the description that Valentin ${ }^{58}$ gave it. Some differences in the form and length of the projecting parts of the border that Valentin considered to be extensions of the principal longitudinal pillars: Here is all that it is possible to

\footnotetext{
${ }^{56}$ Agassiz, Monnographie d'Échinoderemes, pl. 4.

${ }^{57}$ Mongraph. d'Échin. - Anatomie du genre Echinus, p. 49.

58 Loco citato.
} 
say about the differences in the diverse species. But these differences are so transient that is necessary to reject describing them. They cannot be used in any way as a character. In addition, I do not think that it is necessary to consider these projecting parts as absolutely fixed. Their border has projections very usually arranged in front of similar projections of the adjacent serration. They are evidently the beginnings of the crossbars that fill the interval that separates two serrations, to contribute thus to the growth of the rays of the calcareous pieces that make up the rosette. As a result, at the end of a certain time, the spines that at one point were projecting cease being and are replaced by others of more recent formation. The first are still distinct. They often still make a projection above the surface of the rosette and together form an irregular longitudinal band, all parts of which cannot be developed at the same time when one examines the surface of the rosette with a microscope. It gives the impression, very vague, of longtidunal bars leaving from the center and ending in radiating to the serrations of the border. The bars are very clearly shown in figure 60 of plate 4 of the Monographie of Valentin. But it does not appear to be a very exact account of the appearance that he had before him. These are bars that he considers as solid, forming the principal framework, the pillars of the rosette.

The description that Valentin gives of the frame of the rosette is a little defective. He considers it as formed of a calcareous plate riddled with holes that are extended nearly to the inner border, "but without opening into the inner cavity. They are, to the contrary, always closed by small crossbars, so that it looks like the inner border is edged with a calcareous thread. Towards the outer border, the calcareous substance is in general less perforate and more contiguous".

This description is perfectly correct, in most species near the inner edge we see a series of large holes while the rest of the surfaced is perfectly homogeneous except for some regions that we have not determined. Unfortunately there is error and double error when Valentin says that the ring is "composed of a calcareous plate." It is not one that he should have said, it is eight at least.

Figure 62, pl. IV that Valentin gives has the support of its description, is as defective as the latter. Moreover, the error into which the skillful anatomist fell is easily explained. Valentin appears to have studied the frame in place and the calcareous network that he saw at the same time that had prevented him from recognizing details that would have certainly struck him if he had employed another method of examination.

When one dissolves the soft parts of a tube foot in potash, the frame is separated often quite naturally from the skeleton, and one can study it separately. One can see it sometimes perfectly in place and, consequently, having undergone no deterioration. Sometimes its rosette is separated but falls to its side and preserves perfectly its characteristics. If one then agitates the liquid slightly without touching the calcareous parts for fear of altering their integrity, one soon sees always the ring separates itself into four distinct parts that are nothing else than the four sides of the square that it normally represents These parts, examined with a microscope, show perforations especially at their two ends that are in general very irregular. Valentin had seen this character because, in his figures, it is especially at the angles of the square of the frame that the perforations are accumulated.

If one now puts under the microscope each of the four separated pieces, one recognizes that it is not single but well-formed of two parts nearly identical, superimposed, and that one can very easily separate them without breaking. When these parts have been in potash for a long time, they separate all by themselves. One does not often put under the microscope a simple plate, i.e., an eighth of the ring. 
How are these eight pieces fitted on top of each other? We have already seen them form four pieces. Are these four paired piece are only contiguous or overlapping? It is sufficient to compare the length of the isolated plates to the length of the side of the square they form to be assured that there is really overlapping. But, moreover, direct observation shows, with the reality of overlapping, how it is produced. One of the plates of each pair is engaged between the two plates of the other in a way to make a kind of very solid masonry. It is obviously difficult to see this what I have always seen.

We add that the number of pieces that makeup the frame is sometime great and that, in the diademas in particular, they seem to me to pass insensibly to calcareous pieces supporting the tube feet and that it remains to us now to discuss.

We shall ignore the relations of the soft parts, either with the rosette or with its frame.

b. Spicules. - Valentin describes and figures, as is found in the tube feet above the pigmented layer, small calcareous corpuscles in the form of simple arcs in E. lividus and branching at their end in E. brevispinus. The existence of these corpuscles appears to have astonished him greatly. He asked himself if they were not artificial concretions and if they really existed in the living animal. It is these calcareous particles, seen since by several observers, that we call spicules. Valentin found them in the ovary. We have found them in the internal organs, but we have found them in the tube feet of all the species of urchins that we have examined in any detail.

There is more. We have confirmed that, in each species, the form is constant. In the same natural family, one always finds a unique type of spicules in all the species, characteristic of the family. All the secondary forms are easily derived from it.

It is thus a new anatomical character. It is necessary to add it to those that have served up until now to distinguish the families. It is, moreover, either a confirmation of the value of the characters used up until now or, to the contrary, a means of control.

Another consequence is that these spicules resemble enormously some spicules of sponges and holothuroids. They have been preserved like those in fossilization and, without knowledge of provenace it is impossible to distinguish them. This is a reason to be prudent in the diagnostic of spicules that one indicates, or that we can indicate as being in certain layers, either present or ancient.

The position of these spicules is that Valentin indicated. But we still have not been able to determine their relations with the elements of the surrounding tissues and, consequently, their physiological roles seems to us still very obscure. However, is it not allowed to suppose that these spicules serve as points of attachment of muscle fibers functioning to retract the tube feet? In retraction, the spicules nearest the test would be fixed by the contraction of the muscle fibers attached directly to the test. They thus would serve the point of support for the following muscle fibers follow that would fix the second series of spicules. Movement is thus propagated from the base to the summit would result in complete contraction of the tube foot.

In the course of our research, it seems to us that the arrangement of the spicules in the interior of the tube feet is not always the same. In Cidaris, we have seen arranged parallel to each other, the axis being in a direction perpendicular to the axis of the tube foot. But we do not believe that we can say as much for all genera. It is possible that research done in this sense on fresh animals will lead to new differences in the arrangement of these element, and completely clarifying the role they play in the functioning of the urchin. We can at this time only call attention to this point that cannot fail to be rapidly resolved by observers located in suitable conditions. 
We add that spicules are lacking in all species of asteroids that we have examined. A tube foot of an urchin is distinguished easily from the tube foot of an asteroid by the presence of calcareous pieces in its interior. I say intentionally calcareous pieces because the spicules are the only calcareous elements that we shall consider at this moment as a constant in all groups of urchins. The rosette, which we have often indicated as characteristic, is missing in an entire group. But there, as we shall see, the tube feet show in its end a very particular arrangement that is impossible to confuse with any other.

Thus, pedicellariae, rosettes and spicules, such are the parts that we have described in the different species of urchins. As for the asteroids, we shall indicate the diverse modifications that we have been able to recognize in the different genera. We shall take this occasion to make an inventory of the richness of the Museum of Natural History and to describe the new species that its cases contain. We shall have thus the advantage of giving in its correct limits the degree of generalization that it is necessary to attribute to our work. This will accompany a revision of the family of echinoids and give at the same time to the Museum the service of increasing the chances of increasing its collections by making known what it has and what it lacks.

\section{I. - REGULAR ECHINOIDS}

To the characters taken from the form of the test, the relative position of the mouth and the anus, the presence of a very developed masticatory apparatus of a very special form, we shall add this other character that all have their tube feet ended in a disk functioning as a sucker and supported by a calcareous rosette composed in all species of the group as Valentin has described for Echinus lividus, of four or five calcareous pieces united in a way to form a circle with a central, circular lacuna united at the borders and an outer more or less jagged free border. Below these five pieces is the frame composed of eight superimposed pieces superimposed in pairs. These are united towards the middle by pieces that make up the rosette. These eight pieces are superimposed alternatively like a stack of logs. The superimposed parts alternate with the lines of the junction of the segments of the rosette. It seems thus that the frame gives more solidity to the rosette.

The tube feet are supported by spicules of variable form rarely having the form of a simple rod.

There generally are several kinds of pedicellariae.

\section{A. - Tessellated Echinoids}

Fossil urchins in five genera that we have not studied. The five genera are Palochinus, Melonites, Archo\ocidaris, Eocidaris and Perischodomus.

$$
\begin{aligned}
& \text { B. - Cidaroidea } \\
& \text { 1. — Cidaridae }
\end{aligned}
$$

We have studied three genera that make up this family: the genera Cidaris, Leiocidaris, Goniocidaris. In the last genus, we have been able to study the tube feet but we have figured the pedicellariae. We believe we can predict that one will find in the species that compose it all the characters that we are going to report in the species of the two others. These characters are very clear and taken both from the pedicellariae and the tube feet. 
$1^{\circ}$ The pedicellariae are located in the ambulacral areas. They appear to have only two distinct forms. They are distinguished at first glance from the pedicellariae belonging to the other families by their stalk that is not club-shaped and that is not separated from the pedicellaria strictly speaking or head by a space containing only soft parts. The head rests directly on a small calcareous stem whose diameter is a little less than that of the stalk strictly speaking. This small cylindrical stem seems to articulate directly with the stalk that is generally a little swollen at the top which makes the articulation. The stalk ${ }^{59}$ is formed of a bundle of very elongated calcareous rods connected by oblique crossbars of the same diameter. They often have projections on their border that appear to be only incomplete crossbars or those in process of formation.

One very clearly sees longitudinal bars ending in a point there where is inserted the terminal stem. As a result, they penetrate to insert into the middle of a belt of pointed rods that hide its base. The rods that compose the stem appear to me to be a little thinner, more pointed and less regular than those that form the outer surface of the stalk. I have not been able to decide positively if it is absolutely contiguous with the calcareous rods that make up the stem and those forming the interior of the stalk. This makes a difficulty because of the belt of rods in which the stems are embedded and that hides its base. It is impossible to remove these rods without also more or less destroying the stem. The discontinuity, if it exists, is very difficult to prove. I have also some reasons to believe that this discontinuity does not actually exist. Indeed, I have never seen the isolated stem, nor have I seen the stalk absolutely lacking the stem. However the dissolving action of potash would have corroded the tissue connecting these two parts if they had the same nature of the conjunctive issue of urchins.

I am thus led to think the stem is not articulated with the stalk, but that it is simply the continuation. Its thinness comes from the stopping of growth of the rods that form the outer covering of the stalk at a certain height to end in a point. This arrangement probably has the function of providing a solid insertion for the muscles that open the pedicellariae.

Such are the perfectly constant characters that make up the stalk of the pedicellariae of Cidaris. We also find in the conformation of the pedicellariae distinctive signs that permit not confusing a pedicellaria of a cidiarid with a pedicellaria of an echinid, provided one has a little experience.

Having at our disposal only individuals that were for the most part dried and consequently always more or less deteriorated, it has been impossible to decide in a certain clear manner how many kinds of pedicellariae cidaroids possess. One can in some individuals distinguish very clearly two kinds of pedicellariae. We have never seen more. But it happened sometimes for us to encounter only one of them. The buccal membrane, so rich in pedicellariae of a special form (ophiocephalous pedicellariae of Valentin) in echinoids, is here completely lacking in these organs and on the other hand entirely covered with imbricated scales.

The two pedicellariae of cidaroids can be designated by the names of armed pedicellariae and unarmed pedicellariae. We cannot determine at this moment the particular location of these kinds of organs, assuming that they are regionalized as one is often led to believe. The study of fresh or better preserved individuals can alone answer this question. But this is very certain, it is that the armed pedicellaria are more frequent in the individuals preserved in the museums. One can conclude that they are the more robust, or better fixed, of the better protected. One finds them especially in the ambulacral areas.

${ }^{59}$ PI. 3, fig. $1 a, 3,5,6 a$, 7, etc. 
The armed pedicellariae ${ }^{60}$ have each of their jaws made up of a calcareous blade folded into a half cone in a way to have two longitudinal borders. These two borders are very finely and very regularly toothed. They are connected by an inner calcareous blade, inserted very deeply to allow the two ends to make a very notable ridge. This blade has very numerous and very large lacunae. They stop very abruptly at the upper part of the pedicellaria in curving forward in a way to make a bar on which are some teeth much greater than those that are cut into the edges of the free borders $^{61}$. Above this bar is generally an empty triangular space, limited below by the bar, laterally by the continuation of the free borders. These have in this portion, which is very often enlarged, one or several large teeth. One also see some in the interior of the pedicellaria, above the triangular space. Finally, the jaw of the pedicellaria often ends in a hook.

Inside, the inner calcareous blade is continuous with the anterior border of the apophysis, whose line of insertion posteriorly is reinforced by an irregular calcareous strip, very areolated, that one can follow up to the top of the transverse bar of which we have already spoken and that it appears to contribute to form, or at least in which it merges with the anterior inner blade.

The base of the pedicellaria, on which rests the principal blade that makes up the jaw and the apophysis, is slightly concave below in a way to make a kind of central groove for the insertion of the head of the pedicellaria on the stem. It often appears to continue with the basal crenulations that allow the jaws of the pedicellaria to engage each other.

The unarmed pedicellariae ${ }^{62}$ differ especially from the armed pedicellariae by the absence of teeth on the borders that appear perfectly smooth, the absence of the upper bar, the greater thickness of their borders, and the form of their jaws that are generally thinner, more elongated, rounded at the top, and in the form of spoons. We have found them only two times. But we are certain more happy observers have found them in all species of cidaroids.

The rosettes ${ }^{63}$ of the tube feet have come to our attention only by the very jagged form of the border. This seems to indicate an organ perpetually in the process of growth.

The frames are constituted as we have indicated. They have a row of large rectangular holes the entire length of the inner border. There are sometimes behind another row of small round holes. The outer border is simply sinuous.

We have already said that these organs not able to furnish distinct, well-marked characters in the group of regular urchins because of the very constancy of their form.

It is not the same for the spicules ${ }^{64}$ of the tube feet. We have been able to study them in the genus Goniocidaris. But in two other genera Cidaris and Leiocidaris, they always have the form of elongated rods, sometimes bristly on their entire surface, sometimes on the outer side with numerous truncated spines that make them sometimes resemble holly sticks with only part of the small branches cut in a way to leave their form bristly when defense is necessary.

We have encountered this form of spicules as bristly rods only in cidaroids.

These rods are arranged in the interior of the tube feet in a way that their axis is perpendicular to that of the tube foot. They are extremely numerous, often nearly contiguous, at least in the contracted state of the organ.

\footnotetext{
60 PI. 3, fig. $1 a, b, c, 3,6 a$, etc.

${ }^{61}$ PI. 3, fig. $2 b$ and $c$.

${ }^{62}$ PI. 3, fig $9 a, 11 a$.

${ }^{63}$ PII 3, fig. $2 b$ and $4 a$.

${ }^{64}$ PI. 3, fig $1 d, 2 c, 3 b$, etc.
} 
It is now necessary for us to describe the various modifications that rosettes, spicules and pedicellariae can have.in the different species of the three genera of cidaroids that we have studied.

\section{GENUS CIDARIS.}

CIDARIS METULARIA, Lmk ${ }^{65}$. - We know only armed pedicellariae in this species. - They are large and short. Very large at the base, that has ordinary crenulations, the jaws taper gradually in forming a curve with double inflexion. A little before the bar is a slight swelling on each side. Above, the border of the pedicellaria is slightly enlarged with three long teeth on each side. - The empty space above the bar has the form of a trefoil. - On the jaws, seen from the back, is the top of the apophysis that is continued as a very wide blade that is nothing else than the inner blade. On each side of the apophysis are blades of reinforcement that are wide, very jagged and is merged by the base with the basal piece, while on the top they merge with the borders.

The rosette is small. Its borders are very jagged. - The spicules have the form of slightly curved rods, larger at one end than at the other, and having four very irregular rows of spines that make their surface appear bristly.

CIDARIS BACUlOSA, Lmk ${ }^{66}$. - We have likewise found armed pedicellariae.

Their general form is nearly the same as in the preceding species. Only the thinning of the jaws is gradual and with a curve with inflexions. The jaws, instead of ending in a slightly enlarged portion with three paired, lateral spines end in a median hook. The empty space above the bar is triangular.

The rosette is larger. Its inner borders also appear jagged.

The spicules are elongated into curved rods having spines only on their outer border. These spies are long, spaced, pointed, sometimes bifid. In some rods, those nearest one of the extremities, are united by crossbars that are also spiny, in a way that this region of the spicule looks like a slightly perforated plate. This arrangement has only one of the extremities of the spicules when it exists. I am disposed to believe that the spicules we observe are nearest the rosette. It constitutes thus, like that seen in diademids, a kind of intermediate between the spicules strictly speaking and the calcareous pieces that form the frame of the rosette.

CIDARIS PISTILlARIS, $\mathrm{Lml}^{67}$. - Here again I have seen only one kind of pedicellariae, armed pedicellariae. - These pedicellariae are more elongated than in the preceding species and the jaws that constitute it taper gradually and without having the obvious curve from the base to the top. The free borders are perfectly rectilinear, nearly imporate, very regularly and very finely toothed up to the top of the bar, where one sees a little stronger tooth. Below, the border is slightly depressed, having three or four small teeth, then a much longer and more projecting tooth than the others. Finally, is a terminal hook, median, very strong, and separated from this large tooth by a deep groove.

The inner blade has in its lower part very large and very numerous lacunae that become perfectly circular on the upper part.

The transverse bar has four teeth on its trajectory, two outer and strong, two inner, weaker ones. Above is an empty, triangular space that corresponds to the two upper strong teeth of the

\footnotetext{
${ }^{65}$ PI. 3, fig. 2.

${ }^{66}$ PI. 3, fig. 4.

${ }^{67}$ PI. 3, fig. 1.
} 
free border. Finally, on the calcareous blade, located immediately below the terminal hook, are two small teeth not far from the border and projecting a little near the middle of the groove that unites the upper teeth of the border to the terminal hook.

The rosettes and their frame have nothing special.

The spicules have the form of bars slightly swollen in the middle and bristly with long, thick spines, not numerous and inclined on the axis of the spicules.

CIDARIS ANNULIFERA, Lmk. - Examination of the specimens of the Museum was impossible because of their deterioration.

CIDARIS TUBARIA, Lmk. - All the tube feet and all the pedicellariae are likewise missing.

CIDARIS KROHNII, Agassiz ${ }^{68}$ - — We again know only armed pedicellariae. - They are more elongated than those of $C$. pistillaris. The stem on top of the stalk is also thinner and more elongated. The free border of the jaws is very finely toothed. The teeth of the transverse bar are less projecting. The triangular space that in $C$. pistillaris is nearly equilateral, becoming here to the contrary a very elongated isosceles triangle.

The spicules ae very long, very curved, slightly tapered at both ends. They have no spines on their inner border but one sees them on the outer border and on the rest of their surface. They are directed outwardly.

CIDARIS VERTICILlATA, Lmk. - The armed pedicellariae of $C$. verticillata - the only ones we know - approach those of $C$. metularia. Each jaw is very wide at its base, much thinner at its top, in such a way that the sides show a marked inflextion. Seen in profile, these jaws are irregularly convex in their dorsal part

The free border has curved teeth towards the base, projected, pointed, and unequal. The upper border, which is large and rounded, has numerous teeth, dense, irregular, and pointed. Following them on each side is a tooth much more projecting, then others equally very robust and very spaced. As they descend on the border, the teeth become less and less projecting and closer together. Finally, they are completely lacking on the lower quarter of the border, up to the place where the three articulating crenulations appear.

The apophysis has itself crenulations on its lower part that unite with the basal part by a concave region, leading to a kind of spine. From this part, a new concave region ends in the area of the dorsal region, which is extended under the basal piece.

The reinforcing piece that borders the line of insertion of the apophysis is equally very developed.

The stalk of the pedicellaria ends in very long spines forming an elongated crown around the stem that shows nothing special. - It is the only time that we have found this kind of arrangement. Usually, the calcareous rods that form the outer covering of the stalk, instead of ending by diverging, seems to the contrary to converge or end in a point without changing direction, which can appear as a kind of abrupt break of the stalk, a break that really does not exist.

We have unfortunately been able to study neither the spicules nor the rosettes of this species.

We must add to this list: $1^{\circ}$ Cidaris rosaceus, L. Rousseau of Oceania, a species that Rousseau places near $C$. hystrix, but differing by its shorter spines and its more granular test. - We have

${ }^{68}$ PI. 3, fig. 3, $a$ and $b$. 
been able to study the spicules and rosettes of this species. These different pieces have characters common to all cidarids and approach particularly the analogous pieces of C. Krohnii.

$2^{\circ} \mathrm{L}$. Rousseau names as before a young cidarid coming from Callao, probably confused later with Cidaris annulata. - We give ${ }^{69}$ the figure of the spicules and the pedicellariae of this species. It is easy from the comparison of these same pieces of $C$. anulata and to confirm the considerable differences that authorize us to keep these two species separate. We propose for the latter the name of Cidaris Callao.

\section{GENUS LEIOCIDARIS, DESOR.}

LEIOCIDARIS IMPERIALIS, Lmk. - The pedicellariae and tube feet are destroyed in the specimens of the Museum.

LEIOCIDARIS HYSTRIX, Desor. - The pedicellariae and tube feet are destroyed in the specimens of the Museum.

LEIOCIDARIS PAPILLATA, LESKE ${ }^{70}$. - We have found in this species armed pedicellariae and unarmed pedicellariae. The jaws of the armed pedicellariae taper gradually from their wide base up to the top that ends in a pointed hook that is only slightly projecting. The borders are strongly and irregularly toothed. The strongest and most spaced teeth are the closest to the top. The inner blade stops at a very great distance from the top. It is nearly flush with the border so that one cannot distinguish the projecting bar and tooth. The empty space still remains. It is oval and very large. The length of the lateral borders have numerous teeth, very slightly projecting. These borders are very wide. The inner blade is riddled with regular holes. Behind it is a kind of reinforcing piece analogous to that which leaves the top of the insertion of the apophysis. The stalk and stem have nothing special.

The unarmed pedicellariae are formed as always of jaws at that are wide at their base, then tapered very quickly to nearly a third posteriorly and from there widening slightly to the middle of the remaining length in a way to form a very elongated spoon.

The bars that make up the spicules are more or less elongated, very irregular and very deeply cut on their outer border rather than bristling with spines.

We have observed neither rosettes nor their frames.

LEIOCIDARIS THOUARSII ${ }^{71}$. - We know only one kind of pedicellariae, the armed pedicellariae. They have some resemblance to those of Cidaris metularia in general, being as wide at the base as they are, much thinner and rounded at the top. The borders are weakly toothed up to the height of the upper transverse bar that is very near the end. From this bar up to the top that is rounded are three or four very strong teeth on the border but not thrown down on the sides as in $C$. metularia and not fixed on a special enlargement of the pedicellariae. The empty space located above the bar has a nearly rectangular form and does not recall in any way the trefoil of $C$. metularia. On the transverse bar are three or four small spines. The inner blade is sunken into the cavity of the piece. On each side of its insertion is a perfectly regular line of vacuoles. The rosette is very large and its borders very jagged as in the other cidarids.

\footnotetext{
${ }^{69}$ PI. 3, fig. 7, $a$ and $b$.

70 PI. 3, fig. $11 a, b$, and $c$.

${ }^{71}$ Pl. 3, fig.10.
} 
The spicules have the form of bars whose two inner and outer borders have blunt, unequal extensions arranged in the form of spines.

LEIOCIDARIS STOKESI ${ }^{72}$. - The pedicellariae of Leiocidaris Stokesi are elongated, tapering gradually from the base to the top and ending in a point or rather a wedge but without a hook. The free border is perfectly straight and very regularly toothed. The inner blade ends in a bar with two lateral teeth and other small intermediaries. Above is a triangular space.

The spicules are elongated, curved and generally without spines on their inner border. But the outer border and the rest of their surface have a very great number.

We have found in the flasks containing debris of pedicellariae, spines and scales of Cidaris, labeled as coming from $C$. Stokesi, pedicellariae that we can attribute to this species only with doubt and even, very probably, not belonging to it. We are keen to give the figure of $\mathrm{it}^{73}$. They are evidently, anyway, pedicellariae of a cidarid.

\section{GENUS GONIOCIDARIS.}

Our information about Goniocidaris is very incomplete. We have been able to examine only one species, Goniocidaris geranioides. In the speciemens of this species available to us, we have not been able to find any tube feet. We can describe, consequently, neither spicules nor rosettes.

We have been very happy to find a pedicellaria and we have been able to confirm that its general constitution is exactly the same as in other cidarids. The stalk and its stem exist. As for the pedicellaria $^{74}$, it has three jaws with straight borders, finely and regularly toothed along its entire length. These jaws gradually taper from the base up to the top that ends in a small hook. Below this each border has a pointed tooth, stronger and more projecting than the others. The inner blade is inserted very deeply, its two borders are nearly parallel the entire length of their insertion. We note a perfectly regular series of vacuoles ${ }^{75}$. This blade ends at a very great distance from the top by a transverse bar with small teeth. The empty space located above this bar has a perfectly triangular form.

The Museum has Goniocidaris Quoyi. It was collected from Australia by Péron and Lesuer. We do not have specimens sufficiently preserved to be able to describe the pedicellariae.

\section{Diadematidae}

We just saw in the family Cidaridae three general having the same characters in the constitution of their spicules and pedicellariae. Passing to the division of Latistelles or Echiniens, we are far from encountering the same homogeneity. It seems to us that we confuse, in the same family, beings that should be separated into distinct divisions, admitting of course that in the generic sections adopted today are considered as having the same value.

Thus the species in the old genus Diadema of Lamarck, have been separated either by Gray or Desor into three genera. These are the genera Diadema, Savignya and Astropyga, distinguished either by pores of the tube feet or by the indentations of the peristome. Well, if one studies the

\footnotetext{
72 Pl. 3, fig. $6 a, b$ and $c$.

${ }^{73}$ PI. 3, fig. 6 c.

74 Pl. 3, fig. 12.

${ }^{75}$ Some vacuoles thus arranged are encountered very frequently in various other cidarids.
} 
spicules of the pedicellariae of these animals, one can recognize such conformity that is found tends to merge these three genera and return to the old genus of Lamarck. At the least, if one conserves the three genera of Gray and of Desor, it appears to us necessary to indicate their affinities in forming for them a distinct family of Diadematidae. One will pardon us for the lack of euphony of this name, considering that it will be uniquely used by naturalists whose ears are not used to much sensitivity. We had to consider, in our choice, the original name of Lamarck and which we should have to preserve the memory above all.

The characters we give for this family are exclusively taken from living beings. It is impossible for us to indicate at this moment with certainty the fossil genera that we have to report. But this is not a consideration that should stop us. It will be without doubt easy for scholars who have made fossil urchins a deep study to fill this hole.

We characterize the family Diadematidae in the following way:

Tube feet ending by rosettes with very jagged borders, supported by irregularly branched spicules that can be gradually transformed, especially in the area of the rosettes, into perforated and very irregularly jagged plates. One or two kinds of pedicellariae never ending in hooks, with a claviform stalk whose pedicellaria is separated by a space containing only soft parts.

We will point out that, either by the uniformity of their pedicellariae that have some relation with the unarmed pedicellariae of cidarids, or by the form of the spicules, some of which, in the area of the rosette, recall a little those of some cidarids, the diademids form a kind of transition between this latter group and those of echinids strictly speaking. They approach the latter especially by the form of the stalk and their pedicellariae as well as for a few characters furnished by the test.

The pedicellariae always have very thick borders and, so to speak, hemmed with a kind of calcareous ribbon that, at the point of junction of the widened basal portion and the jaws, send an extension towards the median line where it meets the extension from the symmetrical ribbon. These two extensions seem to be united to form and anterior border of the apophysis. This is, as always, regularly perforated with circular holes. - It rests on a basal triangular tiered blade with cogs on the border. There is also at the base of the jaws kinds of very slightly ramified calcareous crossbars that seem to reinforce it.

The stalks are in general formed of a thin stem, composed of very elongated sticks united by small crossbars and ending in a rounded thick club that is perforated.

The spicules are entirely irregular with a very variable form. The simplest is a spur ${ }^{76}$ whose stem lacks the wheel. But the curve of the branches can vary. New branches are superimposed in a way to give the most varied aspects.

\section{GENUS DIADEMA, GRAY.}

Diadema SAVignY, Michelin ${ }^{77}$. - We have seen only one kind of pedicellariae with each jaw formed of a nearly equilateral triangular part with a large number of very regular perforations, rounded, superimposed by a blade with parallel borders, rounded at the top, widely and deeply toothed on its borders, having numerous, longitudinally elongated perforations.

The rosette has very deeply cut borders. Very frequently it is composed of six plates.

The spicules are small and have very variable forms. Very often they have the form of a spur with the wheel removed. But other forms can be found as shown in figure 16 of plate 3 .

\footnotetext{
${ }^{76}$ PI. 4, fig. $2 b, 3 c$, etc.

77 Pl. 4, fig. $2 b$.
} 
DiADEMA TURCARUM, Rumphius ${ }^{78}$. - There are two kinds of pedicellariae that differ only by the more or less elongation of the jaws of the pedicellaria. The lower part is thinner from the base to the top and has numerous round holes, serves as the base for a kind of elongated spoon, elliptical, with scalloped borders. Each scallop has a large number of small teeth.

The second kind differs from the first only because this spoon, that is the distal end of the jaw of the pedicellaria, is much more elongated and narrower.

The rosette is also composed of six pieces deeply notched on their outer border.

The spicules have branches ${ }^{79}$ nearly equal, irregularly arranged, obtuse at the top and looking sometimes like a spur, sometimes like a horned horseshoe, sometimes like a star with three branches. - In the area of the rosette are several elongated spicules in an arc having some teeth on the outer border.

DiADEMA CALAMARIUM, Gray. - Two kinds of pedicellariae have been observed. One greatly approaches the pedicellariae already described. The other is farther away from it.

The first ${ }^{80}$ has three jaws with a basal portion that narrows towards the top and supports the jaws. Only here the basal part has a length almost equal to that of the jaws and is more elongated consequently. The jaw is narrow, its two edges are parallel, united at the free end by a rounded edge very finely toothed. We distiguish again on the lateral edges only slightly projecting teeth, widely spaced. These pedicellariae have, moreover, characters common to all the pedicellariae of the diademids.

The pedicellariae of the second kind ${ }^{81}$ are small. The jaws, regularly perforated with oval holes whose great axis is directed longitudinally, are very widened at the free end, slighted narrowing up to the area of the lower edge, then widening abruptly in a way to form the basal part whose lower edge is slightly swollen in the middle.

The extensions from the edges form a kind of horizontal crossbar in the middle of which the apophysis goes towards the base. We give a figure of this pedicellaria still covered with its soft parts and connected to its stalk.

The rosettes show nothing special. The marginal holes are small. Behind them are several more or complete rows of round, still smaller holes.

The spicules ${ }^{82}$ have the same characteristic forms, but their branches, instead of being obtuse as in the two preceding species, end very generally in a point. A form encountered very frequently, though more or less regular, is that of a horseshoe hung back to back with a trident. This fundamental theme, as that of the spur, can be varied in a thousand ways.

\section{GENRE SAVIGNYA, Desor.}

SAVIGNYA SPINOSISSIMA, Desor (Astropyga spinosissima, Coll. Mus.). - We have not been very happy in encountering pedicellariae of this species. The rosettes have nothing special.

\footnotetext{
78 PI.. 4, fig. 2 c.

${ }^{79}$ Pl. 4, fig. 3 b.

${ }^{80}$ Pl. 4, fig. $3 c$.

${ }^{81}$ Pl. 4, fig. 6 a.

82 Pl. 1, fig. 6.
} 
The spicules of the tube feet ${ }^{83}$ are located below the first layer of longitudinal muscles. One finds there all transitions between the simple forms that we have already reported in the other species and those of the irregular blades, elongated, perforated, applied like plates on the underlying case in a way that their greatest length is in the direction of the axis of the tube foot. We distinguish here and there some rare spicules having the form of a pointed arc with two ends that we find frequently in echinids strictly speaking. These plates are especially numerous in the adjacent part of the rosette. They form two rows on each side of the tube foot. We distinguish here and there some rare spicules having the form of a pointed arc with two ends that we have found frequently in the echinids strictly speaking.

\section{GENUS ASTROPYGA, Gray.}

The Museum has Astropyga radiata, the only species of the genus, with completely denuded tests.

We give ${ }^{84}$ figures of a pedicellaria, of a segment of the rosette and spicules of an unidentified diademid listed in the collection of the Museum under number 163.

Figure 5 represents likewise the spicules of the tube feet.of an unidentified diademid listed in the collection of the Museum under number 158.

\section{3. - Echinidae.}

The family of echinids is remarkable for the variety of pedicellariae in the urchins that make it up. In Echinus (Toxoneuptes) lividus, Valentin counted three. Buccal pedicellariae or ophiocephalous are characterized by their special location, the short and massive form with their jaws always ended in the lower part by calcareous arcs that are semicircular, or more or less of this form.

Gemmiform pedicellariae, remarkable for the usually great development of their soft parts while the calcareous parts are thin and armed on the other hand with hooks or extremely sharp points.

Tridactyl pedicellariae have soft parts that are little developed and the calcareous frame formed of three pieces generally more or less end in spoons, never armed with long and pointed teeth.

Finally, Valentin reported with doubt a fourth kind of pedicellariae that is much less abundant, very small, supported by a very thin stalk and with very short jaws that are very enlarged at the top. Valentin wondered if these could be pedicellariae in the process of developing. - I believe I can confirm that they are actually quite distinct organs because I have found them with a perfectly constant form in most of the urchins that I have examined. I never encountered intermediate forms between them and that of other pedicellariae. I designate them trifoliate pedicellariae because of the foliated appearance of their three jaws.

The living genera that we include in the echinids are:

Temnopleurus, Ag.; Melebosis, Girarad; Microcyphus, Ag.; Echinus, Lmk; Sphorechinus, Desor; Tripneustes, Ag.; Holopneustes, Salmacis, Ag.; Mespilia, Desor; Amblyneustes, Ag.; Psammechinus, Ag.; Toxopneustes, Ag.; Loxechinus, Desor; Heliocidaris.

\footnotetext{
${ }^{83}$ PI. 4, fig. 6.

${ }^{84}$ PI. 4, fig. $4 a, b, c$, etc.
} 
Unfortunately, the Museum has only one Temnopleurus preserved in alcohol and extremely delicate.

The specimens of Salmacis bicolor are dried. I have not been able to discover any pedicellariae on them. - It was impossible for me to examine the pedicellariae of Melobosis, Mespilia, Amblypneusetes, Loxechinus, Holopneustes, Phymechinus, Heliocidaris.

In Microcyphus Rousseaui, I have confirmed the existence of ophicephalous pedicellariae like those of Valentin. Moreover, the spicules are also in an arc. But this is all I know.

The genera that I have been able to study are the following:

Echinus, Psammechinius, Sphochinus, Toxopneustes, Tripneustes.

I am led to think that the characters common to echinids of three genera can be extended to those that I have not been able to study. However, this requires study.

Here are the characters found in the tube feet and pedicellariae of echinids.

Four kinds of pedicellariae:

$1^{\circ}$ Ophiocephalous pedicellariae. - These organs are found constantly in groups on the buccal membrane and alone on various other parts of the test. - Their stalk is short, club shaped, fibrous, separated by a long soft space from the pedicellaria. It is formed of very wide, very massive jaws, tightly applied to each other and able to open only slightly. - Each of the jaws is formed of a more or less grasping distal part, elliptical, short, strongly edged on its borders that are scalloped and finely toothed. The scallops of a jaw of the pedicellaria correspond to its adjacent scallops in a way to mesh exactly with them. The dorsal blade of this gill has holes elongated in the longitudinal direction. In the interior is a thin calcareous blade located in the median line, sending on both sides lateral extensions that go to unite with the borders of the dorsal blade. - These borders, or rather their thick part, continue and converge towards the median line of the inner face of the gill while continuing to have teeth. From their point of junction leaves the inner border of the apophysis. This is projecting and goes to insert below on the basal horizontal part that is, as usual, formed of tiered pieces and supports below a semicircular arc, sometimes a little distorted, sometimes also having a calcareous piece that connects its top with the middle of the posterior border of the pedicellaria. The basal portion of the pedicellaria from the top of the apophysis to its base is nearly as long as the active portion. The dorsal blade that constitutes it is riddled with a large number of generally rounded hole. It is equally strongly edged and ha at its lower part two or three rounded crenulations that go to mesh with the crenulations of adjacent jaws in a way to give the organ solidity.

All these characters are so constant that we have difficulty to indicate any modifications of details in the structure of the ophiocephalous pedicellariae whose existence is moreover absolutely constant and easily to confirm in nearly all cases.

The muscles that close the pedicellariae are arranged as usual. Those that open it leave the upper part of the semicircular arcs and go to insert on the lower surface of the two adjacent jaws. When these fibers contract, the three jaws mesh at their bases in perfect contact with each other, mutually serving as a fulcrum, rolling over each other. Their lower portions get closer and the upper portions necessarily separating. It is the same with the semicircular arcs, but the fibers that connect the head of the pedicellaria to the club of the stalk are inserted at their top.

$2^{\circ}$ The gemmiform pedicellariae have a little more variation in form than the preceding. Most often, one finds them formed of a very wide base, forming a kind of a saddle on a donkey, surmounted by a stem that ends usually in a single hook. Nevertheless, the stem can have one or 
several long curved hooks that always coincide with some modifications in the form of the basal piece. Around this thin and delicate skeleton, although so well armed, are grouped very voluminous soft parts, so voluminous even that they led Valentin to consider gemmiform pedicellariae as more important than the others.

We add that each jaw ends below in a basal blade having a large perforation in its center.

The apophysis is inserted along the median line of the lower shield and a basal blade that is perpendicular. It widens as it approaches this blade, and seems to be divided into tiers composed of transverse calcareous rods, connected by a large number of small, perpendicular crossbars. The dorsal shield always has cogs at its base that allows it to mesh with the two adjacent shields. Moreover, it extends onto the median line, a little below the basal piece, either spines or other forms. It is on thee extensions and on the lower surfaces of the adjacent pieces that are inserted the nearly horizontal muscles that open the pedicellaria.

$3^{\circ}$ Tridactyl pedicellariae are very clearly distinguished because their three jaws are elongated, more or less thin, and lacking semicircular arcs. These jaws have the form of elongated spoons that, after a slight narrowing towards the middle of their length, increase again to form a basal portion larger than the spoon itself and having at its base the usual notches.

The borders of these jaws ae frequently seamed and nearly without teeth that recalls the unarmed pedicellariae of diademids. Sometimes there are also toothed scallops on the entire length of the spoon. There are very sharp and widely spaced simple teeth along the rest of the stalk up to the basal dilation. The apophysis itself can have these kinds of teeth. The arrangement of the muscular apparatus is the same as those of the gemmiform pedicellariae, except sometimes a much less development of the adductor muscles.

$4^{\circ}$ I finally reach the fourth kind of pedicellariae, the trifoliate pedicellariae. They are made up of three thin calcareous blades, a little wider at their free end than at their base, slightly narrowed in the middle of their length so that each jaw is divided into an active part and a basal part.

The upper border of the distal, active part is always slightly sinuous. Its lateral borders and the basal part are strongly seamed. At the point where the seams of these two parts are united is a transverse blade that goes from one side to the other and is slightly raise on the midline. From this point rises part of the apophysis that is slightly projecting and attaches to the basal horizontal blade.

The distal end of each jaw is pierced with numerous, regular round holes. It is the same for the basal portion, but the holes of the latter are much smaller than those of the former.

These pedicellariae are extremely small. They are supported on a fenestrated stalk nearly always formed of two adjacent calcareous rods, connected by small longitudinal crossbars. At their lower part, these rods end in a more or less cylindrical swelling, while the upper part ends in a kind of thick, very perforated ball.

The rosettes of the tube feet are generally composed of four or five pieces, with an inner border less irregularly jagged than in the preceding tribe.

The spicules very generally have the form of a $\mathrm{C}$ whose two ends are pointed and the two have perfectly symmetrical. Sometimes the added apophyses of variable form have points where the ends of the arc curve inward.

\section{GENUS ECHINOCIDARIS}


We note that we have excluded from the family of echinids strictly speaking the genus Echinocidaris. We hesitate now to form for it alone a family, especially since numerous affinities connect it to the true echinids. Sometimes it certainly merits a separate place and a little outside the true echinids.

The spicules in this genus have, in fact, a form completely special that we consider, until more information, as characteristic of the genus. They are perfectly straight rods rounded at the two ends, slightly swollen in the middle where there are small perforations. Sometimes these rods can be transformed into true perforated shuttles but these are connected by all kinds of passages of the simplest kind. It is a character as clear, as sharp as those that we have already indicated in Cidaris and diademids.

We have confirmed in Echinocidaris the presence of gemmiform pedicellariae, completely similar to those of true echinids. It is the only kind of pedicellariae that we know at this time, but new research appears necessary to us on this subject.

ECHINOCIDARIS STELLATA, Desmoulins. - Nothing remains of the tube feet or pedicellariae. (Individuals of de Blainville.)

ECHINOCIDARIS DUFRESNII, Desmoulins. - Individuals described by de Blainville, but lacking pedicellariae and tube feet.

ECHINOCIDARIS PUNCTULATA, Desm. - The gemmiform pedicellariae have well developed semicircular arcs up to the extension of the jaw strictly speaking A median arc connects the base of the jaw to the top of the arc. The distal end of the jaw has oval holes, while the holes of the basal part are rounded.

The inner blade appears reduced to a blade with parallel borders.

The outer borders of the rosettes have shallow notches and are rounded at the top and wide at the base.

The spicules are often very wide in the middle and sometimes take an irregular lozenge form. They are very irregularly perforated in the widened portion.

ECHINOCIDARIS SPATUlIFERA, Ag. — Dried specimens without tube feet and pedicellariae.

ECHINOCIDARIS ÆQUITUBERCULATA, Desm. - We have not seen pedicellariae.

The frame of the rosettes is often remarkable for its irregular form and by the small, numerous perforations.

The spicules ${ }^{85}$ are elongated, widened only in the middle portion that has small perforation. We find some aberrant forms among these spicules.

ECHINOCIDARIS PUSTULOSA, Desm. — Individual named by Lamarck, without pedicellariae.

ECHINOCIDARIS NIGRA, Agassiz. - Several individuals, two from Agassiz, but without tube feet and pedicellariae.

${ }^{85}$ PI. 4, fig. 9. 
ECHINOCIDARIS GRANDINOSA, Ag. - The ophiocephalous pedicellariae ${ }^{86}$ are small, swollen at the base and with semicircular arcs near the base and nearly hidden on the lower surface of the pedicellariae. Distal part of the jaws scalloped, with oval holes, having an insignificant inner blade connected to the dorsal blade by three of four lateral expansions. Dorsal blade slightly convex in its upper part, very wide below where the holes are much smaller. Basal piece formed of calcareous pieces arranged in tiers and connected by small crossbars perpendicular to their direction. They have on the lower part a nearly horizontal semicircular arc.

The rosette has very wide pieces on its border that have shallow notches.

The spicules ${ }^{87}$ are straight rods except with swollen ends.

ECHINOCIDARIS SCYTHEI, Philip. — Does not exist in the Museum.

\section{GENUS ECHINUS, Lmk.}

We have been able to examine only one species of the genus Echinus as it is defined today. This is Echinus melo.

The ophiocephalous pedicellariae have in their structure nothing that can make them immediately distinct. The semicircular arc that ends below is simple, much wider in the area of its points of attachment than at its summit and has sometimes perforations in its widest parts.

Each of the gemmiform pedicellariae has on their three jaws formed of a basal piece in the form of a shield and of a stalk ended in a single hook.

The rosettes are deeply notched and each piece has seven to eight grooves.

The spicules have the form of arcs with pointed ends and reflected inwards like the spicules of many sponges and holothuroids. The Museum has:

Echinus acutus, Lmk; E. elegans, Düben and Koren, from Bergen; E. Flemingii, Düben and Koren; Echinus subangulosus, de Gl.; E. magellanicus, Philipp.; E. longispinius, Ag; E. lezaroïdes, Ag., and some other young Echinus whos indentificatoni still cannot be established in a definitive manner.

There are no pedicdellariae in the collection. We have only spines.

\section{GENUS PSAMMECHINUS, Ag.}

PSAMMECHINUS MILIARIS, Lmk. - The pedicellariae are in this species are very characteristic.

The ophiocephalous pedicellariae ${ }^{88}$ are large, toothed on their entire border up to the two teeth that merge with the base. The semicircular arcs are large, simple, inclined about $45^{\circ}$ on the base.

The gemmiform pedicellariae ${ }^{89}$ have three jaws whose base is gradually enlarged to its lower part that is widest, about three times the length of its upper part, which is, to the contrary, the narrowest. The distal part of the jaw is constituted by a blade with nearly parallel borders, slightly narrower at the top, which ends in two hooks located on the same plane. Each of the borders is armed in its upper part with six to seven thin teeth, very long and very pointed. The armed part forms about half the length of the stem. The dorsal part has oval holes, elongated longitudinally. The holes of the basal part are rounded. - The apophysis is connected to the two borders by its

\footnotetext{
${ }^{86}$ PI. 4, fig. 7 a.

${ }^{87} \mathrm{Pl} .4$, fig. 7 c.

${ }^{88}$ PI. 5, fig. 1 c.

${ }^{89}$ PI. 5, fig. 1 a.
} 
top that is wider than the middle and has two lateral bands going towards the borders. From this bifurcated top to the middle of the apophysis are three or four round holes whose diameter decreases as they approach the middle. The base of the apophysis also widens and has numerous small perforations arranged in horizontal lines. This base is tiered as usual.

The tridactyl pedicellariae ${ }^{90}$ have the form of a spoon slightly enlarged in its upper fourth. The basal part, equally widened, forms about a fifth of the total length. The entire length up to the widening that forms the spoon has pointed teeth, short, widely but irregularly spaced. The borders of the spoon are scalloped. The scallops themselves have a number of small teeth, obtuse and very dense.

The free border of the apophysis has a number of very large, pointed teeth, wide at their bases that come together to form a curve continuous with the regular curve. The teeth are spaced.

The plates of the rosette of the tube feet are slightly notched on their border. Most of the projecting teeth end in a kind of shallow sugar cube similar to that which Valentin figured at the end of the same parts in Echinus lividus.

The frame, composed of eight superimposed pieces in pairs, has large quadrangular perforations the entire length of the inner border and small holes behind this row of large perforation. These holes are especially numerous at the ends of the pieces.

The spicules ${ }^{91}$ have the form arcs hooked at the ends and having at the two ends of their dorsal arc two apophyses, one directed above, the other directed laterally and a little towards the base.

PSAMMECHINUS MICROTUBERCULATUS, Agassiz. - The pedicellariae of this species are similar in some regards to those of the preceding species.

The ophiocephalous pedicellariae ${ }^{92}$ are much less massive and very clearly separated by a considerable intermingling of the two parts, one basal, the other the distal end of the jaw. The basal part, very swollen in the middle region, has in this region a diameter greater than the greatest diameter of the distal end of the jaw. The two calcareous bands from the borders of the distal end of the jaws for the apophysis are joined a little above the horizontal midline of the basal part. This has a large number of small, round perforations. Those of the distal end of the jaw are, to the contrary, elongated in the direction of the axis of the pedicellariae and much larger. The inner blade is very simple and often reduced to a kind of cross whose angles are replaced by curves and whose four arms adhere to the dorsal blade of the pedicellaria.

The semicircular arcs are large, inclined on the base and simple.

The gemmiform pedicellariae ${ }^{93}$ have the same general form as those of Psammechinus miliaris. But they end in a simple median hook, and the teeth of the border of the distal end of the jaw are shorter, more widened at their base, very irregular both in form and in arrangement. Moreover, instead of occupying a region of the distal end of the jaw as in the preceding species, they occupy the entire length from the terminal hook to the beginning of the basal part. These, towards the middle of the lower part have a kind of projecting button that is nearly rudimentary in Ps. miliaris.

The tridactyl pedicellariae ${ }^{94}$ have only two distinct parts and not three as in Ps. miliaris. The basal part forming a little more than a fifth of the total length, taper gradually from the base to the top, with a completely unarmed apophysis. - the distal part of the jaw is very elongated, oval

\footnotetext{
90 PI. 5, fig. $1 b$.

91 PI. 5, fig. 1, d.

92 PI. 5, fig. 2, $b$.

93 PI. 5, fig. 2 a.

${ }^{94}$ PI. 5, fig. 2 c, one of the jaws.
} 
with a very regular form, with borders scalloped toward the top that have a very large number of very small teeth, very regularly obtuse and dense that also distinguishes from the pedicellariae of Ps. miliaris. We note in the interior a very regular internal blade regularly notched on its borders and have no perforations as is usual.

The notches of the blades of the rosettes are wide and shallow.

The simple spicules are hooked at the two ends.

PSAMMECHINUS VARIEGAtUS. Ag. - We know only tridactyl pedicellariae in this species. They resemble those of the preceding species, but their form is shorter. The narrowing that separates the basal part from the distal part is much less pronounced. One sees on the scallops only simple obtuse teeth on the distal part.

As in all species of this genus, the plates of the rosette of the tube foot have wide and shallow teeth. The teeth end in a sugar cube that is a little flattened. - The marginal perforations of the frame are relatively small.

The spicules are small, in an arc, slightly hooked at the end and not sharp.

PSAMMECHINUS $\mathrm{n}^{\circ}$ 248, Coll. Mus. - We know this species that appears new has only gemmiform pedicellariae and tridactyl pedicellariae.

The gemmiform pedicellariae ${ }^{95}$ are very near those that we have already described in Echinus. We find almost constantly analogs in the echinids that we still have to study and in the echinometrids.

A kind of rounded basal shield, having an apophysis along its vertical median, is united below with a kind of incomplete plate on which this same apophysis is supported, having in the middle of its lower border a kind of eminence divided into three rounded parts. - Above this shield, a narrow blade with parallel borders ends in a single empty hook at its median part. - Such are the parts making up these pedicellariae.

The tridactyl pedicellariae ${ }^{96}$ are very elongated and have only two distinct parts: the basal part forms nearly a fourth of its total length and narrows gradually from its base to the top, keeping straight borders; - the distal part of oval form. - They are unarmed but seamed their entire length.

The distal end keeps nearly the same length its entire length; the constriction that separates the basal part is not marked.

We have not seen spicules or rosettes.

The known species of Psammechinius that we have not been able to study are the following:

P. decoratus, Ag.; P. semituberculatus, Ag., (Museum); P. subangulosus, Ag. (Museum); P. excavatus, Ag. (Museum); P. Koreni, Ag. (Museum); P. longispinus, de Blainville; P. laganoides, Ag., (Museum); P. Magellanicus Philippi; P. aciculatus, Hupè (Museum).

The species belonging to the Museum of Paris are in such a state of desiccation that we cannot study them.

GENUS SPHÆRECHINUS, Desor.

${ }^{95}$ PI. 5, fig. $3 b$.

${ }^{96}$ PI. 5, fig. $3 a$. 
SPHÆRECHINUS ESCULENTUS, Linné. - The four kinds of pedicellariae are easy to find in $S$. esculentus.

The ophiocephalous pedicellariae ${ }^{97}$ are small, short, a basal part larger than the distal part from which it is distinguished, as always, by the more numerous and smaller perforations.

The semicircular arcs are simple, but well developed and slightly inclined on the base. The inner blade of the distal part of the jaw lacks multiple notches and simply widens at its two ends.

The gemmiform pedicellariae are formed of a short basal piece, not oval or discoidal, but tapers gradually from the base to the top. It has in the area of its upper end a short and pointed spine on each side. - Above the basal shield is raised the narrow blade that ends in a simple hook and constitutes the distal end of the jaw.

The tridactyl pedicellariae ${ }^{98}$ are distinguished by the great width of their basal part at its lower part and its thinness at its top where the width is no more than a fifth of the width of the base. The borders of this region are straight. Its form is obviously that of an equilateral triangle. The distal end of the jaw is nearly two and a half times as long as the basal part. It keeps the smallest diameter its entire length. It is rounded at the end, seamed on its outer border that is completely unarmed. The dorsal perforations are elongated in the direction of the axis and are very narrow.

The trifoliate pedicellariae ${ }^{99}$ have served as the type for the general description that we have given of these organs. We will not occupy ourselves with it. We refer for the details to the figure we give of one of their blades.

The plates of the rosette are very widely notched on their border. These notches are very irregular.

The spicules are in the form of hooked arcs.

We have not yet described another living species of this genus, Sphoechinus gibbosus of the Galapagos Islands. - This species is in the Museum, but it is in too poor a condition for us to be able to give information on its pedicellariae and tube feet.

\section{GENUs TOXOPNEUSTES, Agassiz.}

Toxopneustes Lividus, Agassiz. - This species is the one studied by Valentin. - The descriptions and the figures he gave of the pedicellariae, the spicules and he rosettes of the tube feet are correct. We can thus dispense with discussing them extensively.

But we must recall here two mistakes already reported relative to the frame of the rosette. This apparatus is described and figured as formed of a single piece, while it is really constituted by eight pieces as we have already had the occasion to say in our generalities.

Valentin indicated the presence of trifoliate pedicellariae in this animal, but wondered if it was not the early stage of other pedicellariae. It is still an opinion we must dispute. We have found in fact no intermediate form linking these pedicellariae to others. - They form thus a fourth kind of organs perfectly distinct from the three others.

Toxopneustes DRoBACHIENSIS, Müller. - We use with regret the name given this species by Müller that has been preserved in the galleries of the Museum. The name of T. neglectus given it

\footnotetext{
97 PI. 5, fig. 8 a.

98 PI. 5, fig.. $8 c$.

${ }^{99}$ PI. 5, fig. 8 b.
} 
by Lamarck is much more euphonious. It would be worthwhile in this regard that it prevail over the barbaric name imposed by Müller.

Toxopneustes neglectus has ovoid ophiocephalous pedicellariae and has no marked narrowing between the basal and distal part of the jaw. Their entire border is scalloped from the top down to the three teeth of the narrowing. These scallops are very regularly and very finely toothed. - The semicircular arcs are slightly inclined on the base. They often have a bar uniting the top to the base of the pedicellariae, and one notes also on the rest of their inner curve a small ridge directed towards the median bar and may sometimes fuse with it to thus limit a lacuna. Immediately above the semicircular arcs the basal blade has many perforations larger than those on the rest of the dorsal part of the basal portion.

The gemmiform pedicellariae ${ }^{100}$ are formed of a basal shield having an apophysis whose base is scalloped on the two sides and perforated regularly in the corresponding region. Above this shield is raised a blade thicker than wide, linear, ended by a hook having a median lacuna and a kind of tooth at the base of the right border looked at from above.

The tridactyl pedicellariae ${ }^{101}$ are massive, formed of the blades in which the basal piece is scarcely distinguished from the distal part. This basal part is strongly notched on each side and allows the apophyses to be seen. They have small teeth on their free border that are very spaced and very projecting. - The free border of the distal end is scalloped and finely toothed.

The borders of the plates of the rosette have long projecting rods, rounded at the top. - In addition to the large marginal perforations, the pieces of the frame ${ }^{102}$ have very few holes.

The spicules ${ }^{103}$ have nearly the same form as in Psammechinus miliaris. They are meshed with some arced spicules that have simple hooks.

The Museum has the following species: T. brevispinus, Ag; T requituberculatus, Ag.; T. granularis, Ag.; T. Delalandii, Ag..; T. dubenii, Ag.

\section{GENUS TRIPNEUSES, Agassiz.}

TRIPNEUSTES VENTRICOSUS, Lmk, Ag. - We have been able to study here the three kinds of pedicellariae and confirm that these organs are not essentially different from their homologs in the preceding genera.

The ophiocephalous pedicellariae ${ }^{104}$ occupy their usual position. Their jaws have nearly everywhere the same width. They are a little widened at their base where one sees, as usual, three or four teeth for engagement. The semicircular arcs form a nearly irregular half circle whose plane is very slightly inclined on the plane of the base of the organ. - The two sides of the apophysis has rounded notches. The distal end of the jaw is rounded, scalloped on the borders that are armed in addition with numerous small teeth, rounded and regular that one sees also very clearly on the calcareous bands that connect the two borders of each jaw at the top of its apophysis. The inner blade, well developed, has wide and numerous perforations, irregularly rounded. The larger ones are marginal while the smaller ones are located towards the center of the blade.

At the dorsal region, the perforations of the distal end of the jaw are oval and elongated in the direction of the axis of the organ. Those of the basal part are smaller, regular and rounded.

\footnotetext{
100 PI. 5, fig. $7 a$.

101 PI. 5, fig. 7 c.

102 PI. 5, fig. 7 b.

103 PI. 5, fig. 6 b.

104 PI. 5, fig. 4 c.
} 
Their color is often violet.

One sees this coloration also in the gemmiform pedicellariae ${ }^{105}$ whose muscle masses are much less developed than in the preceding genera. Each jaw of these pedicellariae is composed of an oval basal shield surmounted by a calcareous blade with parallel borders having on the left, when regarded from above, a slight ridge with its terminal part and ending in a curve, very elongated hook with a large median lacuna. The borders of the basal shield are strongly seamed. The apophysis, thin in the median region, is enlarged at its lower end where it has some elongated lacunae and connected at its base to the shield by some transverse calcareous bands. These are connected by some longitudinal crossbars that form a kind of tiered screen. The dorsal blade is reinforced on each side of the apophysis by a very perforated irregular calcareous blade.

At its lower part, the apophysis is continuous with a notched calcareous strip on both sides that occupies the median region of the blade of the distal part of the jaw.

The tridactyl pedicellariae ${ }^{106}$ resembles those we described for diademids. Each jaw is made of three parts. A lower or basal piece that is an isosceles trapezoid with seamed borders, but smooth except at the base where there are three notches for engagement. This part has the apophysis. Above the basal part is a median part with parallel borders, seamed and with short teeth, pointed and spaced. Finally, the upper part has a few teeth that are wider, short, rounded and that form a kind of terminal spoon. This is the true functional end of the jaw.

These pedicellariae are also very often colored violet.

The rosettes are often formed only of four plates. The border of these plates are mostly toothed. These teeth are extremely irregular and never end in a point. The frames show nothing special.

The spicules ${ }^{107}$ are in arcs, very small, slightly swollen and blunt at the two ends.

TRIPNEUSTeS Suboeruleus, Lmk (sp.); Ag; (g.). - In this species, the ophiocephalous pedicellariae ${ }^{108}$ scarcely differ from those of the preceding species. However, their apophysis lacks lateral notches and the inner blade that, instead of being continuous pads of the border, is inserted deeper. It usually lacks central perforations, so that it has a thin calcareous blade, sending extensions from both sides that go to attach to the dorsal blade.

The gemmiform pedicellariae also have the same appearance as in the preceding species. The basal shield is extended below on the median line in three flat, very short tubercles.

The tridactyl pedicellariae ${ }^{109}$ are very different. One sees only two distinct parts: the hornshaped distal part of the jaw opened anteriorly and the basal part with which it is directly continuous. The perforations of the distal part are oval, directed obliquely to the axis.

The plates of the rosette are as in the preceding species.

The spicules ${ }^{110}$ are in hooked arcs and pointed with two ends. They are very small.

TRIPNEUSTES BICOLOR, Val., coll. Mus. - We have been able to study in this species only the ophiocephalous pedicellariae and the gemmiform pedicellariae.

\footnotetext{
105 PI. 5, fig. $4 a$.

106 PI. 5, fig. $4 b$.

107 P. 5, fig. $4 d$.

108 PI. 5, fig. $5 a$; an isolated jaw.

${ }^{109} \mathrm{PI} .5$, fig. $5 b$; an isolated jaw.

110 PI. 5, fig. 5 c.
} 
The ophiocephalous pedicellariae ${ }^{111}$ are remarkable only for their irregular arcs and having perforations.

The gemmiform pedicellariae ${ }^{112}$ have the same structure as in the two preceding species. The basal shield seen by its inner part ends below in two or three pairs of flat mamelons or rounded teeth located on each side of the median line. - The apophysis has two longitudinal rows of teeth with hooks that project slightly. It is connected to the base of the shield by the cogs that we have had to report constantly. The blade that supports the terminal hook is perforated and slightly enlarged at its top. The hook and the other parts are as in the preceding species.

The spicules ${ }^{113}$ are small rounded arc, slightly swollen at the two ends.

The rosettes show nothing special.

The species that remain to be studied are the following:

Tripneustes saricuds, Agassiz (Museum); T. fasciatus, Ag. (Mus.); T. angulosus, Ag. (Museum) $)^{114}$.

\section{GENUS BOLETIA, Desor.}

We have confirmed in Boletia pileolus the presence of ophiocephalous pedicellariae as usual and gemmiform pedicellariae ${ }^{115}$ whose jaws are formed of a rounded basal shield and a narrow calcareous blade three times longer than the shield and ends in a long curved median hook that does not seem to us to have an elongated median perforation.

It remains to fill the lacunae that we leave in the study of this species and to study the following species:

Boletia heteropora, Desor (Mus. Paris); B. maculata (Val.); B. bizonata, Lmk. (Mus. Paris).

\section{GENUS LOXECHINUS, Desor.}

It has only one species, Loxechinus albus, Desor from the coasts of Chile. We cannot give any information about the pedicellariae of this animal.

GENUS HELIOCIDARIS, Desmoulins.

In Heliocidaris variolaris the spicules are perforated plates recalling those that we have encountered in diademids. One also encounters, but in very small number, spicules with an arced hook. We have seen debris of tridactyl pedicellariae. This genus that has been considered, rightly or wrongly, as forming a transition to echinometrids, has particular characters. It would be interesting to study completely the tube feet and pedicellariae of these animals that compose it. Unfortunately, the individuals of the Museum are insufficient for that.

\section{4. - Echinometridae}

\footnotetext{
111 PI. 5, fig. 6 b.

112 PI. 5, fig. $6 a$, an isolated jaw.

113 PI. 5, fig..6.

${ }^{114}$ A new species will be described later. It is designated in the collection under the name T. Peronii. T. pentagonus and $T$. planus of Ag. have no interest to us, not having been able to study their pedicellariae.

115 PI. 5, fig. 9 c.
} 
In terms of the pedicellariae, as well as those of the constitution of the tube feet, the echinometrids are much nearer the echinids than to the diademids or cidarids. - Except, of course, the lacunae that could not be filled, we will find, in fact, constantly here ophiocephalous, gemmiform, and tridactyl pedicellariae, with forms approaching greatly those we already know, belonging evidently to the same types.

Sometimes some modifications in the details in structure of apparent insignificance have such a constancy that one is forced to take them into account. All the more so that they allow to distinguish immediately with a glance the pedicellariae of echinometrids from those of urchins strictly speaking.

These differences related to the ophiocephalous and gemmiform pedicellariae that seem to participate in the irregularity that is already shown so visibly in the form of the test.

In echinids we have seen that the semicircular arcs of the gemmiform pedicellariae nearly always have the same development in the three jaws. In the echinometrids, to the contrary, one of the semicircular arcs is more developed and passes under the two others that it seems to enclose. This difference in development can be more or less apparent.

The modification of the gemmiform pedicellariae is much more positive and consequently more characteristic. In fact, in the echinids we have seen constantly symmetrical hooks on the gemmiform pedicellariae arranged in relation to the midline. In such a way that they always end in a single median hook, often with a longitudinal lacuna that makes it appear to form two lateral bands that are fused to the median line in a way to form a point, — or by two symmetrical hooks starting at the same level at the upper end of the pedicellariae.

In the echinometrids, this is not the case. In all cases that we have been able to study, the gemmiform pedicellariae end in two hooks, but these two hooks appear at different heights, although very near the top of the pedicellaria. The upper hook can be either on the right or on the left.

Seen in profile, the pedicellaria appears thus to end in two hooks located at different heights ${ }^{116}$ although very near the top of the pedicellaria but never at the same time at the same point when one examines the organ with the microscope. If one observes the pedicellaria from the front and especially from the back, one will see the narrow terminal blade ends in a way to form two tiers, each corresponding to a hook ${ }^{117}$,

The tridactyl pedicellariae show no particular asymmetry.

The rosettes of the tube feet and their frames are constituted as in the echinids.

The spicules that support the tissue of the tube feet have, in all species that we have examined, the form of simple arcs, hooked and pointed at the two ends.

We see the modifications that characterize the echinometrids are perfectly clear, but they are only modifications of the echinid type. The type does not change from cidarids to diademids and from them to Echinocidais to the urchins strictly speaking.

The echinometrids are not numerous. They are separated into three genera:

Echinometra - Acrocladia - Podophora.

These genera are especially characterized by the form and arrangement of the rods of the test. If we limit ourselves to this characteristic, it seems that Echinometra forms in the urchins with an elliptical test a group parallel to those of the echinids strictly speaking including the diademids,

\footnotetext{
116 PI. 6, fig. $1 d, 6 a$.

117 Pl. 6, fig $2 b, 3 b, 4 a$, etc.
} 
while Acrocladia, of which Podophora is only an aberrant type, will be parallel to the cidarids. But this comparison is not possible when pedicellariae and the spicules are taken into account. We have seen the cidarids, diademids, Echinocidais even are very far from the urchins in regard to these organs and form as many groups. Here, to the contrary, in spite of the differences that the rods can show, pedicellariae and spicules are identical. We cannot draw any distinctive generic character, in a way that the group of echinometrids are homogeneous from this point of view. The comparisons that we report at first glance are much more apparent than real.

\section{GENUS ECHINOMETRA, Breynius.}

ECHINOMETRA HETEROPORA, Agassiz. - Elongated ophiocephalous pedicellariae, with a basal portion shorter than the distal end and slightly swollen. The borders of the distal end are scalloped and toothed. Simple semicircular arcs. One of them is larger than the others.

Gemmiform pedicellariae ${ }^{118}$ with an apophysis having a free border raised perpendicularly to its base, then inflected abruptly towards the hooked blade. The distance from the top of the apophysis to its base is obviously less than its distance to the nearest hook.

Tridactyl pedicellariae ${ }^{119}$ are very elongated, at least four times longer than the diameter of their base when the jaws are closed. The length of the apophysis is less than a fourth the total length of the organ. The top of the jaws are curved into a hook.

ECHINOMETRA ( ${ }^{\circ}$ 274). - The ophiocephalous pedicellariae are more massive than in the previous species. The length of the distal part scarcely equals that of the basal part. The scallops are less pronounced, but their teeth are clearer. The disproportion between the three semicircular arcs is much more evident.

In the gemmiform pedicellariae ${ }^{120}$, the length of the blade with hooks is nearly the same as that of the basal shield. The apophysis has the same structure as in the preceding species. The blade with hooks has on its upper part a median elongated hole enlarges up to the level of the lowest hook where it ends in a rounded shape. The highest hook has in its median region a hole similar to that we have described in the single hook of Tripneustes.

The pieces of the rosette are notable for their great development of the perforation nearest the border.

The pieces of the frame show nothing special.

The spicules are hooked arcs, pointed at both ends.

The species that are still to be examined are the following:

Echinometra lucunter, Gray; E. Maugei, de Bl.; E. acufera, de Bl.; E. Mathœi, de Bl. (P.); E. lobata, de Bl.; E. Michelini, Desor; E. Quoyi, de Bl.

GENus ACROCLADIA, Agassiz.

ACROClADiA MAMILlATA, Lmk. (sp.). - The ophiocephalous pedicellariae ${ }^{121}$ have their distal ends separated from the basal part by a very marked constriction. The perforations of the distal end are much more voluminous than those of the basal part. These have simple semicircular arcs

\footnotetext{
118 PI. 6, fig. $6 a$; an isolated jaw.

119 PI. 6, fig. 6 b.

${ }^{120}$ Pl. 6, fig. 7.

121 Pl. 6, fig. 1 c.
} 
on two of the jaws, while the arc of the third is much larger. The calcareous band that it forms sends towards its base either an additional median arc or two lateral arcs in such a way that this arc seems to be bifurcated at its end.

In the gemmiform pedicellariae ${ }^{122}$, the narrow plate with hooks is two times longer than the basal shield and is stout.

The tridactyl pedicellariae ${ }^{123}$ has three parts. The large one forms a rounded spoon. The other forms a basal shield shaped like an isosceles trapezoid. These two parts are connected together by another part connected with it by a weak, narrower curve. This middle part, like that which forms the spoon, is armed with very short and very spaced teeth. The pedicellaria is weakly seamed on all its circumference. The perforations are all rounded. But those of the basal portion are much smaller than those of the spoon. Sometimes the decrease in size is done gradually by intermediaries in the middle.

The plates of the rosette are widely and shallowly toothed. The teeth that end the projecting parts are regularly rounded.

The frame shows nothing special.

The spicules ${ }^{124}$ are hooked arcs, pointed at the two ends and elongated. They often have a very small spine in the middle of their dorsal region.

ACROCLADIA VIOLACEA, de Bl. - We must consider as a distinct species of Acrocladia that identified in the collection as Echinometra violacea de Blaiinville. If, as we have reason to believe, this assimilation is correct, we cannot, after a complete study of the pedicellariae, accept the opinion of Dujardin and Hupé that Acrocladia violacea is a simple variety of Acrocladia mamillata.

The ophiocephalous pedicellaria ${ }^{125}$ have a very great analogy with those of the preceding species. But the gemmiform pedicellariae ${ }^{126}$ are very different. Their blades with hooks exceed very little in length that of the basal shield. The latter has a thick apophysis whose outer border has two or three large perforations elongated in the longitudinal sense. The dorsal perforations are very large. Finally, small circular perforations are found in the lower part of the narrow blade that supports the hook. There is a very large lacuna in all the inner upper half of this blade. Finally, the highest hook has a longitudinal lacuna analogous to that of Tripneustes.

The elongated tridactyl pedicellariae ${ }^{127}$ taper gradually from the base to the top that curves to the interior in a way to form a kind of large, blunt hook.

The teeth of the rosette are more deeply notched, the spicules ${ }^{128}$ less elongated and thinner.

ACROClADIA HASTIFERA, Agassiz. - The back of the pedicellariae of this species are pink in color. They have a great analogy with those of Acrocladia mamillata.

We have not found ophiocephalous pedicellariae. The gemmiform pedicellariae ${ }^{129}$ are scarcely distinct from those of A. mamillata.

\footnotetext{
122 PI. 6, fig $1 a$ and $1 d$.

123 PI. 6, fig. 1 b.

124 Pl. 6, fig. 1 e.

125 PI. 6, fig. 2 c.

${ }^{126}$ PI. 6 fig. $2 b$.

127 PI. 6, fig. $2 a$.

128 PI. 6, fig $2 d$.

${ }^{129}$ PI. 6, fig. $3 b$.
} 
The tridactyl pedicellariae ${ }^{130}$ are distinguished by a more elongated form, the spoon being oval and no longer nearly circular. These pedicellariae appear unarmed to us.

The spicules ${ }^{131}$ are less elongated than in A. mamillata.

ACROClADIA TRIGONARIA, B1. - The ophiocephalous pedicellariae of this species resemble those of the preceding species ${ }^{132}$. But the gemmiform pedicellariae and the tridactyl pedicellariae are very characteristic.

The gemmiform pedicellariae ${ }^{133}$ are shortened so that the stalk that has two hooks is shorter than the basal shield and even than its apophysis. This latter has the same characters as in the preceding species. But it does not have the lacuna on its free border. The blade that has the hooks has, to the contrary, a large oval lacuna that is extended from its base up to the hooks.

The tridactyl pedicellariae ${ }^{134}$ cannot be divided into three parts so that the spoon at the end, which is very slightly narrowed at the top, rest on the basal piece that is itself slightly enlarged at its base. The upper border of the pedicellaria is curved to the interior where it is notched in a manner to make a double hook.

The plates of the frame of the rosette as well as the spicules are like those in the preceding species.

It is to be noted that the calcareous substance of the gemmiform pedicellariae is colorless while it is colored purple in the tridactyl pedicellariae.

\section{GENUs PODOPHORA, Agassiz.}

This singular genus includes up until now only two species, Podophora atrata and pedifera.

We have only been able to study the first.

In spite of all our research, we have found in specimens of the Museum only one kind of pedicellariae.

These pedicellariae are near tridactyl pedicellariae ${ }^{135}$. They are all the same. Their notched border allows to be seen a straight very clear apophysis. Above the notch the borders are straight, very finely and very regularly toothed.

In their entire length, these organs are uniformly perforated with round holes having essentially the same aspect.

The rosettes, their frames and the spicules ${ }^{136}$ of the tube feet are not obviously different from those we have found in the other echinometrids.

\section{IRREGULAR ECHINOIDS}

We must be extremely prudent in making generalities about irregular echinoids. The collection of the Museum has a considerable number. Unfortunately the species it offers for study are not in

\footnotetext{
${ }^{130}$ PI. 6, fig $3 a$.

131 PI. 6, fig $3 c$.

132 PI. 6, fig. $4 a$.

133 Pl. 6, fig. $4 b$.

134 PI. 6, fig. 4 c.

135 PI. 6, fig. 8 a.

${ }^{136}$ PI. 6, fig. $8 b$.
} 
a state of preservation that one can proceed with assurance when it is a matter of giving negative characters, and they are nearly all that we list.

All we can say, in calling new verifications on this point, is that in all the irregular urchins that we have studied, we have confirmed the absence in the tube feet of a terminal true rosette. These organs end completely different in their analogs in the family of regular urchins. The description of this mode will better find its place when we speak of spatangoids that we have studied better.

In many genera, in whole families we have found pedicellariae only in spatangids.

Nevertheless, and we insist on this point, we do not pretend in any way that they only exist there. Only the study of living and better preserved animals can clarify this question.

Everywhere we have studied them, the tube feet contain spicules of variable form and that we will describe in detail species where we have observed them.

It is confined to the generalities that we can give at this time to the animals the occupy us. So few are the results that we present, relatively to those we have found in the regular urchins, we have the conviction to have obtained from the collection of the Museum all it can give us at this point. It is elsewhere that the research must come, and this explains why we give incomplete results. We cannot predict when it will be possible for us to complete it.

\section{ECHINOCONIDÉS.}

\section{5. - Echinonéens.}

GENUS ECHINONEUS, van Phels.

The species of this species in the Museum are the following:

Echinoneus cyclostoma, Leske; E. minor, Leske; E. crassus, Agassiz (coll. P.); E, ventricosus, Ag. (coll. P.).

We have not been able to study any in a suitable state of preservation.

This genus is the only one in the family that has living species.

All fossil.

D. DYSASTERIDÉES.

E. ClypeastroÏDes.

\section{6. - Laganiens}

GENUS ECHINOCYAMUS, van Phels.

The living species of the Museum are:

Echinocyamus pusillus, Fleming; E. angulosus, Leske; E. tarentinus, Mus.; E. canaliferus, Mus.

GENUS FIBULARIA, Lmk.

Existing at the Museum:

Fibularia ovulum, Lmk.; F. trigona, Lmk. 
We have not studied any of them.

\section{GENUS MOULINSIA, Ag/}

Moulinsia cassidulina, Ag.

The only species of the genus, from Martinique, does not exist in the collection.

GENUS LAGANUM, Klein.

Laganum scutiforme, Desor; L. rostratum, coll. Mus.; L. Peroni, Ag.; L. cingulatum, coll. Mus.; L. Bonani, Klein; L. Tonganense, Quoy and Gaimard; L. Lesueurii, Ag.

We were unable to gather any information about the pedicellariae and tube feet of these species.

GENUS MICHELINIA, Duj. and Hupé.

Michelinia elegans does not exist at the Museum.

$$
\text { GENUS ARACHNOIDES, King }
$$

Arachnoides placenta, Agassiz.

\section{7. - Scutelliens.}

\section{GENUS ECHINARACHNIUS, von Phels.}

The only species of the Museum is Echinarachnius parma, Gray.

$$
\text { GENUs DENDRASTER, Ag. }
$$

Dendraster excentricus, Val. (coll. of the Mus.)

$$
\text { GENus LOBOPHORA, Ag. }
$$

Lobophora bifora, Ag.; L. truncata, Ag.; L. bifissa, Lmk; L. tenuissima, coll. Mus.

The apparently well preserved specimens did not offer us pedicdellariae. The tube feet could not be studied.

$$
\text { GENUS MELLITA, Klein. }
$$

At the Museum:

Mellita hexapora, Ag.; M. testudinata, Klein.

\section{GENUs ENCOPE, Ag.}

Encope maraginata, Ag.; E. perspectiva, Ag.; E. oblonga, Ag.; E. Valenciennesii, Ag.; E. Michelini, Ag.; E. Stokesi, Ag. 
GENUS ECHINODISCUS, Breynius.

At the Museum:

Echinodiscus Rumphii, Breynius; E. digitatus, Desor.

GENUS ROTULA, Klein

Rotula Augusti, Klein, from the Museum.

\section{Clypeasteriens.}

GENUS CLYPEASTER, Lmk.

Clypeaster rosaceus, Lmk.; C. latissimus, Ag.; C. placunarius, Lmk.; C. scutiformis, Coll. Mus.

F. CASSIDUlides.

9. Echinobrissiens.

GENUS ECHINOBRISSUS, Breynius.

This genus has only one living species, Echinobrissus recens. The Museum has only one specimen that is well preserved. We have been able to confirm that the tissue of the tube feet is supported by smooth spicules ${ }^{137}$ in the form of thin rods with two ends and having in the middle a kind of tubercle. Sometimes this tubercle is elongated into a true stalk and the two branches are joined below this solid stalk in an obtuse angle. The form of spicules has variations that are nevertheless very directly related to the shape of the original rods.

We have not seen pedicellariae.

\section{GENUS CASSIDULUS, Lmk.}

A single living species:

Cassidulus australis, Lmk. (P.) that gave us no information.

GENUS PYGORHYNCHUS.

Living species from the Museum:

Pygorhynchus pacificus, Ag. from Acapulco (Mexico)

GENUS ECHINOLAMPAS, Gray.

Species of the Museum:

Echinolampas cyclostomus, Leske; E. oviformis, Lmk; E. Hellei, Val. (coll. Mus.).

${ }^{137} \mathrm{Pl} .7$, fig. 1. 


\section{G. SPATANGOÏDES}

The urchins of this family are the only irregular urchins for which we have been able to confirm the presence of pedicellariae, the only ones also in which we have been able to study the tube feet.

The pedicellariae have appeared to us to be of two kinds. One has a very great resemblance to the ophiocephalous pedicellariae of regular urchins, but are lacking in semicircular arcs ${ }^{138}$.

The other pedicellariae ${ }^{139}$ are near the form of tridactyl pedicellariae but with modifications that allow us not to confuse them with the pedicellariae of any urchins belonging to the other groups. They are always made up of three jaws, each composed of three parts. One, basal, in the form of a shield, has at its lower part on the median line a variable number of small teeth or of appendages of equally variable form. This basal piece has a very projecting apophysis with numerous perforations.

The middle part is constituted of a blade with parallel borders more or less toothed. They are narrow and their length is always much greater than the length of the basal piece. This middle piece supports the third part or spoon that has an oval form, acuminate, with very regular and very finely toothed borders.

In some spatangids, the pedicellariae reach a considerable size.

The tube feet are of two kinds: one is located in the vicinity of the mouth; the others by the pores distributed on the rest of the surface of the body.

None of them end in a flat disk. None of them have an internal rosette that we have always found in regular urchins.

The tube feet of the body ${ }^{140}$ end in a variable number, but in general narrow, digitations covered with a cellular epithelium. Each is supported by a calcareous rod, straight and enlarged at its lower part to give a kind of more or less regularly perforated disk that is inserted on the underlying tissue. To the contrary, at the upper part, this rod flattens and tapers to end in a point after being slightly enlarged.

As a result it has more or less regularly the form of a sword. The surface of these rods, or terminal spicules, is irregular and has very numerous but very small perforations ${ }^{141}$.

The buccal tube feet ${ }^{142}$ are much more voluminous than those of the body. They end in large bunch of long filaments that form a kind of very dense tuft. These filaments all more or less end in a club. They are formed by a perfectly clear cellular tissue containing here and there, especially in the area of the end, calcareous corpuscles irregularly rounded and diversely colored. This soft tissue has a long calcareous rod $^{143}$ with a slightly mammelated surface. They keep the same diameter their entire length. This rod is always curved in an arc but its curve is slight.

Those of its ends that correspond to the free end of the filament containing it is rounded and very slightly smaller. The other end is connected with a calcareous disk having, when looked at by its base, perforations that are very regularly arranged like a rose window ${ }^{144}$. It is by this disk that the rod is attached to the underlying tissues.

\footnotetext{
138 PI. 7, fig. $4 b$ and $7 b$.

139 PI. 7, fig. $4 a 7 a, 2 c$.

140 PI. 7, fig. $2 a$.

${ }^{141}$ PI. 7, fig $3 b, 5 a$.

142 PI. 7, fig. 6.

143 PI. 7, fig. $2 d, 5$ c.

144 PI. 7, fig. 4 c.
} 
The buccal tube feet, like those of the body, have the rest of their tissue supported by calcareous spicules $^{145}$ of variable form and that, consequently, will be described when we concern ourselves with particular species.

From what we have just said, it appears evident that the tube feet of spatangoids can no longer be, as in regular urchins, adhesive organs and of locomotion. But they are perhaps organs of touch. It would be interesting to elucidate this point, and one could do this by attentively studying the histology of these terminal parts so singularly divided into digitations or tufts. This would require observation of fresh animals. We cannot ask the question at this moment.

Whatever it is, the arrangement of the terminal part of the tube feet singularly separates the spatangoides from the regular urchins. This is a new character to add to those we have already indicated.

We have studied all the genera that make up the family of spatangoids. The genera Brissopsis, Echinocardium or Amphidetus, Brissue and Spatangus are the ones that we have been able to observe. But our generalizations will not appear too audacious if one considers that these genera are much the more important of the family and that, in each of them, we have examined seveal species.

The genera Kleinia, Leskia, Gray, Eupatangus, Agassiz, Mora, Michelin, Lovenia, Agassiz and Plagionotus that complete the family contain each a very small number of species and most even only one.

\section{GENUS BRISSOPSIS, Ag.}

BRISSOPSIS LYRIFER, Ag. - The terminal spicules of its buccal tube feet are very elongated and conform to the general description. One conceives, in fact, that these so simple organs can scarcely furnish distinctive characters. Also we indicate them now only to affirm that we have confirmed their existence and to mention the species in which our observations have more specially have been done. We often had to renounce pushing them as far as would have liked. We have had to consider that the specimens we have studied are in a public collection and that we could not submit them to any destruction.

The spicules that support the body of the tube foot ${ }^{146}$ are in the form of thin rods with very singularly disposed projections with a diameter equal to that of the rod itself.

BRISSOPSIS PARMA, Val. (coll. Mus.). - We give the figure of the end of a buccal tube foot ${ }^{147}$ belonging to an animal of this species. One will note that the filament making up the tuft increases in thickness from the base to the top.

BRISSOPSIS ( $\left.{ }^{\circ} 18\right)$. - In this species, the terminal spicules of the buccal tube feet are as in preceding. The spicules of the body of the tube feet ${ }^{148}$ are longer with more numerous small projections. Some are flat and have perforations more or less numerous. Others constitute true calcareous platelets with enormous lacunae. We give figures representing these different forms.

GENUS KLEINIA.

\footnotetext{
${ }^{145}$ Pl. 7, fig. $2 f, 2 a, 3 a, 8,9$, etc,

146 PI. 7, fig. 9.

147 PI. 7, fig. 6.

${ }^{148} \mathrm{P}, 7$, fig. 8.
} 
It has only one species, Kleinia Luzonica that the Jardin does not possess.

GENUS LESKIA, Gray.

A single species, Leskia mirabilis that does not exist in the Jardin.

Genus EUPATANGUS, Agassiz.

A single species, which exists in the Museum of Paris, Eupatagus Valenciennesii.

\section{GENUS BREYNIA, Desor}

Dried specimens in the Museum are Breynnia Crux-Andreo, Desor; Breynia nigra, Ag, from Acapulco (Mexico).

\section{GENUs AMPHIDETUS, Agassiz.}

We have observed on this urchin a kind of pedicellaria ${ }^{149}$ that is near the tridactyl pedicellariae but whose form is obviously very far from that we have given to the pedicellariae of Spatangus in our general description. They are formed very simply by a basal shield having the aspect of an isosceles trapezoid, surmounted by a narrow blade with parallel borders, one and a half times longer than the buccal shield. The upper end, curved at a right angle with the body of the stalk, has an angular groove that separates it into two pointed hooks that are wide at their base. At the base of the shield are, as usual, three of four cogs.

The dorsal tube feet ${ }^{150}$ end in seven or eight short digitations that are rounded at the end, each supported by a sword-shaped spicule ${ }^{151}$ that is slightly curved and whose substances is clearly and irregularly perforated. - The tissue of the tube feet contains calcareous spicules ${ }^{152}$ that are straight or slightly flexed whose surface is rough. Thee spicules are arranged following the perpendicular plane of the axis of the tube foot. They seem to me to be the cause of the very regular horizontal folds of the tube foot in the state of retraction.

The buccal tube feet end in a tuft whose filaments are supported by elongated spicules having the usual form ${ }^{153}$.

The spicules that support the tube feet themselves ${ }^{154}$ have the form of more or less developed calcareous plates, very irregular, perforated whose borders are extended in a variable number of very pointed spines, flat and located in the plane of the plate.

We refer to the figures that are absolutely necessary to give a clear idea of the form of these spicules.

\footnotetext{
149 PI. 7, fig. 2 c.

150 PI. 7, fig. 2 a.

151 PI. 7, fig. 2 e.

152 PI. 7, fig. 2 b.

153 PI. 7, fig. $2 d$.

154 PI. 7, fig. $2 f$.
} 
AMPHIDETUS ( $\left.\mathrm{n}^{\circ} 171\right)$, coll. Mus. - In this species, the spicules that support the digitations of the tube feet of the body are straight and have the form of swords and the perforations as we have often described $^{155}$

The spicules that support the body of the buccal tube feet are long flat rods, sometimes with perforations and ridges that taper gradually to their ends that are a sharp point. The rods are sometime bifurcated or can be broken at an angle in the area of their surroundings. Their borders are sometimes perfectly straight and smooth, sometimes irregularly but slightly notched ${ }^{156}$.

Amphidetus Novæ ZelandiÆ, Val., coll. Mus. - The buccal tube feet have a tuft at the end and the usual terminal spicules. We have not seen the spicules that support the tube foot itself.

AMPHIDETUS ( $\left.\mathrm{n}^{\circ} 193\right)$, coll. Mus. - The dorsal tube feet end in a small number of digitations supported by sword-shaped spicules ${ }^{157}$ that taper gradually from the base to the top. - The spicules of the tube feet are thin rods ${ }^{158}$, more or less inflected and end in a very sharp point at their two ends.

The terminal spicules of the buccal tube feet have the usual form ${ }^{159}$. The spicules of the tube feet $^{160}$ are flat, perforated and ended in very sharp points. Their border often has extensions that are located in the same plane as the spicule and also ends in a very sharp point.

There still exists in the Museum:

Amphidetus gibbosus, coll. Mus.; A. Gaymardi, coll. Mus.

Nota. We must note the form of the spicules that support the bodies of the tube feet of Amphidetus. They are always flat, irregular and their extensions, whose borders are very clearly abrupt, always end in a very sharp point, - Up to here, this character appears to us to be completely special to the amphedetids.

\section{GENUS SCHIZASTER.}

Species of the Museum:

Schizaster giberrulus; S. canaliferus.

GENUS AGASSIZIA.

Agassizia scrobiculata, Val.

\section{GENUS BRISSUS}

We have studied only one of the species of this genus. It is an unidentified Brissus from Mexico. We have been able to confirm that the buccal tube feet have at their end the same character as the other spatangoids.

\footnotetext{
155 PI. 7, fig. $3 b$.

156 PI. 7, fig. $3 a$.

157 PI. 7, fig. $5 a$.

158 PI. 7, fig. $5 b$.

159 PI. 7, fig. 5 c.

160 PI. 7, fig. $5 d$.
} 
The tube feet are supported by small spicules ${ }^{161}$, extremely irregular, sometimes branched, sometimes in the form of small irregular plates, sometimes diversely curved and having extensions of various forms but never ended in spines like those of amphidetids.

The species of the genus Brissus that are found in the Museum are the following:

Brissus areolatus, Val.; B. Scilloe, Ag.; B. fragilis, Val.; B. ventricosus, Lmk.; B. sternalis, Ag.; B. bicinctus, Val.; B. cavinatus, Ag.; B. columbaris, Ag.

\section{GENUS MEERA, Michelin.}

It contains two species:

Mora atropos, Lmk.; M. Lachesis, Desor that do not exist in the Museum.

GENUs LOVENIA, Ag.

Two species of which one is still doubtful. The best known is Lövenia hystrix, which exists in the Museum but dried.

We place next to it L. quadrimaculata, also in the Museum.

\section{GENUS PLAGIONOTUS, Ag.}

Only two species:

Plagionotus pectoralis; P. Desorii.

Only the first is in the collection of the Museum.

\section{GENUS SPATANGUS.}

SPATANGUS PURPUREUS. - We have observed in this spatangoid ophiocephalous and tridactyl pedicellariae, or rather modified analogs of the two kinds of pedicellariae.

The pedicellariae to which we keep the name ophiocephalous ${ }^{162}$ have jaws formed of two parts, a circular basal part, wider than the other, with an inner median apophysis, as usual and lacking semicircular arcs. The horizontal base is wide as in regular urchins. It is the same for the lower part of the apophysis.

Above the basal piece and separated from it by a very pronounced narrowing arise the distal part of the jaw whose general form is that of a square with rounded angles. It is sensibly narrower than the basal part and has like it numerous rounded perforations.

The tridactyl pedicellariae ${ }^{163}$ have the general form we have already described. The basal part is short and slight widened. It is scarcely a fifth of the total length of the organ. It is ended below by three small pointed projections directed in the sense of the axis of the organ with one is median to the two lateral others. The average lamellar part enters at two and a half fifths the length of the organ. It width is a little less than a third of the greatest width of the basal part. The spoon, ending in a pointed very fine tooth, slightly curved at its end, forms the rest of the length. It connects gradually with the middle of the stalk. Its greatest width is nearly double that of its stalk.

\footnotetext{
161 PI. 7 fig. 10.

162 PI. 7, fig. 4 a.

163 PI. 7, fig. $4 d$.
} 
It is in this species that we have studied, as much as possible in individuals preserved in alcohol for a long time, the histology of the filaments of the buccal tube foot tuft. These filaments swell abruptly into a club at their free end ${ }^{164}$. They are composed of a mass of cells with very distinct nuclei and in the middle of which is the spicule of known form. At the swollen end among the cells are numerous calcified bodies with an irregular rough surface and a beautiful violet color. If one removes the calcareous dagger that supports a filament of the disk that ends it below, one can observe the makeup of the disk ${ }^{165}$ and one notes there six lunules in the form of a lozenge whose lateral angles are rounded. These lunules are regularly arranged in a circle on the surface of the disk and do not reach the central region that is large. Between these lunules, on the outer side, one observes others that separate them, whose form is more oval. The intercalated lunules can sometimes be replaced by two other smaller ones. Finally, to the exterior of this double system of lunules, one sometimes observes, but very rarely, others very small in variable number. These disks, seen under the microscope, are of a great elegance.

The spicules that support the tube feet ${ }^{166}$ are extremely irregular. They are sometimes simple more or less sinuous rods, sometimes small calcareous pieces, distorted and branched in a thousand ways, but whose various extensions never end in a point.

SPATANGUS MERIDIONALIS. - We have observed in this species spicules of the tufts of the buccal tube feet that show nothing special except that the lunules of their basal disk have appeared to us less regular than in the preceding species.

We have also seen pedicellariae different from those of the preceding species only by a little more elongated form.

Spatangus Planulatus. - The spicules of the tube feet have the form of irregularly branched rods ${ }^{167}$. The tridactyl pedicellariae that we have observed differ from those of $S$. purpureus by the relative portions of their three parts ${ }^{168}$.

The basal part and the spoon ${ }^{169}$ have nearly the same length. The middle stalk that unites them has at nearly one and a third the length of one of the two first parts.

The basal piece ends below by a slight tubercle on the horizontal surface. The apophysis has the form of a vertical very thin disk. It is relatively more developed than in S. purpureus.

This species closes the list of echinoids that we have studied.

\section{CONCLUSIONS}

It remains for us to summarize rapidly the facts and the new results that are contained in our work.

A. Regarding the sea stars:

\footnotetext{
${ }^{164} \mathrm{PI} .7$, fig. $4 e$.

${ }^{165}$ PI. 7, fig. $4 e$.

${ }^{166}$ PI. 7, fig. 4 c.

167 PI. 7.

${ }^{168}$ PI. 7, fig. 7 c.

${ }^{169}$ PI. 7, fig. $79 a$.
} 
$1^{\circ}$ We have shown that a simple inspection of the pedicellariae allows immediate distinction of the group of asteroids with four rows of tube feet from those with two rows of these organs.

$2^{\circ}$ We have demonstrated in all asteroids in the first category always have two kinds of pedicellariae and we have defined their special location.

$3^{\circ}$ We have made known for the first time in a complete way the structure of the pedicellariae special to Asteracanthion that we have designated as crossed pedicellariae and that their presence is absolutely constant around the spines of the skin.

$4^{\circ}$ We have described and figured for the first time the pedicellariae of all species of Asteracanthion that were available to us to use these organs to characterize the specie.

$5^{\circ}$ We have established likewise the essential differences that distinguish the pedicellariae of asteroids with two rows of tube feet. We had made known their mode of insertion on the ossicles of the skeleton. Finally, we have described and figured all the forms that we have been able to observe, those that are useful to characterize the species.

$6^{\circ}$ We have described all the new species of the collection of the Museum of Natural History and therefore revised the catalogue of the asteroids of this establishment.

It is good to note, however, that we have not included in this work of revision all the species of the Michelin collection recently acquired by the Jardin des Plantes at the instigation of Professor Lacaze-Duthiers.

\section{B. Regarding the urchins.}

$7^{\circ}$ We have shown that the study of the tube feet allows immediately the distinguishing of the regular urchins and the irregular urchins. The tube feet of the first ending in a calcareous rosette, while the tube feet of the second lack it.

$8^{\circ}$ We have made known the structure of the frame of the rosettes, mistaken by Valentin. We have made known, in addition, the mode of ending of the tube feet of spatangoids.

$9^{\circ}$ We have demonstrated in a definitive manner the existence of calcareous spicules in the interior of the tissue of the tube feet of nearly all the echinoids (all those that we have observed), and we have shown that one can use the form of these spicule to characterize entire groups of echinoids.

$10^{\circ}$ We have thus characterized the family of Cidaridae, and we base it on this character that is, moreover, perfectly related with the others. We have reunited some separated genera of the genus Diadema of Lamarck into the same section: that of diadematids. We have had still to separate Echinocidaris from other echinoids to which we have likewise assigned a special character taken from the form of the spicules.

All the echinometrids that form a very natural group are found to have spicules of the same form, which has been a kind of test for the character that we have proposed to use. Finally, although we have had to leave numerous lacunae in the study of irregular urchins, we were able to show, regarding the genus Amphidète, that the spicules of the tube feet furnish again in this group important characters.

$11^{\circ}$ The study of the pedicellariae has allowed us to add a new character to those that already separated the cidarids, diadematids and echinometrids from Echinocidaris and echinoids strictly speaking.

$12^{\circ}$ We have described and figured for the first time the pedicellariae of a large number of species and give thus one more characteristic. 
$13^{\circ}$ Finally, as for the asteroids, we have been able to revise a catalog of the living urchins possessed by the Museum. We have been aided in this last part of our task by an unedited work of revision by our colleague, Louis Rousseau, Assistant Naturalist at the Museum. This work is about the regular urchins. The results are exhibited in the galleries of the Museum.

We do not hide the lacunae that we leave to be filled.

The physiological role of the pedicellariae is still to be discovered. Their histology, their mode of development have been scarcely studied. It is the same for the tube feet.

Perhaps we will be happy enough to resume this work and thus complete that which we submit today to the judgement of zoologists. 


\section{EXPLANATION OF THE PLATES.}

NoTA. - In all the plates, the spicules are shown at a uniform enlargement of 140 diameters. The pedicellaria are at an enlargement that varies from about 30 to 60 diameters. In each plate, the figures concerning the same species are shown by the same number with the parts indicated in the figure.

\section{PLATE 1.}

\section{Pedicellariae of Asteracanthion}

Fig. 1. Asteracanthion glacialis. $-a$, crossed pedicellaria covered with soft parts; $e$, cellular membranous envelop; $t$, intersecting branches of the jaw; $b$, calcareous basal piece that supports and rolls the jaws; $m, m f$, muscles that close the jaw; $m o$, muscle that opens the jaw, $-b$, straight pedicellariae covered with soft parts. The same letters represent the same parts as in the preceding figure. $p$, pedicellaria in the process of formation, budding on an already formed pedicellaria.

Fig. 2. Asteracanthion rubens. - $a$, straight pedicellaria; $b$, crossed pedicellaria; $c$, basal piece of a straight pedicellaria, seen from above; $d$, section of one of the jaws of the same; $e$, the same, seen from the upper surface; $g$, lower part of one of the jaws of the straight pedicellaria, seen from the inner surface and showing, $o$, the orifice by which the adductor muscle enters into the interior of the jaw to insert on to it walls.

Fig. 3. Asteracanthion tenuispinus. - $a$, straight pedicellaria; $b$, crossed pedicellaria; $c$, one of the jaws of a crossed pedicellariae, seen from the inner surface to show the teeth with which it is armed.

Fig. 4. Asteracanthion gelatinosus. Straight pedicellaria.

Fig. 5. Asteracanthion africanus. - $a$, crossed pedicellaria, seen from the surface; $b$, the same, seen from the side.

Fig. 6. Asteracanthion polaris. - a, crossed pedicellaria; $b$, straight pedicellaria.

Fig. 7. Asteracanthion roseus. $-a$, straight pedicellaria.

Fig. 8. Asteracanthion aurantiacus. - a, straight pedicellaria; $b$, crossed pedicellaria, seen from the side.

Fig. 9. Asteracanthion Nove-Boracensis. — $a$, straight pedicellaria; $b$, crossed pedicellaria.

Fig. 10. Asteracanthion stellionura. - straight pedicellaria; $b$, basal piece of the pedicellaria, isolated; $c$, crossed pedicellariae; $d$, one of the jaws of this pedicellaria a little inclined to show the dental armature.

Fig. 11. Asteracanthion from Australia. Crossed pedicellaria.

Fig. 12. Asteracanthion gemmifer. - $a$, straight pedicellaria; $b$, crossed pedicellaria; $c$, a jaw of the preceding, seen from the inner surface.

Fig. 13. Asteracanthion australis. Crossed pedicellaria.

Fig. 14. Asteracanthion sulciferus. - $a$, straight pedicellaria; $b$, crossed pedicellaria; $c$, jaw of the preceding, seen from its internal surface.

Fig. 15. Asteracanthion. - $a$, straight pedicellaria; $b$, crossed pedicellaria.

Fig. 16. Asteracanthion (heliaster) helianthus. - $a$, straight pedicellaria; $b$, one of the jaws of this pedicellaria, seen by the inner surface. 
Fig. 1. Oreaster turritus. - $a$, pedicellaria with jaws; $b$, a valve of a valvular pedicellaria., $c$, section of a valvular pedicellaria and of the ossicle that supports it to show the mode of insertion of the first on the second.

Fig. 2. Oreaster hiuleus. - $a$, pedicellaria with jaws from the ambulacral groove. $b$, valvular pedicellaria in the dorsal papular areas (an isolated jaw, seen from its inner surface.

Fig. 3. Oreaster Linckii. - $a$, pedicellaria with jaws; $b$, skin of the dorsal surface in the area of a papular pore; $o$, papular pore; $p$, small valvular pedicellaria; $g$, dorsal granulations.

Fig. 4. Oreaster from San Diego. - $a$, pedicellaria with jaws from the ambulacral groove. $b$, crossed pedicellaria; $c$, the same, seen from the side.

Fig. 5. Culcita discoidea. - $a$, pedicellaria with jaws from the ambulacral groove; $b$, three plates of the ambulacral groove; $e$, spines forming the inner row of the ambulacral armature; $t$, spines of the inner row; $p$, pedicellariae located between the two rows at the border of each plate; $g$, granulations of the ventral surface. $-c$, skin of the dorsal region in the area of a tubercle, $t$, tubercle; $a$, papular area covered with pores; $r$, projecting lines have tubercles and separating the papular areas; $p$, pedicellaria with jaws.

Fig. 6. Culcita arenosa. - Pedicellaria of the dorsal surface.

Fig. 7. Culcita pulverulenta. - $a$, pedicellaria with jaws from the papular areas; $b$, a jaw of this pedicellaria seen by the inner surface; $c$, valvular pedicellaria of the ventral surface.

Fig. 8. Culcita grex. - $a$, valvular pedicellaria of the ventral surface, in place; $b$, valvular pedicellaria of the papular areas of the dorsal surface, an isolated jaw.

Fig. 9. Astrogonium phrygianum. - Valvular pedicellaria of the ventral surface.

Fig. 10. Astrogonium marginatus. - Pedicellaria of the dorsal region.

Fig. 11. Astrogonium verruculatus. - Pedicellaria of the dorsal region.

Fig. 12. Archaster angulosus. - $a$, Pedicellaria of the ambulacral groove. $b$, pedicellaria of the dorsal surface.

Fig. 13. Archaster typicus. - Pedicellaria of the ambulacral groove.

Fig. 14. Acanthaster solaris. Pedicellaria of the dorsal surface.

Fig. 16. (sic) Luidia Savignyi. Pedicellaria with two jaws from the ventral surface.

Fig. 17. Luidiai ciliaris. Pedicellaria with three jaws from the border of the ambulacral groove.

Fig. 18. Luidia granulosa Pedicellaria with three jaws from the ventral surface.

\section{PLATE 3.}

Fig. 1. Cidaris pistillaris. $-a$, entire pedicellaria; $b$, one of the jaws of the pedicellaria seen from the internal surface; $c$, the same seen from the side; $d$, one of the segments of the tube foot rosette; $c$, spicules of the tube feet.

Fig. 2. Cidaris metularia. - $a$, head of a pedicellaria; $b$, one of the segment of the tube foot rosette; $c$, spicules of the tube foot.

Fig. 3. Cidaris Krohonii. - $a$, a pedicellaria (head and terminal portion of the stalk; $b$, spicules of the tube feet.

Fig. 4. Cidaris baculosa. - $a$, segment of the tube foot rosette; $b$, spicules of the tube feet; $c$, head of a pedicellaria.

Fig. 5. Cidaris canaliculatus (coll. Mus.). - Head and upper part of the stalk of a pedicellaria.

Fig. 6. Leiocidaris Stokesi. - $a$, first form of pedicellariae; $b$, spicules of the tube feet; $c$, second form of pedicellariae. 
Fig. 7. Cidaris verticillata. - $a$, head of a pedicellaria; $b$, upper portion of the stalk of the same, much more enlarged to show the mode of ending of the lower stem.

Fig. 8. Cidaris (from Callao), young age, unpub. (coll. Mus.). $-a$, pedicellaria; $b$ spicules of the tube feet.

Fig. 9. Cidaris annulifera. - $a$, pedicellaria; $b$, spicules of the tube feet; $c$, one of the pieces of the frame of the rosette.

Fig. 10. Leiocidaris Thouarsii. - a, pedicellaria; $b$, spicules of the tube feet.

Fig. 11. Leiocidaris papillata. - $a$, first form of pedicellariae, unarmed pedicellariae; $b$, second form of pedicellariae, armed pedicellariae.

Fig. 12. Goniocidaris geranioides. Head of a pedicellaria.

\section{PLATE 4}

Fig. 1. Diadema savignyi. - $a$, pedicellaria; $b$, spicules of the tube feet.

Fig. 2, Diadema turcarum. - $a$, pedicellaria; $b$ spicules of the tube feet; $c$, a spicule from the vicinity of the rosette.

Fig. 3. Diadema calamarium. - $a$, first form of pedicellaria; $p$, jaw of the forceps pedicellaria; $m$, adductor muscles; $m r$, retractor muscle of the crossed pedicellaria; $p$, stalk; $e$, cellular membranous envelope, $-b$, a jaw of the pedicellaria, the second form of pedicellaria; $c$, spicules of the tube feet.

Fig. 4. Diadema ( ${ }^{\circ} 103$, coll. Mus.). - $a$, a pedicellaria; $b$, a segment of the tube foot rosette; $c$, spicules of the tube feet.

Fig. 5. Diadema ( ${ }^{\circ} 158$, coll. Mus.). - $a$, spicules of the tube feet.

Fig. 6. Savignya spinosissima. Spicules of the tube feet.

Fig. 7. Echinocidaris grandinosa. - a, ophiocephalous pedicellaria; $b$, one of the jaws of the same seen from the internal surface; $c$, spicules of the tube feet.

Fig. 8. Echinocidaris punctulata. - $a$, ophiocephalous pedicellaria; $b$ spicules of the tube feet.

Fig. 9. Echinocidaris aquituberculata. - Spicules of the tube feet.

\section{PLATE 5.}

Fig. 1. Psammechinus miliaris. - $a$, gemmiform pedicellaria; $b$, tridactyl pedicellaria; $c$ ophiocephalous pedicellaria; $d$, spicules of the tube feet.

Fig. 2. Psammechinus micro-tuberculatus. $-a$, gemmiform pedicellaria; $b$, ophiocephalous pedicellaria; $c$, a jaw of a tridactyl pedicellaria.

Fig. 3. Psammechinus ( $\left.{ }^{\circ} 248\right)$. - $a$, tridactyl pedicellaria; $b$, gemmiform pedicellaria.

Fig. 4. Tripneustes ventricosus. - $a$, gemmiform pedicellaria; $b$, tridactyl pedicellaria; $c$, a jaw of an ophiocephalous pedicellaria; $d$, spicules of the tube feet.

Fig. 5. Tripneustes subcoruleus. - $a$, jaw of an ophiocephalous pedicellaria; $b$, jaw of a tridactyl pedicellaria; $c$, spicule.

Fig. 6. Tripneuste bicolor. - $a$, jaw of a gemmiform pedicellaria; $b$, ophiocephalous pedicellaria; $c$, spicules.

Fig. 7. Toxopneuses neglectus. - $a$, jaw of a gemmiform pedicillaria; $b$, spicules; $c$, tridactyl pedicellaria; $d$, Two pieces of the frame of the rosette.

Fig. 8. Sphorechinus esculentus. - $a$, ophiocephalous pedicellaria; $b$, trifoliate pedicellaria; $c$, tridactyl pedicellaria. 
Fig. 9. Boletia pileolus. - $a$, gemmiform pedicellaria; $b$, spicules.

Fig. 10. Spicules of Psammechinus variegatus.

\section{PLATE 6}

Fig. 1. Acrocladia mammillata. - $a$, gemmiform pedicellaria; $b$, tridactyl pedicellaria; $c$, ophiocephalous pedicellaria; $d$, end of a jaw of a gemmiform pedicellaria; $e$, spicules.

Fig. 2. Acrocladia violacea. $-a$, tridactyl pedicellaria; $b$, gemmiform pedicellaria; $c$, one of the calcareous pieces of the rosette; $d$, spicules; $e$, inner surface of one of the jaws of a tridactyl pedicellaria.

Fig. 3. Acrocladia hastifera. —a., tridactyl pedicellaria; $b$ gemmiform pedicellaria; $c$, spicules.

Fig. 4. Acrocladia trigonaria. - $a$, gemmiform pedicellaria; $b$, tridactyl pedicellaria; $c$, upper end of a jaw of the same; $d$, spicules.

Fig. 5. Acrocladia serialis. - $a$, gemmiform pedicellaria; $b$, tridactyl; $c$, upper end of the same.

Fig. 6. Echinometra heteropora. - $a$, gemmiform pedicellaria; $b$, tridactyl pedicellaria.

Fig. 7. Echinometra (Ind). Hawaiian Isands (Remy, 1857). Gemmiform pedicellaria.

Fig. 8. Podophora atrata. - $a$, pedicellaria; $b$, spicules.

\section{PLATE 7}

Fig. 1. Spicules of the tube feet of Nucleolies recens.

Fig. 2. $a$, dorsal tube feet of Amphidetus ovatus; $b$, spicules of the same; $c$, pedicellaria, $e$, spicules supporting the terminal digitation of a dorsal tube foot; $f$, spicules of a buccal tube foot.

Fig. 3. $a$, spicules of a buccal tube foot of Amphidetus $\left(\mathrm{n}^{\circ} 171\right) ; b$, terminal spicules of a dorsal tube foot of the same.

Fig. 4. Spatangus purpureus. - $a$, tridactyl pedicellaria; $b$, ophiocephalous pedicellaria; $c$, basal rosette of one of the spicules that supports the terminal digitation of a buccal tube foot; $d$, terminal club of a dorsal tube foot; $e$, spicules.

Fig. 5. Amphidetus ( $\left.{ }^{\circ} 193\right)$. - $a$, terminal spicule of a dorsal tube foot; $b$, terminal spicule of a dorsal tube foot; $c$, terminal spicule of a buccal tube foot; $d$, spicule of the tube foot of the same.

Fig. 6. Terminal tuft of a buccal tub foot of Brissopsis parma.

Fig. 7. Spatangus meridionalis. - $a$, tridactyl pedicellaria; $b$, ophiocephalous pedicellaria, a jaw; $c$, spicules of the tube feet of $S$. planulatus.

Fig. 8. Brissopsis $\left(\mathrm{n}^{\circ} 19\right)$. Spicules of the tube feet.

Fig 9. Brissopsis lyrifer. Spicules of the tube feet.

Fig. 10. Brissus (from Mexico). Spicules of the tube feet.

Seen and approved, 25 June 1869

Dean of the Faculty of Sciences

MILNE EDWARDS.

Permission to publish 25 June 1869

Vice-rector of the Academy of Paris

A. MOURIER. 


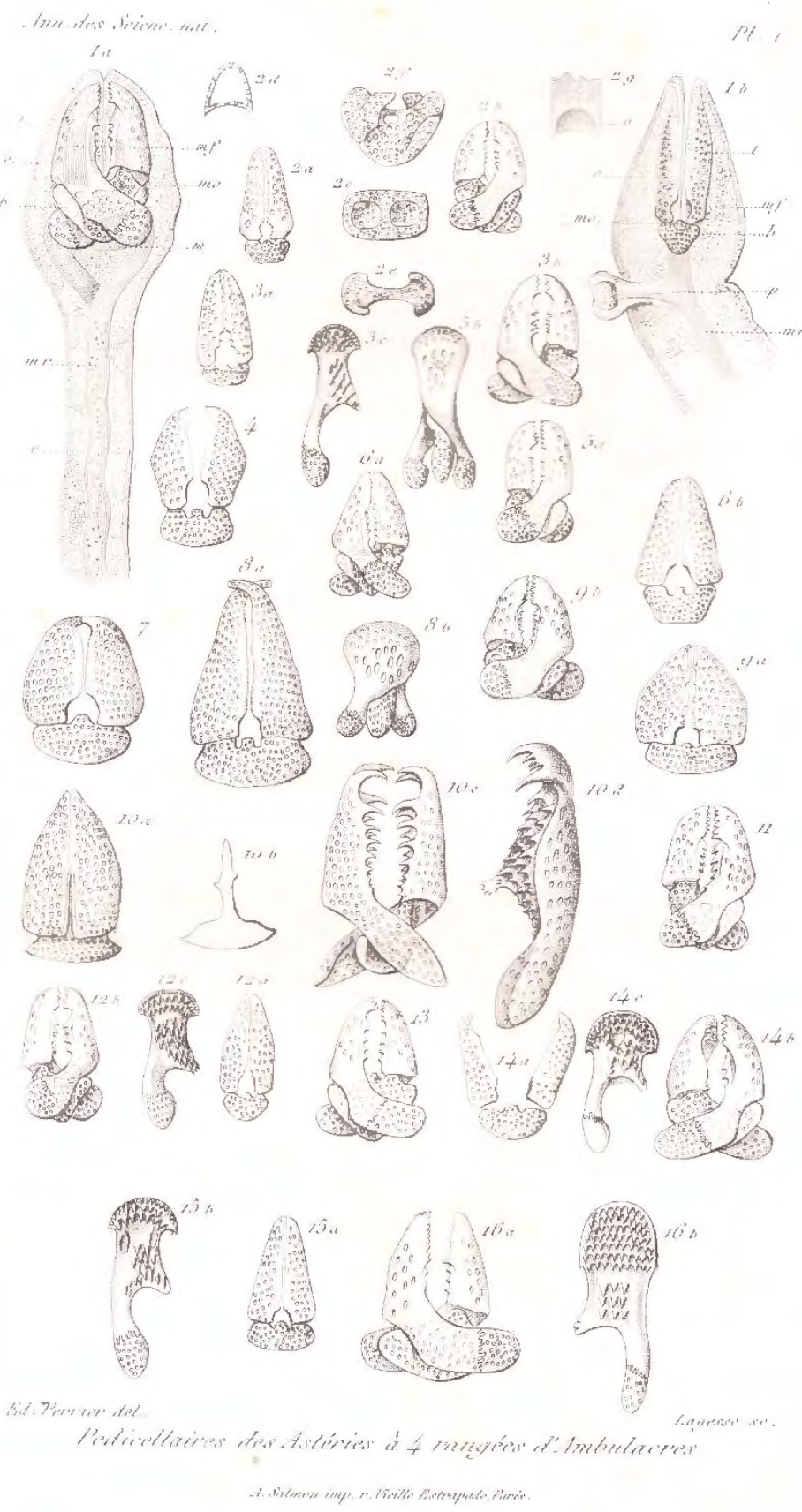




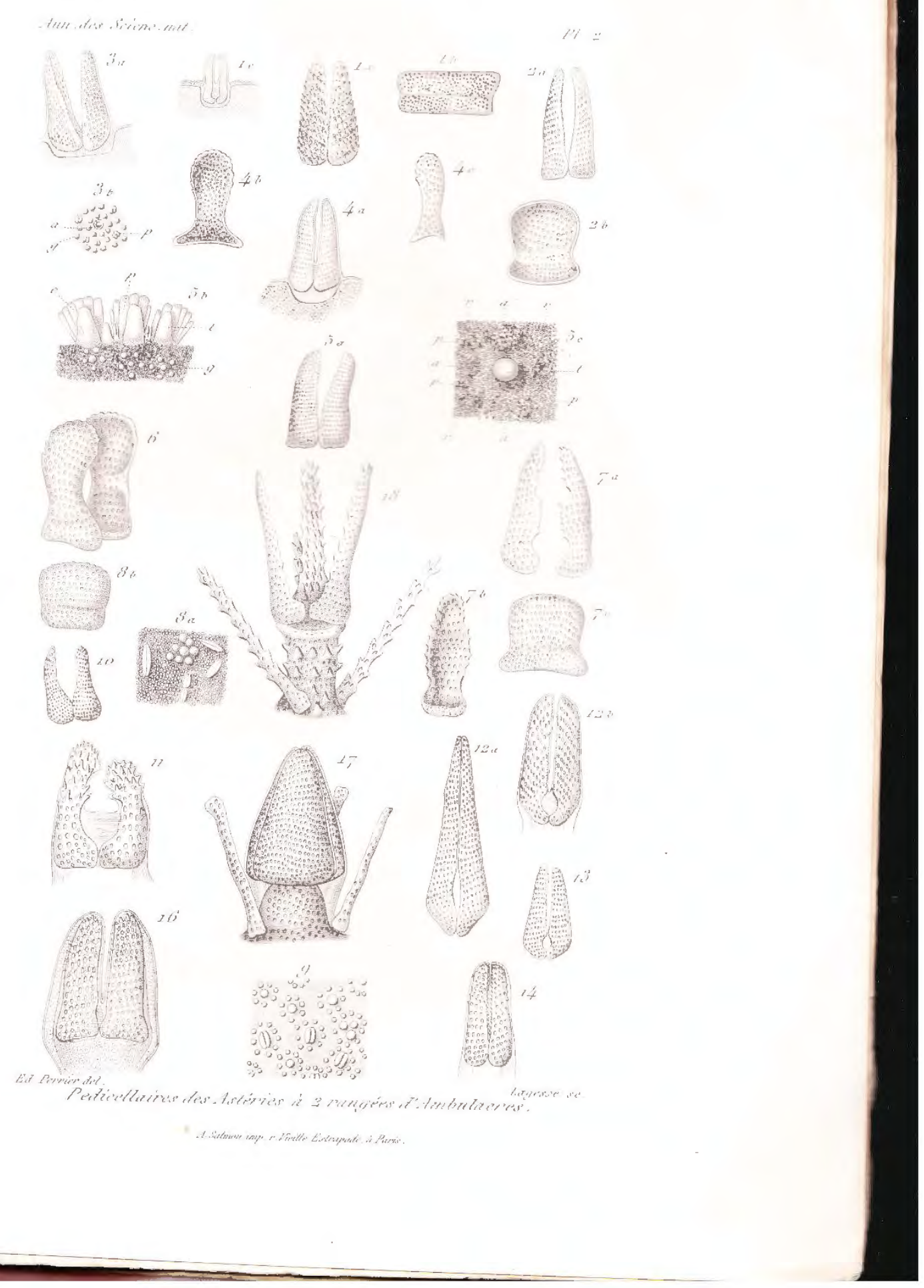




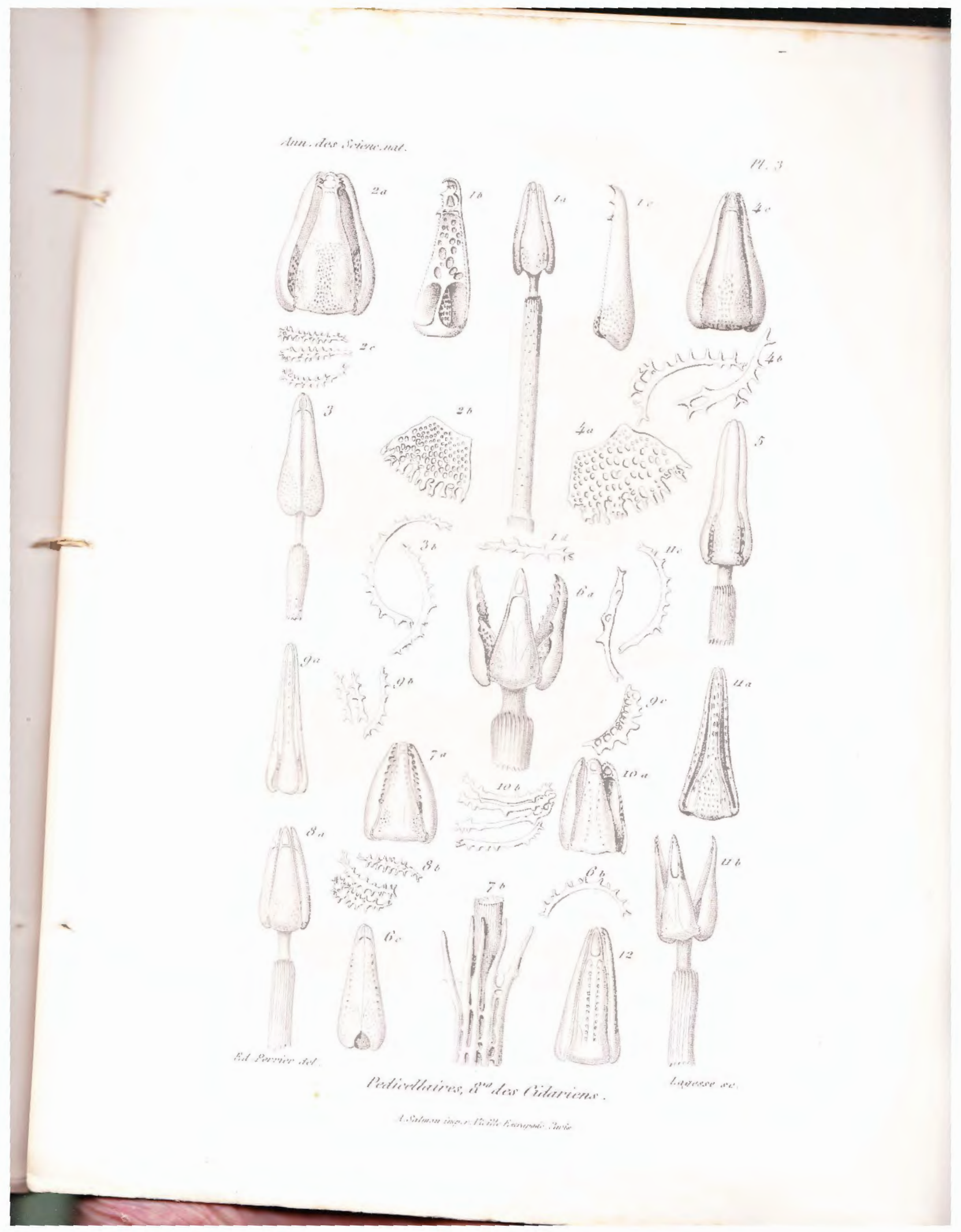




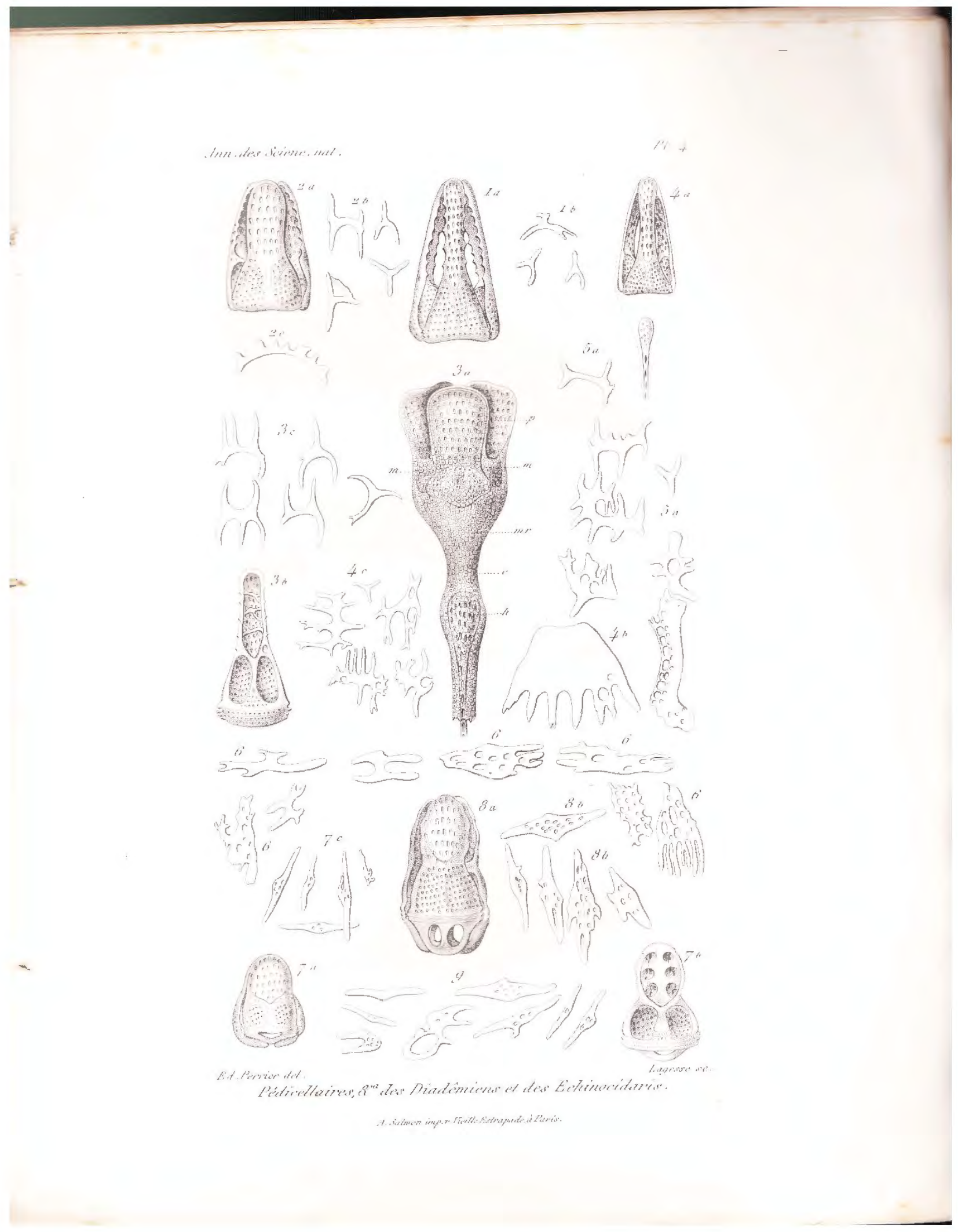




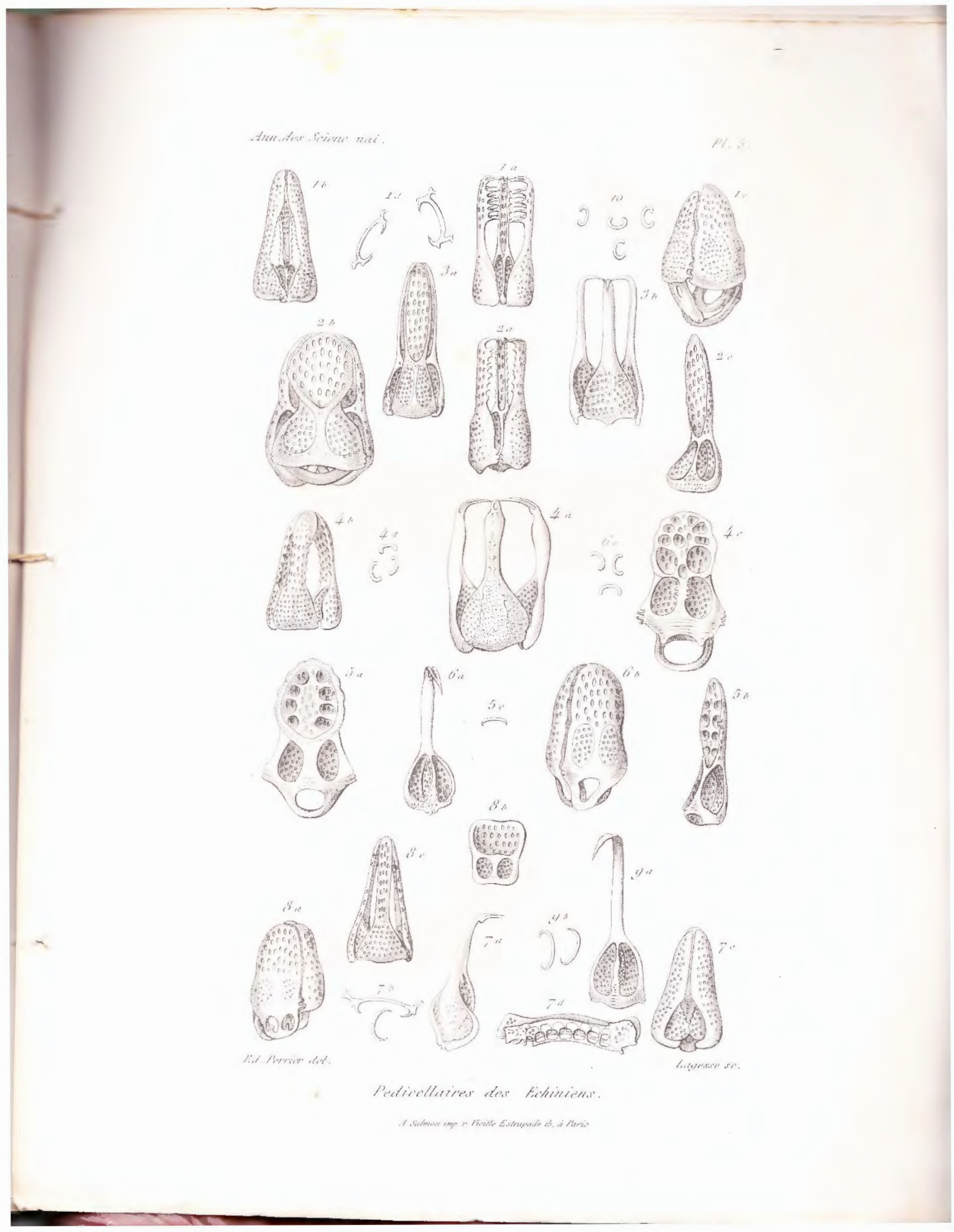




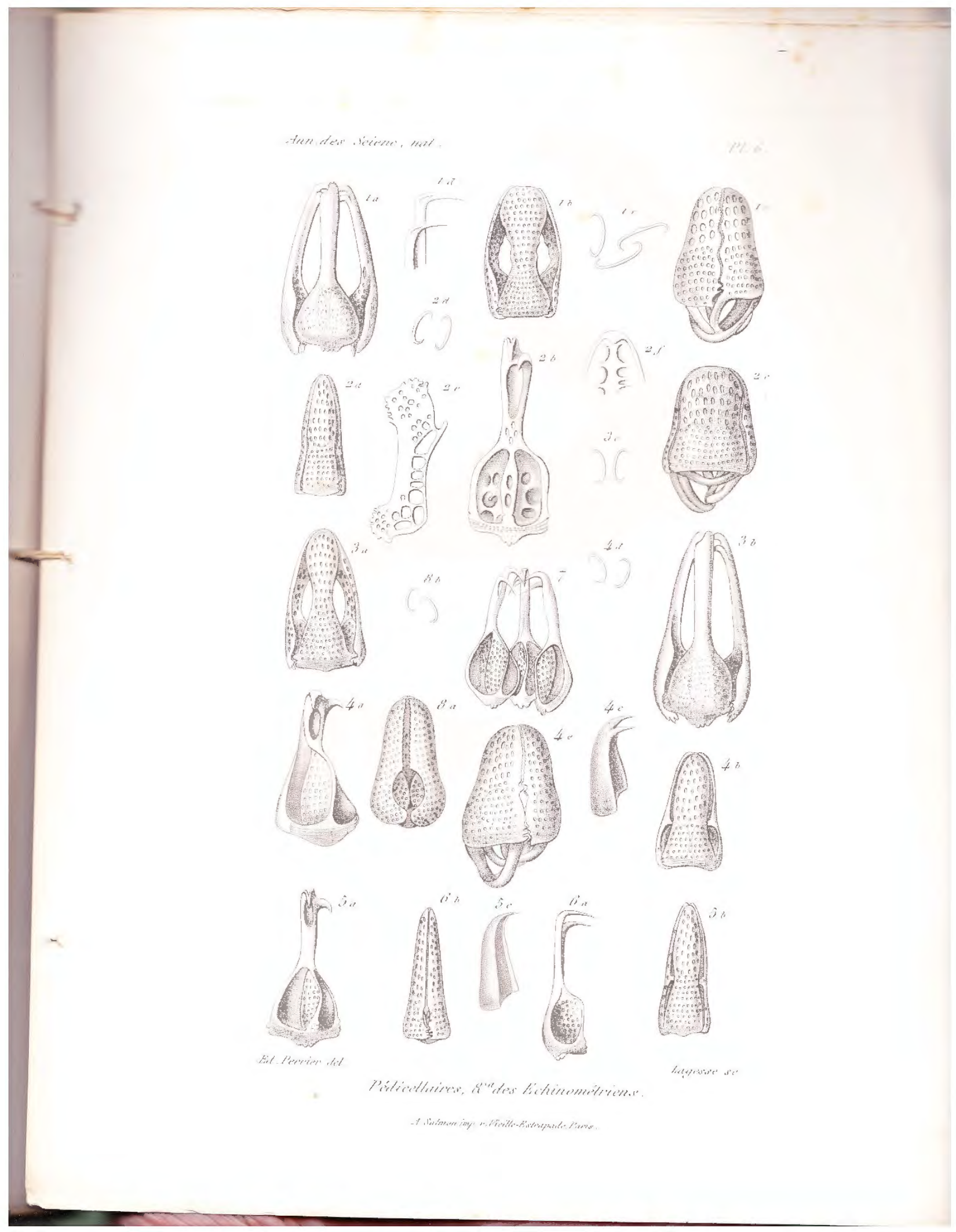




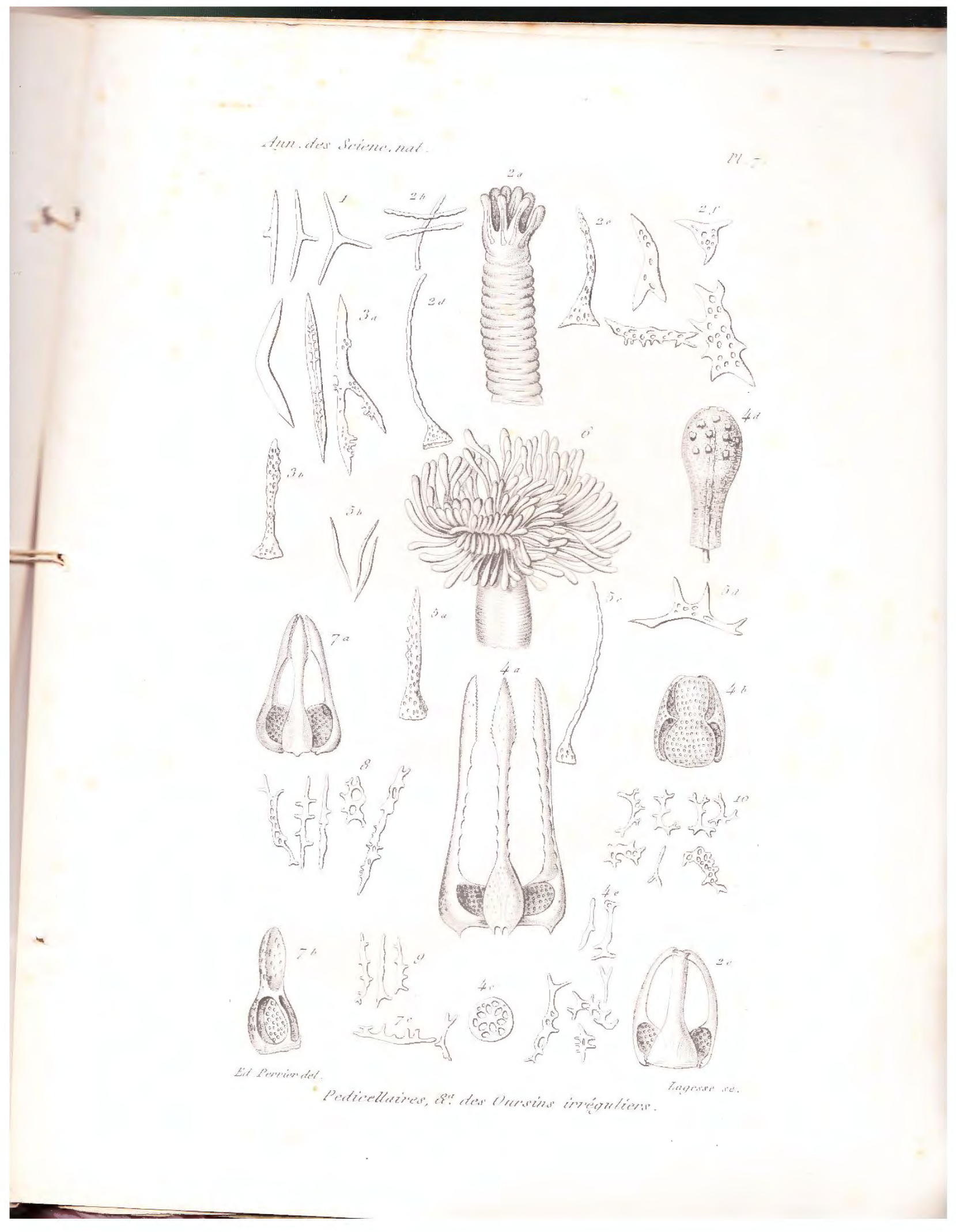

